\title{
Of Labs and Other Places: \\ (Literary) Criticism in the Age of Social Innovation \\ by
}

David Thomas

A thesis submitted to the Faculty of Graduate and Postdoctoral Affairs

in partial fulfillment of the requirements for the degree of

Doctor of Philosophy

in

English Language and Literature

Carleton University

Ottawa, Ontario

(C) 2019, David Thomas 


\begin{abstract}
In the aftermath of 2008, as economic planners grapple with the concurrent onset of secular stagnation and anthropogenic climate change, states have become increasingly jealous custodians of the public purse. In many of the world's advanced economies, policymaking has turned toward the use of "social innovation" funding frameworks that target scarce resources toward precisely-designated areas of strategic concern. The net effect of this process has been to prioritize the development of lab-based interdisciplinary research networks that are tasked with responding to a vexing cluster of "future challenge areas." Researchers from across the disciplines are now expected to demonstrate the social, economic, or environmental "impact" of their research. In this broader context, celebration of literature's "uselessness," long one of its special boasts, has become increasingly difficult to justify or sustain.
\end{abstract}

It is admittedly hard to project what kind of contribution literary scholarship can make in this ends-oriented research context. All the same, this dissertation commits itself to running reconnaissance. Rather than blankly repudiate these new funding frameworks and R\&D initiatives as neoliberal corruptions of a pastoral Keynesian campus - itself an expression of, and ideological bulwark to, the disastrous postwar modernization project I ask how we might explore them as a new terrain of struggle, one whose characteristic constraints and dangers we can foreground together, self-reflexively. These are, after all, the kinds of questions that early-stage researchers will negotiate in practice, if not in theory, as they navigate R\&D platforms and lab networks that more and more clearly subsist at the fraught intersection of a diverse array of conflicting "stakeholder" interests and commitments. 
As this thesis draws to its conclusion, it ultimately confesses to a secret hope that among those literary humanists that do make it aboard the new social lab programs, one or two of them might bring not a commitment to Bruno Latour's "post-critical" pragmatism, but rather copies of Kim Stanley Robinson's Mars Trilogy. Would that it could circulate there as a kind of gateway drug to the anarcho-communist critique of private property - as a tantalizing thought experiment concerning the unpredictable, and to some extent unmanageable, cascade effects that might be precipitated within these new lab networks, given a little luck. 


\section{Acknowledgements}

In offering this all-too-brief account of the debts that I owe and the gifts I have been given I begin by thanking Dr. Sarah Brouillette who has been all that one could ask for in a supervisor - a great mentor, a true friend, and a constant champion. In the absence of her unflagging support and guidance, I doubt this research project would have seen completion. I offer sincere thanks to my committee members, Dr. Stuart Murray, Dr. Julie Murray, and Dr. Annie McClanahan and Dr. Pablo Mendez - I know that their insights, criticism, and encouragement will continue shaping my ideas long after this phase of research has reached its conclusion.

I would also like to acknowledge the support of Drs. Brent Ryan Bellamy, Jeff Diamanti, Sean O'Brien, and Imre Szeman. They opened many doors for me during the degree, personally and professionally, and have always treated me with great kindness and hospitality. I must also mention my good friends, Tad Lemieux, Shaun Stevenson, Rob Mousseau, Ben Schultz and Francois Lemieux. Shaun's pragmatism and generosity have made the process of navigating an uncertain professional environment much simpler than it would otherwise have been. Tad has offered constant incitements to think harder and think deeper. His contempt for cliché and convention has pushed me to develop my ideas in a way that has made them more fully my own. Rob has done much to broaden my understanding of popular culture and was the first to clue me in to the significance of UX research. Ben has long been prompting me to think about architecture and climate change in a more serious way. Francois has provided a steady stream of reminders that “other worlds" are not only possible, but present here, incipiently. His insights into sciences studies have been consistently eye-opening. 
I need also to thank my father, Chris Thomas. Our conversations in the kitchen of 11 Ashville Avenue were my introduction to politics. My mother, Pauline Thomas, is a wise and perceptive spirit. It was a great gift to grow up in the shelter of her care and insight. Lastly, I dedicate this dissertation to my partner, Sharon Coward. A constant reserve of strength, kindness, and laughter, our arguments have made me smarter, our life together, happier.

Financial support for this project was provided by an Armand Bombardier Canada Graduate Scholarship, and an Ontario Graduate Scholarship. 


\section{Table of Contents}

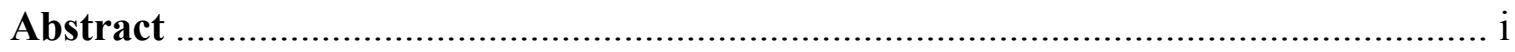

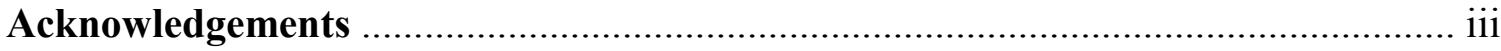

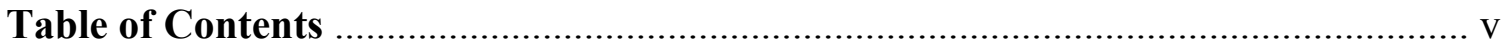

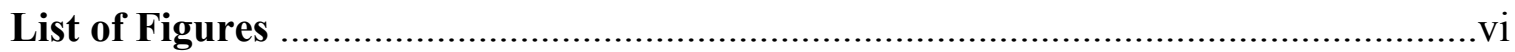

Introduction: Crises that overtake us from every side ...................................... 1

Chapter 1: We have always been 'establishment curators'................................... 15

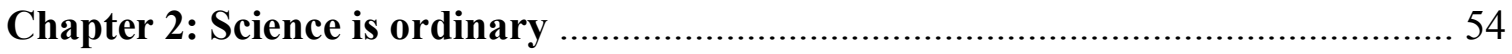

Chapter 3: There are no purely technical solutions ........................................ 113

Chapter 4: Lab of labs, commune of communes ................................................ 170

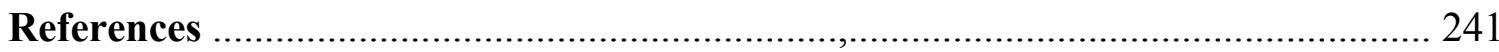




\section{List of Figures}

Figure 1: Evolution of the budget of the EU framework programme for research

Figure 2: The Governor

Figure 3: Goya - Fight with Cudgels. 194

Figure 4: Renderings of the Quayside neighborhood development in Toronto 216

Figure 5: Bird's-Eye View of The Freeport Region 228

Figure 6: Looking West Across the Naturalized Mouth of the Don River. 229

Figure 7: Artist Rendering of Hunts Point Lifelines 229

Figure 8: Growing Ecological Resiliency....... 232 


\section{INTRODUCTION: CRISES THAT OVERTAKE US FROM EVERY SIDE}

[F]rom the springs this water is no longer fit

for the stones it washes: the water of life

is all in bottles \& ready for invoice. To draw

from that well we must put on some

other garment.

- J. H. Prynne, "Die A Millionaire"

You break the mirror that reminds you of your ugliness

- GZA, "Breaker, Breaker"

Like many of today's doctoral candidates, I have often suspected that this course of study was ill-advised. Conceived in response to the dense briars of governmental incentives and economic constraints that define life in today's university, this research project still seems quaintly ill-adapted to the conditions it has emerged within. Combining a commitment to the practice of political critique with close readings of a single literary writer, this thesis' tactical instincts and strategic gambits leave it out of step with dominant currents in Anglophone literary studies. In recent years, the field's principle institutions and academic associations have begun to distance themselves from their longstanding advocacy of critique and close reading. ${ }^{1}$ Quietly, while established scholars have continued to applaud each other for work produced in the older vein, emerging scholars have been counselled to adopt a pragmatic cast of mind. As digital labs and

\footnotetext{
${ }^{1}$ Rita Felski's The Uses of Literature and The Limits of Critique have done much to spearhead the new wave of "postcritical" literary scholarship. Meanwhile, Franco Moretti's Distant Reading and Maps, Graphs and Tress, have popularized the concept of "distant reading." Defined in polemical opposition to literary studies' most foundational practice - close reading - Moretti's work has championed the role that big data analytics can play in unlocking previously undisclosed dimensions of literary texts.
} 
computational suites have sprung up under the watchful eye of administrators and funding bodies, as the enrollment numbers have dropped off and the instrumental diktats been handed down, it has become increasingly hard to deny that the old humanistic commitments to "canon formation" and "critical thinking" are being subordinated to a new set of administrative priorities. It is an open question whether this turn of events is quite as calamitous as some of the old conventions' more ardent advocates tend to suggest. As anthropogenic climate change has taken hold - as we have watched displaced peoples people herded into camps, and looked on as the reefs bleached, and the plains burned - it has become harder and harder to imagine why old-world humanism should be saved from the wreckage. In truth, however, humanists are hardier creatures that we tend to admit, something our ready and rapid adaption to the advent of digital mediation clearly suggests. Although it has often imagined itself a "beautiful soul" in flight from a crude and mechanistic world, throughout its long history, literary humanism has in fact paid its way by building, valorizing, and reproducing the liberal bourgeois sociolect. Amongst other ends, it has supplied liberal society a foundational fund of images and narratives, a vast store of style and story that writers have returned to again and again in their efforts to represent, understand, and aestheticize our alienation, our "unity in separation" (Endnotes, 71-167).

This inquiry does not then claim to position literature, or literary studies, as especially enlightened antagonists to the benighted excesses of the "neoliberal" free market. ${ }^{2}$ Nor is it invested in the idea that aesthetic autonomy now serves as the last

\footnotetext{
${ }^{2}$ For a recent iteration of this argument, one could look to the Warwick Research Collective (WReC)'s Combined and Uneven Development: Towards a New Theory of World-Literature.
} 
residual holdout of the dissident intellect. ${ }^{3}$ It instead takes the position that literary culture is best understood, less as a principled critic of capitalist social relations, and more as a distinct social form, native to particular stages of capitalism's material and demographic development. In each of these stages - themselves defined in the course of capital's real movement, and its crisis-driven bouts of restructuration - literature has adjusted to new conditions, taking on historically distinct characteristics.

Such approaches to the study of literature are relatively thin on the ground. Indeed, even as the "sociology of literature" has enjoyed something of a revival, its new proponents have generally been keen to distance themselves from the political and methodological affiliations of the field's originators. ${ }^{4}$ It has been some decades since the attempt to comprehend literature as an institutionally-mediated "social form" can be said to have been a particularly widespread practice. The promising trails opened up in the 1970s by scholars such as Pierre Macherey, Etienne Balibar, Terry Eagleton, and Raymond Williams have all in later years run rather cold.

Recent books by Sarah Brouillette and Mark McGurl have, however, begun to revive interest in materialist theories of literary production and mediation. Benjamin Noys commends this work in the context of a recent critique of new materialism. Taking aim at new materialist modes of literary inquiry that have responded to the onset of climate change by attempting to ground a "new" aesthetic ontology in the quasi-sacral

\footnotetext{
${ }^{3}$ See Nicholas Brown's Autonomy: The Social Ontology of Art under Capitalism (2019), or Walter Benn Michael's The Beauty of a Social Problem (2015) for examples of this argument.

${ }^{4}$ Here, one thinks of James English's introduction to New Literary History's special edition on "The Sociology of Literature After "the Sociology of Literature" where Birmingham Cultural Studies and Marxist sociologies of literature are positioned as "stale and outmoded" ideas that are little "mourned" by the discipline's more sophisticated practitioners (v).
} 
character of "vibrant matter" (Bennett, viii), Noys complains that such stances enforce "a doxa of transcendence in the name of a freedom from determination. Connections are everywhere, but there is never any exhausted connection, licensing a discourse of fight and unworldliness as the final determination of the literary" (90). As a remedy, Noys highlights key commonalities between Brouillette's and McGurl's otherwise distinct approaches, averring that their “attention to literary 'objects' as embedded within forms of institutional practice that shape literary production and consumption, offers a path to grasp and traverse abstraction without invoking theological forms of transcendence" (91).

In key respects, Brouillette's and McGurl's arguments can thus be seen to cut against the grain of one of the literary field's most prized contentions - that it is possible, and even desirable, to set aside apparently peripheral concerns (such as the influence of the contemporary culture market, or the canonizing interventions of the state's curatorial and pedagogical institutions) to "concentrate" on those that are proper to the field of literary composition. Yet such analytic separations between the aesthetic realm and its determinants - and the notion this distinction is even possible is the beating heart of aestheticist thought - are arguably only conceivable because of the unique way in which the aesthetic is constituted as a social form. Few accounts of the historical emergence of aesthetic autonomy have thought through this problematic with as much rigor as Pierre Bourdieu's. It is now some decades since Bourdieu's theory of the restricted field demonstrated that even artists who could mount plausible claims to aesthetic autonomy artists who had foresworn the production of commercially viable art in order to pursue an ostensibly self-directed vision - still took their bearings in relation to the heteronomous force of the culture market. It was the prick against which they kicked. The avant-garde's 
traditional disavowal of commercial interests, far from establishing a complete autonomy from the marketplace, actually indicated the interdependence of the two spheres.

Commercial and "autonomous" art were parts of the same complex semiotic game.

Artists were players who attempted to outwit each other in their progress from marginal to dominant positions. Successful artists negotiated a series of transitions that saw them move from liminal fringe players to "consecrated" elites, finally able to trade in "cultural capital" for the real thing. In so far as Bourdieu was willing to acknowledge aesthetic autonomy, it was clear to him that artists practiced a limited and historically conditioned form of it, one that unfolded "within" rather than without the broader field of commercial cultural production. Indeed, their refusals of mainstream conventions and their assertions of alternate visions actually played an indispensable role in maintaining the vitality of the whole. Ben Davis puts the matter this way:

An intensifying self-consciousness about fine art is a dialectical counterformation to the intensifying social weight of capitalist industry. They are twinned developments, and are thereby implicated in a whole web of class tensions. Art consciousness is, in this respect, as distinct a symptom of capitalism as wage labor or the commodity form itself. (4)

The call to keep literature's "enduring value" in view seems from this perspective a somewhat coy means of insisting that some key - but tellingly undefined - facets of literary practice escape historical determination, and that it is this set of essential features which actually determine the means by which the literary object is properly received and constituted. Admittedly, one can see the strategic appeal of this argument. For if it were indeed possible to make the case persuasively, the foundational parameters of literary practice would be established on a firm footing, and we would accordingly be in a strong 
position to mount a relatively robust defense of existing pedagogical practices and received aesthetic modes. Literature would warrant the support and sanction of the state in so far as it supplied "humanity" a crucial lodestar; its cannon of texts could be said to serve as an indispensable guide to best practice, a series of standards in reference to which "the brotherhood of man" could plot a steady aesthetic course (Brouillette, "UNESCO" 21). In the early days of postwar educational policymaking, such claims were commonplace, and little contested. Underlying this outlook was the old aestheticist argument that aesthetic judgments found their ultimate summons and ground in the intrinsic qualities of the literary object, rather than in the shifting doxa of aesthetic creeds. Noys classes this kind of argument as one that relies on the invocation of theological forms of transcendence. Bourdieu follows the same line of reasoning in categorizing it as fetishistic. Indeed, he goes so far as to insist that it is precisely the socially-mediated faith in literature's enduring value that drives its historical reproduction as a social form. In the early days of postwar internationalism such faith was a commonplace feature of the elite bourgeois sensibility, undergirding the gigantic pedagogical and developmental programs that international organizations such as the United Nations sought to spearhead and popularize. Somewhere along the line, however, faith in literature wavered, as governments began to look on the popular promotion of the liberal arts with a more skeptical eye. ${ }^{5}$

\footnotetext{
${ }^{5}$ For a comprehensive account of the UN's changing orientation to the promotion of literary culture, see Sarah Brouillette's UNESCO and the Fate of the Literary: "In its earliest years, UNESCO conscripted literature into the project of supporting liberal cosmopolitanism. It viewed the translation of classic literature as a contribution to the work of forging the strong cross-border bonds that were thought at the time to be integral to world peace. Subsequently, in the decolonizing 1960s and 1970s, illiteracy and a lack of access to literary books were lamented as a 'book hunger' in the developing world, and the idea of reading as an unquestionably humanizing universal value was used to argue, though unsuccessfully, for a more balanced communications industry and copyright regime. Finally, in recent years... UNESCO largely
} 
Today, in the face of the prevailing headwinds, it is hard to stave off the overall sense of decline. However strong one's personal sympathies for the old forms might be, it has become difficult to deny that "the literary as we have known it - the B-format literary novel, some hundreds of pages long, studied for its deft and deliberate use of language, and associated with depth, complexity, humanity, expressivity, and particularity - is very much aged, very much on the wane" (Brouillette and Thomas, 515). When one surveys the contemporary literary field, it can thus now seem that recursive attempts to renew, redefine, or revitalize literature and literary studies often do more to sound their death knell than herald their revival. We will, however, fail to grasp the causes of these events, if we insist on attempting to understand literary study's declining social prestige and shrinking market share in relation to the prized tenets of the restricted field - as if literature's eclipse were contingent on writers' or scholars' failure to live up to the received standards of their occupations. ${ }^{6}$ Turning away from this unreflexive faith in aesthetic autonomy, this thesis focuses instead on the role that heteronomous forces play in structuring cultural production from the ground up. It roots itself in the core claim that literary studies closes in on the moment of its exhaustion, precisely because it shares in the fortunes of the social relations that once occasioned and sustained it. But rather than repress or evade this recognition, I instead extend an invitation to a literary crisis of faith,

treats high literature as a commercially self-sustaining leisure product for wealthy, aging publics and unlikely to do much for people living in impoverished conditions" (1).

${ }^{6}$ See, for instance, Rita Felski's widely-circulated The Limits of Critique, where Felski argues that "[a]fter decades of heady iconoclasm, after the bacchanalian joys of ripping up New Critical attitudes and scoffing at Leavisite platitudes, we are left nursing a Sunday morning hangover and wondering what fragments, if any, can be retrieved from the ruins" (15); or Bruno Latour's suggestion that fidelity to the harsh and unforgiving spirit of critique has seen "the humanities ... los[ing] the hearts of their fellow citizens" (“Steam” 239). 
one that is oriented by a broader set of crises - crises that seem to overtake us from every side.

\section{CHAPTER BREAKDOWN}

This "invitation" provides the point of departure for all that follows, but it has a special pertinence for the approach that defines my first chapter. Drawing on Ernest Mandel's Late Capital, and Robert Brenner's The Economics of Global Turbulence, Chapter 1 explores how literary studies fares within a postwar university system where applied science has already emerged as the "the battle-cry of late capitalism in higher education" (Mandel, 262). As Keynesian policy initiatives reorient knowledge production in relation to the projected needs of the real economy, the university emerges as base camp for a sprawling global network of government-backed research laboratories.

It is this mid-century period that talk of humanism's "obsolesce" first begins to surface, as planners begin to question why the state should continue funding economically "unproductive" disciplines such as literary studies. Yet aid ultimately arrives in an unlikely form in the wake of the stagflation crisis of the early 1970s, as a new wave of neoliberal higher education policies begin to position the university, not just as the primary institutional home of capital's tax-funded R\&D departments and vocational training programs, but also as a prime site for the expansion of the credit market. In this new debt-driven and "demand-led" institutional context, the humanities enjoy a conditional reprieve. 
In the immediate aftermath of the 2008 financial crisis, however, the skies begin to darken once again. As credit markets tighten, and as austerity discourses take hold, students respond to dire economic forecasts by seeking out the vocational high ground. Enrollment in the humanities declines precipitously. Meanwhile, unable to depend on the economic doctrines that had steered economic policy during the neoliberal decades, and faced with the grim prospect of a destabilizing planetary climate, planners begin casting around in the dark for answers to a disturbing series of strategic quandaries that lie well beyond the purview of prevailing approaches. In their search for answers, governments ultimately return to one of their most trusted resources - the lab - convening broad-based networks of interdisciplinary "social labs" that are charged with prototyping "sustainable" models of economic development.

One might imagine that this last turn of events delivers a final nail in the coffin for the humanities, yet the picture seems to be a little more complicated. Insisting that the social sciences and humanities "in all their various disciplinary guises, will be firmly embedded" in these new initiatives, policymakers in the EU and other advanced economies are now attempting to "embed" humanists and social scientists in major science and engineering projects (Geoghegan-Quinn, 3). Installed in these large-scale projects from the moment of inception, humanists are now - somehow - expected to serve as the guardians of humane values, ensuring that " $R \& D$ and innovation ...change our society for the better" (3). Defining these pilot programs as part of a broader effort at "integrating" the humanities with science and engineering, policymakers now position the social lab as the manifest destiny of the humanist and social scientist. Once "edged out" by the rise of R\&D networks, humanists are now just as likely to be subsumed by 
them. And taken up in a broader wave of change that has seen research funding allotted on the basis of "challenges to tackle rather than disciplines to be financed" (2), it should not surprise us that recent years have seen the emergence of a new roster of self-branded subfields - Digital, Medical, Energy and Environmental, and so on - that signal their overt alignment with precisely those areas of strategic concern that policymaking has prioritized. This chapter accordingly concludes by charting the rise of the "utilitarian humanities" against the backdrop of the social innovation policy frameworks that have fostered their emergence. But rather than position these new research clusters as developments "within" the discipline, it ultimately suggests that we might better understand them as "exit strategies," developed on the fly, as literary humanists attempt to survive the demise of the of old knowledge production models.

But what exactly can humanists hope to discover on the other side of this flight toward the lab, should they indeed prove successful in carving out new niches within a university system that now prioritizes a "culture of low walls" between disciplines? In tackling this question, Chapter 2 takes the work of Bruno Latour as its central case study. There are key respects in which Latour's foundational contributions to the discipline of science studies can be seen to serve as a basic template for policymaking's current attempts at integrating the humanities with science and engineering. Indeed, in view of the trends under discussion, it is not at all surprising that Latour is, in the words of Graham Harman, "starting to look like Michel Foucault's eventual replacement as the default citation in the humanities" (Harman, "Demodernizing" 248). This is not to say that the attention is entirely unjustified. Latour's prickly appraisals of positivistic hubris, and his unruffled indifference to the postwar university's hierarchization of disciplines, 
have produced a rich reserve of theoretical resources. At the core of Latour's contribution, we find a sophisticated ethnographic account of scientific knowledge production, one that teaches us, most significantly, to understand the laboratory as a social practice.

In more recent years, Latour has also helped to spearhead a new wave of interdisciplinary research platforms and public pedagogy initiatives that bring researchers from across the disciplines into conversation around the vital issues of climate change mitigation and adaptation. Yet the gains of Latour's approach have also been offset by significant losses. Notably, the interdisciplinary influence of Latour's Actor Network Theory (ANT) has helped to ferment a proliferation of "postcritical" and "new materialist" theoretical stances that are all-too-often constructed around the explicit disavowal of the "old" materialist critique of private property. Indeed, it has become conventional to characterize historical materialism as new materialism's outmoded other - a dry and doctrinaire mode of thought that is obsessed with antiquated theories of political economy. Under such conditions, the cost of admission to these new interdisciplinary research forums can be that scholars are expected to trade in a tepid political vocabulary, one that tap-dances around the central role that capitalist social relations have played in driving the Earth System toward a variety of critical, and irreversible, ecological tipping points. In theory, it is precisely such questions that "embedded" humanists should be tasked with raising in these new research hubs. But, in practice, our increasingly precarious institutional position seems just as likely to see us cast in the role of Polonius: 
No! I am not Prince Hamlet, nor was meant to be;

Am an attendant lord, one that will do

To swell a progress, start a scene or two,

Advise the prince; no doubt, an easy tool,

Deferential, glad to be of use,

Politic, cautious, and meticulous;

Full of high sentence, but a bit obtuse;

At times, indeed, almost ridiculous -

Almost, at times, the Fool. (Eliot, 111-119)

There are signs, however, that events might yet fork off along more promising vectors.

Frustrated by the glacial pace of climate change response, Latour, for one, has lately begun to mobilize a more radical political vocabulary. Responding to a polarizing geopolitical climate, Latour has invited his readers to take solace from the idea that worsening climatic conditions seem to be catalyzing the political radicalization of scientists themselves.

In an effort to both capitalize on these openings, while pushing matters a little further, Chapter 3 attempts to fill in the blanks that still tend to define Latourian accounts of political economy. Here, I use Mandel's account of the systemic logic of late capitalism, in exploring why the concept of "innovation" has exerted such profound influence over political and economic discourse in these postwar decades. In the process, I try to conceptualize the postwar era's spreading networks of R\&D laboratories as sites where the reverberating ecological consequences of capitalist growth dynamics are revealed in an especially acute manner. This entails attempting to foreground the role that the technical laboratory has played, not just in driving on the process of capital accumulation and economic growth, but also in anticipating and conceptualizing the 
ramifying ecological consequences of the technologies that it has developed. This chapter concludes by locating today's social innovation policy initiatives within this broader historical context, as I explore the social lab's conceptual debt to the ecological systems theories that first began emerging out of technical laboratories back in the early 1970s. Here, we discover that the social lab's efforts at generating viable models of "sustainable growth" have long been considered a contradiction in terms, not only by grassroots environmental activists, but also by the founders of the research programs that provide today's social labs with their basic institutional template. Turning to the work of Jay Forrester, we will see that although today's social innovation labs draw extensively on his pioneering work in Urban Dynamics, few have acknowledged, much less reckoned with, his claim that "there is no purely technical solution to the challenge of creating a sustainable society" (Lane and John Sterman, 14). Comparing Forrester's heretical stance with those that define the bulk of today's flagship climate change mitigation and adaptation initiatives, we find the EU and other national governments promoting a contradictory policy program - one that was already, in a sense, pre-emptively disavowed by its founder. All the same, in so far as this is a contradictory program, we will also discover the signs of a new batch of incipiently post-capitalistic initiatives that are struggling to supplant the destructive logic of business-as-usual. Seen from this vantage, it would be a mistake, for instance, to conflate the Google-run "living laboratory" that is now planned for Toronto's Eastern Waterfront, with the more grassroots urban food labs that are springing up within the same policymaking frameworks, transforming high-rise green roofs into functional templates for an industrially-scalable model of urban agriculture. 
Chapter 4 attempts to latch onto these fragile shoots of utopian promise, while at the same time circling back to the archives of our own discipline, in search of narratives that might serve as a useful stimulant to the political imagination. Settling on Kim Stanley Robinson's Mars Trilogy as a key resource, I draw on this scientifically-erudite speculative fiction as a means of probing the more utopian political potentialities of the technical laboratory. The dissertation's exploratory forays into science studies are thus bookended by two chapters that attempt to make meaningful interventions in the field of literary studies, while never entirely losing sight of the heteronomous forces that are allthe-while overtaking it. This entails complementing the first chapter's theorical account of the discipline's current travails, with a final chapter that conducts a more conventional close reading of Robinson's complex political vision. Drawing on McKenzie Wark's claim that the novels' attention to "technical issues" ultimately operates as "a Brechtian estrangement device" that "open[s] up a space for thinking about the organization of the Earth," I position the trilogy as an enticement to the anarcho-communist critique of private property (177). With a final turn of the screw, I suggest that Robinson's speculative fiction has, in a sense, already arrived at our current conjuncture ahead of us. Conceptualizing today's social innovation research networks as a new terrain of struggle, I allow Robinson to make the case that the technical laboratory might yet inherit other destinies than those assigned it by late capital. 


\section{CHAPTER ONE: WE HAVE ALWAYS BEEN "ESTABLISHMENT CURATORS”}

Love will save us love will save us love will save us. As if it would be classical to be bitter and cowed. - Amy De'Ath, "Lower Parallel”

Mounting a critique of literary studies' stubborn tendency to naturalize aesthetic norms, Sarah Brouillette parses some of the literary sensibility's more stable and enduring features: "The literary for me is instruction in the bourgeois sociolect as a distinct and individually distinguishing sensitivity to the capacity of language to humanize, elevate, individualize, interiorize, enliven, et cetera" (“Industry" 7). Yet although Brouillette's definition is attentive to the foundational consistencies that allow us to track literature's social evolution - and to speak of it as an enduring social form - she still makes clear that literature's development has been defined as much by rupture and transformation as by stability and conservation. In her analysis, this interplay of breaks and continuities is not the sole product of the hallowed clash of tradition's bulwarks and innovation's provocateurs. For " $[w]$ here[as] Bourdieu and Casanova theorize relations internal to a restricted field," Brouillette "insist[s] that cultural production emerges in definite relation to the real economy as it evolves, moves, disperses, colonizes, and so forth" (Brouillette and Thomas, 553). Taking up such a perspective entails attending to the evolution of the pedagogical institutions and commercial systems of industrialized distribution that have given literary writers their audience, and their longstanding role in the construction of capitalism's social imaginary. Adopting this viewpoint requires us to shift some of our attention away from the literary field's internal conflicts and controversies, in order to bring into focus the ostensibly "external" forces that have shifted, shaped, censored and 
circulated the literary object. As a literary humanist this entails trying to grasp the social forms that we participate in and reproduce as culture's state-sanctioned critics and curators.

Admittedly, the task of demystifying our institutional practices has become significantly easier now that realpolitik has emerged as the humanities' lingua franca. For as developments in the real economy have nudged the humanities into a more precarious economic position, our institutional self-understanding has grown more modest. Indeed, "[d]emystification is now a condition, not a project" (Research and Destroy). Faced with a flurry of pragmatic "manifestos" ${ }^{\text {" }}$ it is no longer difficult to identify the core strategic concerns that have actually shaped the university in all its postwar phases and guises. For the new priority accorded to technical expertise, data management, and "impactful" research is not so much a wholescale departure from the practices of an earlier and more enlightened era, as it is a fuller disclosure of the instrumental imperatives that have shaped the modern academy since its inception. As policymakers and administrators have defined academic practice, and steered the development of core curriculums, their single dominant concern has remained securing optimal conditions for the ongoing viability of the capitalist mode of production. In the parlance of contemporary policymaking, this undertaking is more often described as an effort to promote and ensure a nation's "global competitiveness."

Over forty years ago, Ernest Mandel laid out his understanding of these events, rooting his explanation of the expansion of the global university system in the crisis

\footnotetext{
${ }^{7}$ See, for instance, the Harvard University Press blurb to Jerome McGann's The New Republic of Letters which touts the book as a "manifesto for the humanities in the digital age" (Harvard UP), or Rita Felski's The Uses of Literature which describes itself as a "yea-saying" "manifesto" on the "uses of literature" (8).
} 
tendencies of the real economy, and in the specific needs, capacities, and systemic fragilities of monopoly capital. Mandel's analysis of the university's postwar trajectory highlighted how core curriculums - and, indeed, entire disciplines - had been developed to supply the cognitive needs, and manage the structural vulnerabilities, of monopoly capitalism.

In the immediate postwar years, as the US's gigantic industrial conglomerates were drawn into ever intensifying internecine competition, and as emerging overseas industries began to threaten American market share, new waves of innovation fell harder and harder on the heels of the old. The net result was a continual acceleration of “technological turnover time," as competition for market dominance saw manufacturers across the globe propelled into a - reciprocally reinforced - struggle to increase the technological sophistication of their manufacturing processes. These developments expanded demand for highly-skilled workers, trained in the applied sciences and attendant disciplines, even as it ensured the obsolescence of older trades and vocations. Established forms of work were automated out of existence, while "[a]pplied science, specialized and subjected to the capitalist division of labour - fragmented science, subordinated to profit maximalization by the monopolies [emerged as] the battle-cry of late capitalism in higher education" (262).

The exponential expansion of the global university system was in large part a product of its ability to successfully mediate this nexus of systemic tendencies, economic needs, and social tensions. From a managerial perspective this was no small undertaking. For the anarchic - and potentially economically catastrophic - ramifications of accelerating cycles of "technological renewal" presented capitalism with problems that 
demanded considered and sophisticated responses. Given the speed at which technological development had begun to unfold, gigantic manufacturing plants now risked becoming "technologically out of date" in the time that it took to construct them (Mandel, 227), while the ecological impact of energy-hungry modes of highly-automated production threatened to destabilize the environmental conditions on which social reproduction and the valorization process ultimately relied.

Though the language used to describe the ecological content of these rapid cycles of spatial expansion and technological renewal has changed over the years - as concerns over pollution, acid rain, and peak oil, gave way to the harsher vistas of desertification, ocean acidification, and mass extinction - capitalism's ecological footprint has remained a consistent policymaking preoccupation throughout the postwar period, a fact that profoundly reshaped the academy, leading to a proliferation of new disciplines all housed under the broader rubric of the Earth sciences. Concurrently, in managing the tactical quandaries that its planetary expansion began to generate, monopoly capital became increasingly reliant of the construction of long-term logistical strategies, designed to mitigate the financial risks that resulted from now frequent and gigantic reallocations of industrial capital. Mandel describes the resulting development of Research and Development departments as a programmatic expansion of capital's "preproductive spheres" (223). And as the viability of the entire global economy became increasingly contingent on more and more rapid cycles of technological renewal, innovators in key sectors were well placed to effectively monopolize the "technical process." University administrators were quick to understand this turn of events, and accordingly positioned their institutions in a mediating role, both as a natural home to late capital's research 
hubs, and as the aspirational individual's most secure pathway to highly-remunerative forms of technical expertise.

As policymakers worked to maintain economic dynamism - and attempted to mitigate and manage its social and ecological fallout - the structures and goals of the university underwent constant recalibration. Over time humanistic inquiry took on an increasingly residual aspect. As Mandel put it back in 1972, "[t] he main task of the university is no longer to produce 'educated' men [sic] of judgment and property - an ideal which corresponded to the needs of freely competitive capitalism - but to produce intellectually skilled wage-earners for the production and circulation of commodities" (261). This remark houses an interesting, if somewhat implicit, appraisal of classical humanist pedagogy's key historical functions. One is left to infer (for Mandel offers little in the way of further commentary) that humanism - including induction into modern and classical languages, aesthetic theory, liberal historiography, and the fundamental principles of common and contract law - once provided capital with the kind of cosmopolitan agents that were essential to the mercantile expansion of the world market. Contrarily, the subsequent development of vast industrial conglomerates entailed the pedagogical production of new modes of social conduct and technical expertise.

Mandel went on to imply that this field of conditions would precipitate the rapid demise of academic humanism. Ironic, then, that the next forty years witnessed an incredible flourishing of humanist inquiry and instruction, as the liberal arts held onto their relative share of the higher education market, even as absolute enrollment numbers skyrocketed across the board (Mandler, "Pimlott" 423). One must infer from the baseline demographics alone, that this turn of events saw more papers published and more courses 
undertaken in these forty years than in all of humanism's many prior years of existence. These developments are the larger matrix within which writers published and promoted their work. It should go without saying that an appetite for the literary, and the social prestige afforded to its differing tiers of practitioners and affiliates, was facilitated and supported by these broader systemic tendencies. Indeed, household names - such as Salman Rushdie, Zadie Smith, Ian McEwan - could hardly have forged careers in the absence of this broader web of institutional supports and preconditions.

Yet, if contemporary conditions within the academy are indeed an indicator of future trends, literary studies' long, late summer appears to be coming to its close. Indeed, at our own juncture, Mandel's forecast has begun to seem more prescient, a development that leaves in its wake a host of unanswered questions. In his own search for answers, Joshua Clover echoes Mandel's account of the development of the postwar university system, proposing that the public university in all of its historical phases has been constrained and shaped - and subject to expansion, contraction, restructuration - by the dynamism and crisis tendencies of the real economy. In Clover's terms, failure to recognize the fundamental interpenetration and interdependence of state and capital has

led to these fantastical idealisms wherein the general capitalist economy supposedly has all this money lying around and it is being denied to public education out of some ideological villainy, some set of opinions about education, and this could simply be reversed if "we" were persuasive enough. ("Public Contradiction" 3)

Looking in particular at transformations within the UC system, he argues that California education policy "floated on the long postwar boom" (3), with the collapse of the tax base following the 1970s global economic crisis meaning the defunding of - among other 
things - the UC system. In this light, the growth of the student loan industry has at least two things to do with declining profits in manufacturing: tuition rates rise with defunding of universities, and banks that once invested in manufacture seek what Clover calls "routes for fallow capital" (3). While acknowledging that there is always some time and place in which there is divergence from the rule, he stresses that, conclusively: "The public university is one of private capital's expressions" (3).

Clover's intervention adds to Mandel's theory of the university the benefit of hindsight and the additional acuities of economic historian Robert Brenner. Mandel's Late Capitalism was still a product of capital's golden age. Its publication was roughly concurrent with the onset of the energy crisis that brought the belle époque to its lurching conclusion, and the new dynamics that this particular crisis brought into play thus largely escaped his field of vision. Brenner's work highlights aspects of postwar economic history that were unavailable as Mandel wrote.

Much of Brenner's later work has focused on the turbulent transition from belle époque to long downturn, and has drawn attention to a progressive reallocation of capital investment, away from industrial manufacturing and into the so-called FIRE (Finance, Insurance and Real Estate) sector. The dynamics that Clover describes are a notable feature of this much more fundamental and foundational trend. Brenner understands this trend to be contingent on intensifying competition between large industrial manufacturers, a phenomenon that we have seen Mandel explaining in his own terms. For Brenner, the same modes of competition that drove accelerating cycles of technological renewal within the industrial also served to depress prices. Struggle for market share reached such a pitch of intensity that companies became accustomed to operating with 
radically reduced profit margins. In-house investment in industrial $R \& D$, technological renewal, and production plant "shakeout," accordingly declined. And in response to a corresponding falloff in rates of return, investors became shyer of the manufacturing sector, and sought to diversify their portfolios. As "fallow capital" sought new routes to profit, the structural importance of the FIRE sector intensified. From the late 1970s through to the first decade of the new millennium, the finance industry's signature methods and investment strategies become more and more computationally sophisticated, systemically pervasive, and vertiginously leveraged. For a time, this teetering new financial architecture succeeds in restoring the economic dynamism of the world-system. During this period, investment in $\mathrm{R} \& \mathrm{D}$ of course continues at pace, even as investors diversify away from a primary focus on the manufacturing sector. Indeed, as the FIRE sector rises to prominence, it oversees a push toward investment in untried - and ostensibly risky - research-intensive fields such as medical science and bioengineering. Under such conditions, R\&D labs are often working less to drive up industrial productivity, and more to secure a stranglehold on lucrative medical and agricultural patents - a development that is reinforced by the insurgent medical insurance industry. At the same time, the finance industry's imbrication within computation networks promotes widespread investment in computer engineering. Brenner sums up the fall-out of these dynamics in the following terms:

Between 1980 and 1990, FIRE made use of some 35 percent of the net stock of office, computing, and accounting equipment employed by the total economy; by contrast, manufacturing's share was around 25 per cent. Ironically, then - but all too understandably in view of the fortunes made there - the most technologically dynamic of US industries during the 1980s and 1990s probably contributed less 
than any other to raising US living standards by means of its own immediate output. (215)

It is in this climate of burgeoning technocratic hubris, and underlying economic frailty, that humanism undergoes an unexpected (and absolute, if not relative) phase of expansion. Though this development appears to complicate Mandel's account of the overall trajectory of university curriculums, the dynamics he identified continue to unfold, though they are now compelled to do so in the context of the topsy-turvy investment strategies that came to the fore with the onset of the long downturn, as capital seeks out new routes to profit. The university remains geared toward securing economic dynamism, though in view of this end it begins to diversify its structural role. It positions itself not just as the primary institutional home of capital's tax-funded R\&D departments and vocational training programs, but also as a prime site for the expansion of the credit market and finance industry, and as a key conduit to the neoliberal individual's speculative investment in future earning potential.

This was the culmination of a plan that had been in the wings for some time. As early as the first years of the 1960s, policymakers in the economic core had begun to worry over signs of declining economic dynamism. In their attempts to develop viable postindustrial economic strategies, planners and economists drew up a speculative set of funding models that would eventually come to serve, decades hence, as the backbone of the "knowledge economy." As planners in the aging industrial zones rethought their longterm pedagogical strategies, anticipating the era of capital flight and dwindling tax bases that eventually came to pass, they were taxed with mediating between "the twin pressures of rising private demand for admission to HE and heavily constrained public budgets." 
(Woodhall, 6). As the long downturn deepened, and as state coffers ran dry, the prevailing approach finally crystalized around human capital theory. Through the $1980 \mathrm{~s}$ and 1990s, wave after wave of higher education reforms reimagine a course of postsecondary education as a speculative "investment" in human capital. This development shifted the financial buck away from the ailing social democratic state and onto the aspirational individual, who was now enjoined to avail herself of the alchemistic powers of easy credit. As in many other areas of the economy, public deficits were thus effectively transferred onto private households. Within such frameworks, especially at the undergraduate level, higher education became increasingly "demand-led" and in key respects, demand-driven funding models gave the educational consumer the upper hand over the professorial gatekeeper (Mandler, "Pimlott" 411). On the most functional and rudimentary of levels, higher education was now understood not as a privilege but as a product, as an individual's investment in human capital and future earning potential, rather than as a meritocratic preserve of a "gifted few."

As these interlocking processes were ramified and reinforced by wave after wave of expanding cohorts, the university found itself more and more deeply enmeshed in financial markets and the business of securitization. We have now arrived at an especially convoluted conjecture that Robert Meister still manages to parse in remarkably concise terms:

What we have now is, rather, a generalized use of the higher education system to generate the kind of debt, backed by all sorts of government protection, that can be used to manufacture other forms of security, some of which is rated AAA (like a synthetic US Treasury bond). What is important for this financial engine is not whether you, as a sub-prime borrower, can repay your debt, but whether you can 
create increased amounts of debt that remain liquid and can satisfy the demand of global bond markets for safe collateral (without the US government having to borrow more in order to create it) ... The financial story of US universities is no longer primarily about state funding, or private funding in the form of donations, and so forth; we are now talking increasingly about the university's access to the bond market and its ability to issue tax free bonds to private sector actors, including for-profit corporations. (Meister)

We can thus see the university emerging as one of the principle sites of the FIRE sector's expansion. In Meister's terms, the university - once revered as a bastion of civil society, and inculcator of elite modes of conduct - now secures its subsistence by serving as one of late, over-leveraged capital's key financial engines.

An interesting irony emerges here. For, despite the general humanistic consensus on the matter, these neoliberal funding frameworks actually serve as friend rather than foe to humanism. Indeed, as Mandel noted back in the late 1960s, the humanities had been in the crosshairs of central planners for at least a decade, as they made moves to synchronize university curriculums and undergraduate intakes with the projected needs of the real economy. Yet under the financializing regimes that eventually took hold in the wake of the stagflation crisis, the winnowing hand of administrators and policymakers was stayed. Indeed, demand-driven funding models have actually become an awning under which residual disciplines, such as literary studies, find shelter. So long as the student loan industry is able to continue its expansion, administrators are given few incentives to cull disciplines that emerged in earlier stages of capitalism's development. All debtors are considered equal, and established disciplines are regarded as viable enterprises to the extent that they continue securing a sizeable cohort of paying students. And thus while humanists have lately made a cottage industry out of complaining that the 
neoliberal financialization of the university had undermined the humane "values" that they seek to uphold and promote, humanism was actually - at least according to the metric of "scale" and social complexity - among the primary beneficiaries of neoliberal higher educational reform.

Yet in the wake of the financial crisis it seems evident that conditions in the real economy are again dictating transformations within the structure and mandate of the university. Given the sheer scale of student debt - which, in the US alone, is now said to exceed \$1.4 trillion (Friedman) - analysts are concerned that widespread defaults could trigger a new financial meltdown, ushering in a crippling recursion of 2008 dynamics (Meister). Meanwhile, unable to reverse the effects of the last crisis, the global economy has sunk into a deepening condition of "secular stagnation," as leading economists grit their teeth and forecast decades of negligible or negative growth (Summers 2013; Summers 2016). Prevailing economic doctrines are accordingly losing their luster across the board. Naturally the hegemony of coeval education models has also begun to fracture. At the highest policymaking levels educational planning in the EU and other advanced economies is tilting back toward a more overtly Keynesian concern with the real economy, while, at the admissions gate risk-averse and future-shy undergraduates are seeking out the vocational high ground. Literary studies is being squeezed from every angle and, within the professoriate, the question of how to stay relevant in changing times is accordingly close to everyone's thoughts. 


\section{iLIT: LITERATURE REMEDIATED}

These underlying trends and anxieties find concrete expression in the new clutch of humanistic branding exercises that have risen to prominence in recent years. Responding to higher education policymaking's interdisciplinary focus on the real economy and the world ecology, high profile literary scholars and literary associations are now increasingly prone to make a show of their work's social utility. The Digital Humanities is arguably the key case in point here, with their signature emphasis on the construction and promotion of "digital archives, quantitative analyses, and tool-building projects" (Klein and Gold, ix). But to make a full appraisal of the situation we also need to factor in the whole roster of self-branded subfields that have emerged in more recent years, mimicking DH's fundamental strategies of distinction and institutional design. "Energy," “Environmental," and "Medical" Humanities labs are springing up alongside the digital ones, adopting many of the structural characteristics of their institutional forerunner with alt-ac teams assigned to compiling, managing, and visualizing databases, while famous scholars synthesize the results and tout the merits of a newly problem-focused, policy-oriented mode of interdisciplinary inquiry. In this institutional context, the celebration of literature's "uselessness," long one of its special boasts, has become increasingly impossible to justify and sustain.

In view of these developments it is arguable that I have been somewhat misleading in my discussion of literature's looming “obsolescence.” Strictly speaking, in the present moment it is probably more accurate to say that "the literary" is undergoing diverse forms of remediation. Within the academy, understanding of literature's remediation has thus far been focused in a primarily retrospective direction. Scholars 
have applied "digital tools" to archive and analyze the established store of canonical and extracanonical texts, and have championed technology's presumed potential to unlock as yet undisclosed facets of the written word. It is possible, however, to turn this strategy on its head, in order to explore how the literary sensibility has escaped the pages of the book, migrating onto digital platforms, and surviving the decline of the literary novel as a popular form. Indeed, in attending to the ways that writers are carving out new niches as producers of "prestige" cultural "content" - most notably in a television industry that has been swept to cultural dominance by the impact of digital distribution - it is easier to apprehend the general trajectory of literary practices' enduring, if changing, cultural influence and agency. The literary sensibility - with its focus on "complexity, depth, individuality, inwardness" (Brouillette, "Industry" 7) - has outlived the novel's cultural hegemony, consolidating and extending its social influence via the advent of self-styled "visual novels." As they arrive on our flat screens organized in "Chapters" and "Parts," they quietly index quality television's ongoing appropriation of the cultural prestige - and one-time social function - of the literary novel, as television comes to serve as the narrative base of elite watercooler conversation, and as the central platform on which narrative culture now unfolds. In the meantime, the core texts that the postwar academy canonized and popularized still continue to serve as key (but residual) loci of cultural capital and prestige, and their archives are therefore among the first to migrate onto digital platforms or undergo computational analysis.

Yet our reticence, as a discipline, to grasp how writers have found new venues for their work seems to be a product of some of the ways in which English literary studies has, over the course of its many decades of existence, lent its understanding of the social 
role of the writer an increasingly narrow focus. Indeed, the field's unwavering attachment to the canonical triad of "poem, play, and novel" bears much of the blame here. This particular coupling of genres - one that has functioned for over a century as the implicit base referent of the term "literature" - made considerably more sense prior to the rise to dominance of audiovisual narrative.

For while our understanding of the core modalities of literary writing has scarcely been modified since the days of Trilling and Leavis, new technologies - products of capital's accelerating turnover time - have all the while continued redefining the field of cultural production. Writers have responded by plying their trade far beyond the pages of the book, playing indispensable roles in the broadcasting, film, and streaming industries, and penning some of the most widely repeated and roundly praised phrases in the modern languages. One immediately thinks, here, of the highly literate and canonically-allusive work of contemporary writer-director auteurs such as Steve McQueen, Sofia Coppola, or the Cohen brothers. Yet the point is probably most aptly made in relation to the writing of Golden Age screenwriters such as Dalton Trumbo, Anita Loos, or Budd Schulberg. Despite the increasingly lofty profile of today's writer-directors and television showrunners, the names of most of our great cinematic screenwriters remain relatively obscure. Indeed, a century or so after the initial rise of audio-visual culture, there are few who could hope to find their names mentioned in the same breath as canonical dramatists such as Shakespeare, Shaw, or Beckett.

There are signs that some of these oversights are being gradually redressed, a contingency that opens up - in theory if not in practice - the possibility of a more thoroughgoing rewriting of the literary canon than the canon wars managed to achieve. It 
would probably be in the discipline's immediate financial interests to pursue these directions, for as Rita Felski has recently argued, "departments of literature ... are especially hard hit by a legitimation crisis that is affecting all of the humanities" ("Uses" 22). One would imagine that it precisely for this reason that literature departments have served as the principle institutional seedbeds to so many branches of the utilitarian humanities, as intimations of mortality see scholars making new bids for "legitimacy" and relevance.

Felski has proved especially adept in this regard, and as a recipient of a substantial Niels Bohr Professorship, is now well positioned to see her Latourian branch of "postcritical" literary studies "develop[ing] new frameworks and methods for exploring the many social uses of literature" (22). If recent arguments provide a guide to future practice, Felski's understanding of "the literary" seems likely to involve the "forging [of] closer links to the study of other media" and the rejection of "tenuous claims to exceptional status" that she has advocated elsewhere (22). Yet given the contorted economic structure of the contemporary literary academy - especially the toxic intergenerational interplay of tenure and casualization - it is doubtful that this latter task will ever be pursued on the kind of universal scale that it, at least in theory, warrants. Indeed, it actually seems more likely that literary studies will undergo - alongside and in response to the incursion of "utilitarian humanities" labs - a partial retrenchment to the most paperbound definitions of the literary, as established scholars fight successful rearguard defenses of position from the high ground of tenure. In the meantime, the social role of the writer will continue to expand beyond the discipline's narrowing field of vision. Literature will know many afterlives. For even as popular induction into the old 
literary cannon wanes, television writers and showrunners - schooled in its lore continue to measure their ambitions in relation to the established print culture landmarks. Indeed, their works' allusions to the old precedents already sees the influence of the literary tradition echoed in the dominant narrative mediums of the digital age.

While the development of the utilitarian humanities thus seems set to secure literary studies a reduced but viable presence on the contemporary campus, and while we can count on old world literary studies retaining a place in the liberal arts curriculums of the world's highly-moneyed elite schools (where they will serve as a marker of superelite cultivation), many of the next generation of literary humanists will have little choice but to follow the lead of writers, in seeking out new niches. For although tenure track positions are now infamously thin on the ground, it is a less discussed fact that the current postgraduate cohort is the largest on record (Jaschik). Some among this phalanx of new doctors will carve out careers by moving from contract to contract within the university sector, as the spread of public-private labs facilitates the incursion of casualized creative class employment models into humanities and social science departments. Though these working conditions are considerably more precarious than the established professoriate are accustomed to, this relatively well paid and prestigious form of work will probably prove preferable to the rawer deal of sessional instruction, where many more new doctors will attempt to find an unforgiving toehold. But given that neither option promises secure employment - long one of the key draws of the academic sector - many new PhDs will be encouraged to ply their trade outside of the academy.

The more insistent champions of the digital humanities would have us believe that, absent experience in quantitative and computational analysis, humanities students 
will struggle to "forge" careers in "the information-intensive and media-rich environment[s]" that define professional work in the new millennium (Hayles, 22). Yet this perspective seems to offer a slightly myopic appraisal of contemporary economic and cultural conditions. Indeed, it belies an awareness of how deeply and pervasively the business of cultural curation has penetrated into the practice of brand building. The barriers between the highly-valorized field of the tech industry and the domain of cultural curation and critique are increasingly thin. One only has to look at the current curatorial strategies of Apple, Amazon, Facebook and Google to begin to see how the capture and control of prized cultural content has emerged as a key marketing strategy for some of the Fortune 500's most valuable companies. In a case such as Apple, it has become evident that many tech companies now see the possession of key cultural property rights as a means of acquiring and maintaining a dominant market share, as they openly position their software and devices as the most reliable, immediate, and secure point of access to "exclusive" or otherwise scarce and inaccessible cultural content. In order for these ploys to work, such organizations need to be highly attuned to the vagaries of the contemporary culture market, aware of the sites where cultural prestige and market appeal are, at a given time, most powerfully concentrated. The rise of influential consultancies such as ReD Associates - staffed by cohorts of anthropologists, sociologists and cultural critics sees the world's largest brands increasingly willing to pick the brains of humanists and social scientists in their search for a more fine-tuned understanding of the dynamics that animate the field of cultural production (Dignan; Baxter).

In consequence, it seems that alongside Digital, Medical and Energy Humanities labs, we will in time also witness the rise of creative economy R\&D hubs designed to 
produce a new mode of market-facing and brand-oriented cultural curation and analysis. Such developments would be welcomed by EU Higher Education policymakers, who have recently gone so far as to mandate the complete assimilation of Social Science and Humanities (SSH) research to the kind of problem-focused prototyping centers that characterize R\&D in the tech industry. Under the EU's new guidelines, research funding will henceforth be allotted according to "challenges to tackle rather than disciplines to be financed" (Geoghegan-Quinn, 2). Again, it is here that we should look for the proximate causes of the trends currently overtaking our disciplines, as the injunction to directly contribute to "boosting competitiveness, creating jobs and supporting growth" colonizes every available corner of the academic system (EC, "Leadership" 3 ).

Indeed, to survive the combined contraction of patron states, credit markets, and undergraduate cohorts, many new humanists will have little option but to bid goodbye to their more familiar objects of analysis, as they attempt to make their way through the new knowledge production platforms. Yet of all the things that one could bemoan about the present age, it seems unlikely that this development should be a principle object of complaint. For although such tendencies open up some scant but tantalizing prospects for cultural curation's new batch of discipline-orphaned doctors, it is hard to deny that against the backdrop of unremitting ecological carnage, escalating social disparities, mass incarceration, and the rise of the ethnonationalist security state - the fate of classical humanism remains a lamentably limited concern. Indeed, many of the contradictions of our geo-historical moment are made manifest, here, in the terror with which aspirant humanists greet the latest batch of academic job listings, and the relative equanimity with 
which we meet global governance's latest failure to forestall the onset of anthropogenic climate change.

Variants of the same dynamics play out at every tier of the Anglophone literary academy, where "immune responses" to the incursions of utilitarian humanities labs have often served to distract from their deeper systemic causes. For instance, few critical accounts of the Digital Humanities' rise have avoided the pitfall of pastoralizing older knowledge production regimes. The final statement of Timothy Brennan's recent riposte to the Digital Humanities offers a concise case in point here, as Brennan closes out a spirited " $j$ 'accuse" with a damning one-liner, suggesting that DH has conspired to turn "many humanists into establishment curators and made critical thought into a planned obsolesce" (B14). Though sympathetic to Brennan's frustration with the grandiose language in which DH has made its successful bid for legitimacy, and though supportive of the general drift of his politics, one does bridle a little at the implicit suggestion that the fate of "critical thinking" is so unquestionably tied to the reproduction of exiting literary studies programs. And one might also add that in offering an honest account of the historical development of the discipline we must be careful not to allow present constraints to lull us into a rose-tinted perspective on literary humanism's history. Can it really be said that it has taken DH to "turn" literary humanists into "establishment curators"? Perhaps we get closer to the truth of our abiding historical role if we admit that Brennan's stinging phrase actually unwittingly names the principal social function that literary humanists have performed since their discipline's inception.

Granted, what "the establishment" asks of its "curators" changes over time. A comprehensive genealogy of literary pedagogy would find us tacking back all the way to 
the earliest days of print culture. Yet there are many accounts now of the co-development of urbanization, industrialization, and mass literacy in the "developed" economies, such that it is actually relatively straightforward to show that the concept of the literary came into common currency precisely as elites attempted to regulate, curate, and categorize the voluminous output of the industrial printing press. Think of Thomas Babington Macaulay's notorious “Minute on Indian Education"; or Matthew Arnold's “sweetness and light" as source texts for faith in the civilizing, softening, humanizing impact of exposure to elite culture. Looking at a more contemporary period, scholars including Michael Szalay, Eric Bennett, Juliana Spahr, Jodi Melamed, and Mark McGurl have helped establish how the literary sensibility was mediated and more fully popularized in the immediate postwar period, as the print culture canon was institutionally mainlined by the belle époque's sprawling network of tax-funded campuses. As we have already seen, in touching on Joshua Clover's argument, the existence of these relatively easilyaccessible schools rested upon the early postwar period's robust, and historically exceptional, levels of economic dynamism, and on the advanced economies' correspondingly large state coffers. In this era, in areas of advanced economic development, literature thrived as a luxurious but accessible cultural good, conspicuously consumed alongside other markers of affluence and enfranchisement.

Indeed, in the years following the GI Bill, unprecedented numbers of Americans flooded into a higher education system in which a liberal arts education served as the cultural matrix of the postwar managerial class. In the UK, the Tripartite and Comprehensive systems also sent a comparably unprecedented proportion of young adults into higher education, putting them into contact with culture's standard bearers. 
Yet as Mandel points out, a decade or so deeper into the postwar period it is starting to become evident that the "classical humanist university" is being consigned to a residual institutional position - displaced by the rapid proliferation of disciplines that educational policymaking was supporting in its efforts to supply industry with students trained in the hard sciences and the ballooning administrative and managerial arts. In the decades since, as state supports continue to fall away, classical humanism has persisted in the same liminal condition that Mandel first identified in the early 1970s, enjoying a strangely exuberant dotage as the demand-driven logics of the student loan industry conspired to sustain its relative share of the higher education market. ${ }^{8}$

The history of the university sketched in broad strokes above gestures towards the ways in which capital's real movement has elicited profound systemic changes in the disciplinary production of knowledge. Underlying this argument is Mandel's thesis that we can witness the university - and thereby disciplinary knowledge production sui generis - mutating (and expanding and contracting) in relation to "longwave" cycles of capital accumulation, and in response to corresponding changes in world-ecology and in the real economies' demographic and technical composition. Depending on one's historical and disciplinary vantage the demands exerted by capital's real movement at a particular juncture will thus arrive as boon or curse, funneling revenue streams toward or away from one's areas of opportunity, interest, and concern. In the case of literary studies, a combination of longstanding policymaking hostility, contracting credit markets, and rising levels of student aversion are now seeing revenue streams choked off from

\footnotetext{
${ }^{8}$ See also Peter Mandler; "Ben Pimlott Memorial Lecture 2014: The Two Cultures Revisited: The Humanities in British Universities Since 1945": 400-423.
} 
every direction. In response, scholars and academic associations are attempting to reposition and redirect the discipline's goals and mandates to better accord with policy directives, a development that is also calibrated in relation to their efforts to win back leery undergraduates.

Given a still-widespread preference for Foucauldian analytical categories, these trends will almost inevitably be read as the final triumph of neoliberalism's "stealth revolution"; yet I hesitate to take this view of the matter myself. Instead, I read policymaking's increasingly heavy-handed funding interventions as a partial departure from neoliberal doxa, one that is coming into effect with the failure of existing economic models, as governments undertake an increasingly desperate search for ways to intervene in a stagnating world-system and a destabilizing planetary climate.

Indeed, at the present conjuncture we now see governments convening think tanks and real-time "innovation" hubs around questions to which they have as yet few answers, as the social innovation "prototyping" program emerges as the watchword of higher education policy. In the heyday of Keynesian educational planning it was enough to double down on the battle-cry of "fragmented science, subordinated to profit maximalization by the monopolies," in the effort to sustain the onward rush of modernization (Mandel 262). During the giddy years of deregulation planners were content to promote the market's salvific entry into every quarter of life and governance, a phenomenon that helped to preserve and proliferate the postwar university's wide array of disciplines. But in the wake of the 2008 crisis, as the world-system continues to hemorrhage momentum, and as the ecological expense account of the postwar era comes due, planners no longer promote the fractal fragmentation of disciplines, and are instead 
convening broad-based interdisciplinary research teams tasked with synthesizing multifaceted "design responses" to a forbidding cluster of "future challenge areas." Here - as an instructive example of a much more broad-based phenomenon - is the EU's concise explanation of their new approach:

A challenge-based approach will bring together resources and knowledge across different fields, technologies and disciplines, including social sciences and the humanities. This will cover activities from research to market with a new focus on innovation-related activities, such as piloting, demonstration, test-beds, and support for public procurement and market uptake. It will include establishing links with the activities of the European Innovation Partnerships (EIP).

Funding will focus on the following challenges:

- Health, demographic change and wellbeing;

- Food security, sustainable agriculture and forestry, marine and maritime and inland water research, and the Bioeconomy;

- Secure, clean and efficient energy;

- Smart, green and integrated transport;

- Climate action, environment, resource efficiency and raw materials;

- Europe in a changing world - inclusive, innovative and reflective societies;

- Secure societies - protecting freedom and security of Europe and its citizens. (European Commission, "Societal Challenges")

Though the EU is at the leading edge of these developments, the trends are global ones. In states where direct federal intervention into higher education structures is permitted in cases as diverse as the EU, Canada, Australia, Nigeria, and Indonesia - one can look to government policy documents and programs to find iterations of the same mandates and initiatives playing out. Meanwhile, in the United States, where federal intervention into higher education takes place at arm's length, the charge is being taken up by private 
institutes such as the Rockefeller Foundation, who act in proxy for the government itself, in setting up, for example, a national Social Innovation Labs project.

In an effort to dive a little deeper into the systemic logic that underpins these developments, I think a quick glance at the EU's policy briefing on social research will prove illustrative. The whitepaper Testing Social Policy Innovation was published in 2011, and it offers member states a series of recommendations on how to develop the kinds of research programs that policymakers now deem necessary as they struggle to maintain a residual semblance of postwar welfarist provisions. In the opening paragraphs of the document - produced in conjunction with the London School of Economics' LSE Enterprise - the European Commission "stresses the need for modernisation of welfare states given the implications of the demographic change and of the financial and economic crisis" (4). They go on to observe that the "modernisation of social policies requires systematic introduction of ex ante result orientation in financing decisions and a systematic approach of the role social policies play in the different stages in life" (4). It is quite clear that the term "modernization" means something a little different in this context than it did in days of the immediate postwar period. In those days the concept of "modernization" was all but coterminous with the expansive sense of futurity that prevailed as developmental programs such as the Marshall Plan saw the US pouring vast funds into the increasingly global development of "modern" infrastructures and pedagogical institutions. There, the stress was laid on the construction of a "new" internationalist order that would extend the benefits of technoscientific modernization to an expanding catchment of enfranchised global citizens. 
Here, rather than directing propulsive global expansion into new frontiers, one instead has the sense that policymakers are stoically confronting the fallout of a crumbling order. The concept of modernization as it is used in the EU document, seems to take on a strangely retrospective character, as state officials attempt to prop up existing social welfare systems by making austere and deliberate use of "innovative" social science. Little wonder that policymaking documents increasingly stress the goal of "sustainability" over that of development. It is in this broader context, in which policymakers attempt to sustain the "unsustainable" institutional legacies of postwar modernization, that international organizations have begun to place stress on the concept of "social innovation":

In this context the role of policy makers is crucial in guiding the reform process, selecting the appropriate policy priorities and for an effective follow-up and increased sustainability of the results. In order to play this function, policy makers need tools that allow them to assess the investment returns of the chosen policies in terms of social outcomes (increase in inclusion and employment, reduction in cost of service at same quality level, contribution to the economy...). (4)

The document goes on to outline the kind of "tools" that policymakers will need to make use of as they attempt to manage this seemingly unmasterable set of demands and circumstances. Among the contemporary social state's preferred procedural devices is a heuristic method known as the Theory of Change (ToC). The basic concepts of the device are included, in full, in TSPI, and its terminology will be familiar to workers in most branches of the contemporary welfare state. It goes without saying that this procedural, pseudo-algorithmic, language is especially reviled in humanist circles:

A good ToC uses six different building blocks: 
1. Needs: is the assessment of the problems faced by the target population.

2. Inputs: are the resources that will be consumed in the implementation of the intervention. Those include the time spent by the agents implementing and evaluating the project and the costs involved (i.e. the services and goods service providers will need to purchase). The critical question is: to what extent will these resources enable the delivery of the intervention?

3. Outputs: is what will be delivered. It can be information, a subsidy or a service. The key question here is: how likely is the intervention to produce the intended short-term outcome?

4. Outcomes: are the results of interest likely to be achieved once the service has been delivered. Outcomes in the social policy area usually appear in the medium term.

5. Impact: is the change in outcomes that is caused by the intervention being tested.

6. Finally, a ToC should document the assumptions used to justify the causal chain. These assumptions need to be supported by research and stakeholder consultations. This will strengthen the case to be made about the plausibility of the theory and the likelihood that stated outcomes will be accomplished. (8) What is under discussion here is the promotion of a lean, low cost mode of social engineering designed to target resources efficiently, garnering maximum "impact" for minimum cost. Tellingly, in those case studies that are highlighted to illustrate best practice, the underlying story is one in which existing services are bring contracted and withdrawn. In a particularly galling example, we can see how clearly the wellbeing of the individual citizen is made entirely subject to the budgetary objectives of a social state in retreat: 
Between 2004 and 2006, the UK Department for Work and Pensions conducted the Job Retention and Rehabilitation Pilot, a set of workplace and health interventions meant to help people with long-term health issues stay in work. Given the nature of the intervention, it was decided that the primary outcome of the pilot was the employment situation of participants. Their health situation, which might have been affected by the intervention was considered a secondary outcome. (11)

Here, in a grain of sand, is "modernization" in its autumnal years.

The ramifications of this policymaking outlook on the contemporary fate of the humanities might appear a little obscure. Yet consider the EU's directives on the allocation of social science research funding. Acknowledging " $[\mathrm{t}]$ he tough economic context, as well as the intense pressure on governments and organizations to demonstrate effectiveness," the European Commission concludes that "leaders are increasingly selective when it comes to supporting research projects" ("Testing" 9-10). Humanities funding, routinely funneled through the same wing of the state that oversees social science projects, is now increasingly contingent upon one's ability to learn this alien language of inputs, outputs, impacts and outcomes. One must actively demonstrate that they can either help the state deliver social reproduction at a considerably lower cost, or help it supply industry economically-actionable forms of knowledge and governmentbacked paths to profitable investment.

A relatively recent address from Máire Geoghegan-Quinn, European Commissioner for Research, Innovation and Science, offers a nice crystallization of this policymaking climate. Geoghegan-Quinn spells out how "Horizon 2020" - the EU's 
flagship economic policy program - will impact the form and content of humanities and social science research:

Instead of programmes dedicated to particular research disciplines, Horizon 2020 seeks to solve, through research and innovation, our biggest challenges, such as climate change, an ageing population, and/or energy security. Horizon 2020 defines six major societal challenges - soon to be seven, at the request of the European Parliament. The Social Sciences and Humanities, in all their various disciplinary guises, will be firmly embedded in all the challenges. "Embedding" means that the Social Sciences and Humanities can make their contribution where they are most needed. It means that they can provide the necessary knowledge and understanding to tackle the challenges. It means that the social, political and human aspects are not forgotten alongside the technological aspects. (3; emphasis added)

I though it worth italicizing the subtle modulation of the imperative form into the conditional, in order to underscore the strange interplay of authoritarianism and solicitation that so often defines these documents. This characteristic use of carrot and stick on the one hand reassures humanists and social scientists that they have a future, and on the other makes clear the content of it.

That these reassurances need to be made in the first place is striking, and it is doubtless true that the condition of precarity that Geoghegan-Quinn addresses, summons, and purports to mollify, is actually the necessary precondition for the stance of boundless disposability that she goes on to presume. In this regard, it is surprising how little public or academic conversation has surrounded the Horizon 2020 initiatives themselves. Indeed, it is a telling comment on the functional efficacy of these kind of documents and addresses that their directives generate so little discussion. The labs have been convened, 
the target-area-focused sub-disciplines have proliferated, "neoliberalism" has been roundly denounced, but debate about the content and rationale of the frameworks themselves has proved relatively scarce.

Again, I suspect this oversight is at least partly due to the predominance of Foucauldian analytical categories, which conceive of neoliberalism less as that set of resurgently laissez-faire economic policies that supplanted the defunct Keynesian consensus, and more as that mode of entrepreneurial subjectification that was promoted in conjunction with them. Naturally, the most productive accounts of the neoliberal period attempt to understand the connections between these coeval phenomena, but it remains the case that an overt focus on neoliberalism as program of subjectification, rather than as macroeconomic policy initiative, is apt to overlook the university's ongoing imbrication in the periodic bouts of systemic restructuration that capitalism's crisis tendencies have always necessitated.

Marx argued that capital's moving contradiction is always sawing off the branch on which it sits; each new regime of accumulation claws its way out of the demise of the last only to dig its own grave. In this scheme of things governments are given little scope to devise returns to more pastoral arrangements, nor to script social conduct in any form that they see fit. Indeed, their planning and pedagogical initiatives are constantly informed and circumscribed by the need to secure "economic growth" - which amounts, in times of crisis, to finding capital new routes to profit. And as we will see further in our brief survey of the current batch of programs, in the end this always entails making every other social, ecological, or political consideration subordinate to the anticipated and projected needs of industry and investors. 
We can put this thesis to the test as we return to Geoghegan-Quinn's address. With only Foucauldian categories on hand, one will likely read the program she outlines as an intensification of neoliberal praxis, rather than as a departure from it:

The increasing importance, indeed the necessity of the Social Sciences and Humanities, has spurred us on to create a bold, new vision for them at the European level. It is a vision shared by the European Parliament and the Member States and by many stakeholder organisations. It will require commitment, effort and openness from everyone involved. Researchers, businesses, innovators and entrepreneurs are of course the primary customers of Horizon 2020. But Horizon 2020 sets them in the wider context of how R\&D and innovation shape our economy and can change our society for the better. The programme focuses on challenges to tackle rather than disciplines to be financed. (2-3)

Indeed, all the red flags are present and correct. How else to parse the phrase "[r] esearchers, businesses, innovators and entrepreneurs are of course the primary customers of Horizon 2020," than as evidence of the completion of the neoliberal program? My suggestion here has been, however, that we read interdisciplinary research hubs less as neoliberalism's final victory over social democratic decency and good sense, and more as a novel development that is nonetheless fully congruent with late capital's longstanding dependence on the acceleration of "informational turnover time" via the expansion of its "preproductive spheres."

The intensification of this longstanding imperative becomes clearer still if we factor in the EU's concurrent promotion of "Knowledge Triangle Theory," a governmental schema that adopts "business"; "higher education"; and "research and technology" as its constituent parts (Technopolis, 8). One of the key doctrines of Knowledge Triangle Theory is that insight and innovation are best catalyzed by constant 
"non-linear" exchanges between the three sectors. Here, as ever, the bogeyman is the statist planned economy, and the goal of this new theory of knowledge production is - to borrow Mandel's terms - to accelerate informational turnover time in developing more "lean" and "adaptive" modes of research, innovation, and information dissemination (Hassan, 19). The theory thus acts as one of the primary conceptual devices steering the EU's higher education programs away from monolithic disciplinarity, towards experimental modes of collaborative interdisciplinarity:

The core principle that distinguishes the KICs from other, more traditional, research and innovation arrangements is the explicit link between all the elements in the full innovation cycle, from education and knowledge creation to new market opportunities and innovative business support. (Technopolis Group, 6)

With this schema in mind the EU began pilot programs - so-called Knowledge and Innovation Communities (KICs) - designed to put key avatars of the three sectors into close and collaborative contact around a familiar cluster of problem areas: technology; climate; and energy. As in the case of its social innovation policies, the KIC's underlying web of "co-location" research hubs function through a kind of checklist proceduralism. Teams are compelled to continually monitor impact, taking regular performance measurements, in their efforts to gain a rapid and self-reflexive purchase on the effectiveness of their interventions, and the acuity of their theories. In view of this end, and in view of the demand to accelerate knowledge production turnover time and drive down inefficient expenditure, individual "co-location centres" are said to be granted a considerable measure of autonomy, allowing them to escape the inevitable slowdown that results from centralized ministerial oversight. 
Yet, as in the area of social innovation policy, there is drum beat of rising tension discernible just below the European Institute of Innovation and Technology (EIT)'s public statements, and their relentless tone of pragmatic optimism and selfcongratulation. Climate change and other maladies all continue to surface as the ostensible grounds of their KIC initiatives' legitimacy. Yet despite the invocation of these high-minded ends it is evident that the dominant goal of these new knowledge production networks and real-time innovation labs remains delivering monopoly capital its "preproductive zones" and R\&D departments at a reduced cost to both state and business:

While participating in a KIC incurs costs in terms of money and other resources, it may also lead to significant savings as a result of resource pooling, infrastructure sharing and knowledge creation. The existing activities and innovation projects are closely aligned with market developments. They identify promising possibilities for new forms of collaboration and pioneer new value chain configurations in emerging sectors, in the case of Climate-KIC, or in emerging niches of already consolidated sectors, as happens in KIC InnoEnergy and EIT ICT Labs. Within a KIC ecosystem, industrial partners are advantageously positioned to be early adopters of new technologies and can benefit from ready-made market analysis to commercialise the innovation. A particular gain for industry from its involvement in the KICs is easy access to a network of talent and expertise in cutting-edge research and to novel ideas from innovative SMEs and entrepreneurs. (10)

In this respect it will come as no surprise that in most KIC statements the words "growth" and "competition" recur with a steady grinding rhythm, while the labs and co-location centres are tasked with securing "stakeholder" buy in, in many cases insisting on a sevenyear contract in order to reduce the risk of project failure. In return, investors, funders, 
and partners are promised research which is specifically tailored to the up-to-the-minute needs of their organizations and industries.

Yet at the present conjuncture, the relationship of these longstanding dynamics to the institutional position of the humanities and social sciences has been transformed, such that the "acceleration imperative" is no longer acting as the wedge that Mandel saw driving humanism into the outer dark, and more as a mode of capture designed to affect the complete (and mandatory) assimilation of the arts and social sciences to a new breed of fully-interdisciplinary R\&D. Indeed, today's policymakers often express a strange and somewhat inchoate "need" for what they refer to as the "insights" of humanists and social scientists. In this regard, the cumbersome and somewhat incongruous title of the EU white paper "The need to integrate the Social Sciences and Humanities with Science and Engineering in Horizon 2020 and beyond" maps the prevailing vectors rather well. Leafing through its pages, humanists may be surprised to find themselves metamorphosing into late capital's canaries in the coal mine. "Embedded" in flagship $R \& D$ programs from the point of inception, they are asked to serve there as the guardians of "humane values":

In this short paper, we, the advisory group to FET - the largest H2020 programme solely devoted to groundbreaking technologies - propose that much more attention should be paid by Horizon 2020 and its successor to supporting multidisciplinary and interdisciplinary research that brings together engineering, natural science and the social sciences and humanities in a way in which no one discipline is pre-eminent, but all work together, each inspiring and depending on the others. Robotics, mobiles and Internet based technologies have already caused revolutions in social organisation well beyond the communication area. Similar effects are being caused by the explosively developing bio- and pharma- 
technologies. In the past, each radical shift in human society has been driven primarily by one key enabling factor - from wood, stone, bronze, and iron, to steam, electricity, factory automation, and the Internet. Today, science and technology enabled shifts will redraw not only our economy, culture and society, but also our biology and our ethics. It is thus of utmost importance to incorporate a social sciences and humanities research component in the development of these new technologies from the earliest stage. (2)

There seems to be a hope, here, that the mere planning-stage presence of the humanist or social scientist will serve as a brake on late capitalism's most destructive tendencies. The outlines of this unlikely model of salvation become clearer still as the paper goes on to map out the regulatory role that "embedded" social scientists and humanists will be tasked with fulfilling:

Horizon 2020 is the EU's main programme aimed at securing Europe's global competitiveness. How could the social sciences and humanities contribute more to this mission, so that science and technology developments fulfil their primary purpose, which should be serving humanity and sustaining the environment? (3) The systemic tensions that threaten to broach the surface of this ostensibly simple pair of sentences are pronounced. The left hand remains reluctant to acknowledge the right. Capitalist social relations - euphemistically referred to as "global competitiveness"remain determinative in the last instance. Yet a clear-eyed consideration of the possible costs of this enduring political commitment are evaded, as the fig leaf of a second "primary purpose" is introduced into the picture. Nowhere in this scheme of things is there scope to question whether these two "primary purposes" are actually reconcilable. That being so, the founding intent of this knowledge synthesis program seems to be to stimulate "technological renewal" and maintain the velocity of "informational turnover 
time" while at the same time pre-emptively anticipating and mitigating the worst forms of socio-ecological blowback.

It is tempting to offer a merely satirical take on these developments, if only as an ego defense against the uncanny interplay of abjection and grandiosity that defines the humanist's role in these proceedings. Yet there are still many outstanding questions to be asked about exactly why policymaking is effecting this programmatic synthesis of knowledge production in the first place, one which effectively announces the end of academia's "two cultures." This particular development seems to have had few obvious systemic precedents in Keynesian and neoliberal periods and is as such one of the distinguishing features of the post-2008 knowledge production paradigm.

But although many humanist critics of the neoliberal university now hearken back to the earlier order as a kind of golden age of humane good sense - one in which the humanist academy made essential social contributions as a revered seat of "critical thinking" - we have seen that Keynesian pedagogical planning was no particular friend to classical humanism. Here is Mandel, again, writing at the tail end of the 1960s surveying a familiar field of conditions, one in which the STEM disciplines have already emerged as late capital's indispensable central nervous system:

The hallmark of this growth of scientific labour - elicited by the cumulative growth of scientific knowledge, research and development, and ultimately determined by accelerated technological innovation - is the massive reunification of intellectual and productive activity, and the entry of intellectual labour into the sphere of production. Since this reintroduction of intellectual labour into the process of production corresponds to the immediate needs of late capitalist technology, the education of intellectual workers must likewise be strictly 
subordinated to these needs. The result is the crisis of the classical humanist university, rendered anachronistic not only for formal reasons (excessive number of students, backwardness of material infrastructure, changes in social background of students, which demands an above-average expenditure in the university sector, and so on) and not only for overall social reasons (attempts to avoid the emergence of an unemployed intelligentsia; attempts to restrain student revolt, and to step up the ideologization of science for the purpose of manipulating the masses) but also and above all for directly economic reasons specific to the nature of intellectual labour in late capitalism; the constraint to adapt the structure of the university, the selection of students and the choice of syllabuses to accelerated technological innovation under capitalist conditions $(260-1)$

And thus, to this relatively impartial observer of classical humanism's postwar fate, it is all too evident that the state has supported the STEM disciplines in lieu of all others simply because nation states have had little other option than to throw the bulk of their $\mathrm{R} \& \mathrm{D}$ resources into accelerating technological innovation, committed as they are to making their territories attractive to industry and investors. And yet despite the overriding continuities between the conditions that Mandel describes and those that prevail today, changes are observable. While contemporary policy documents are remarkably dictatorial in nature, they nonetheless offer our era's vast cohorts of untenured humanists and social scientists lines of flight and prospects of professional survival that many among this older generation of economic planners may have been little inclined to provide, had the subsequent expansion of the FIRE sector not seen the student loan industry come to serve as one of the neoliberal period's key financial engines.

Yet as the jockeying for position unfolds it is becoming clear that literary studies is unlikely to be "saved" without first being transformed. Surveying emerging trends 
within the discipline, we consistently find literature scholars attempting diverse and sometimes antagonistically disposed remediations of their signature practices, as they strive to make their existing skillsets legible and credible in the eyes of educational policymakers and funding bodies. It is hard not to read recent calls to arms such as Felski's The Uses of Literature, or other keynote works of the utilitarian humanities such as Jerome McGann's A New Republic of Letters or Katherine Hayles' How We Think, as entrants in an academic version of Dragon's Den, made to appeal to a network of publicprivate funders who now act in a manner analogous to venture capitalists, apportioning funds to those academic ventures that seem must likely to yield "impactful" results.

Yet the success of these different initiatives will tend not to preserve the discipline in the monolithic form that we inherited from the era of programmatic modernization, but will rather initiate the development of distinct branches of literaryinflected interdisciplinary inquiry. Indeed, the utilitarian humanities' ostensibly intradisciplinary strategies of distinction are probably best understood in this light, as a set of passkeys designed to give humanists access to the interdisciplinary research platforms and innovation labs that international governance has marked out as the new "horizon" of humanities and social science research. Thus, despite the temptation to see the Digital, Environmental, or Energy Humanities as developments "within" the discipline - indeed, they generally position themselves in precisely these terms - it would probably be more accurate to view them as exit strategies, developed ad hoc, as humanists attempt to escape the demise of the old knowledge production models.

Yet as my sketch of humanism's imbrication within the different phases of the postwar modernization program illustrates, these developments need not lead us to 
conclude that the humanist academy is only "now" becoming the site of capitalist activity, as there is scant evidence to support the strangely persistent claim that humanism and the social sciences have ever served as some meaningful last line of defense against the incursions of capitalist practice and market rationality. In recent decades, the enduring enchantments of bibliophilic radicalism have helped to lure cohort after cohort into indenturing debt and exploitative contract employment, while the Angel of History's socio-ecological dumpster fire all the while burned all the brighter, even as the student loan industry poured its financial fuel on the flames. As the devastation continues to mount up around us it remains hard to see how prevailing applications of "critical thinking" have made any significant dents in the disastrous spread of capitalist socioecological relations. Will critique fare better in the new forums and prototyping hubs where policymaking is now insisting it contributes its "insights"? One doubts it. Yet, strangely, there sometimes seems to be an occult hope - even on the part of policymakers themselves - that this might prove to be the case.

Despite the increasingly dystopian tenor of life at the tail end of the new millennium's second decade, we should thus not overlook the fact that these new policymaking initiatives do - by their very nature - leave the door open to the "internal" problematization and "public" politicization of an increasingly wide spread of major infrastructural and governmental projects. Making a virtue of necessity, the next chapter turns to the work of Bruno Latour, in attempting to puzzle out exactly what humanists can expect to find as we arrive, reluctantly, at the threshold of the laboratory. 


\section{CHAPTER TWO: SCIENCE IS ORDINARY}

While Latour's influence in the social sciences has been a matter of note for some decades, it is in only recent years that his work has become a touchstone for scholars in the mainstream of Anglophone literary studies. Uptake of his key concepts and stratagems seems to be occurring with accelerating speed. The enthusiastic reception of Rita Felski's Uses of Literature and Limits of Critique has demonstrated and extended the range of his influence, both as a leading theorist of new materialism, and as a notable proponent of the kinds of cultural and social inquiry that are currently favored in higher education policymaking circles.

In the course of three decades of intense intellectual activity Latour has furnished us with many interventions of enduring intellectual significance. As Benjamin Noys observes, "there is something salutary and even necessary" about the turn to objects that Latour has helped to spearhead, especially at a time when climate change and the everintensifying automation of production processes are forcing us to confront the worldsystem's entanglement in the obdurate path-dependencies of matter and machines (3). As we grapple with the fallout of social innovation policy, we can also learn to see Latour's work as an indispensable guide to the institutional logics of the lab environment. His "microstudies" of laboratory life, and his historical reconstructions of the "pasteurization of France," offer a vital if incomplete map of the institutional terrain that is now bearing down on humanists and social scientists alike. Latour's ethnographic studies of scientific and technical research form in their own right a kind of prototype to the synthetic modes 
of applied interdisciplinary research that we have seen global governance mandating in its efforts to "integrate" the social sciences and humanities with science and engineering.

In the Anglophone literary academy, the turn to Latour seems to have gained its initial traction in a scholarly context where book history had already successfully promoted a widespread interest in the materiality of the book, and where the emergence of speculative realism and object oriented ontology (OOO) had begun to push theories of the singular irreducibility of the literary object back to the forefront of critical agendas (Harman, 200-201; Morton, 214-216). Summing up the field of play in the years just prior to Latour's rise to literary critical prominence, Noys observes:

While explicit reference to Latour is fairly sparse, and should not be exaggerated, it is possible to argue that there is a wider "structure of feeling," which is precisely concerned with the feeling of objects "in both senses": a haptic attention to the material surfaces of objects and a sense or defense of the rights or status of objects as sites of feeling. (82)

Having offered this relatively fair-minded appraisal of Latour's intellectual appeal, Noys goes on to outline some urgent correctives to the overall thrust of new materialist thinking, arguing that contemporary scholars now need to answer new materialism's "haptic" focus on thingly relations by cultivating a more self-reflexive account of knowledge production. As we noted in the introduction, for Noys this entails developing modes of analysis that appreciate how deeply the critic, artist, and scientist are "embedded within forms of institutional practice" that shape their habitual modes of seeing (91).

One might imagine that as one of the founding figures of laboratory studies, Latour's work would prove especially well equipped to tackle this kind of task. Yet 
Latour's specific relationship to the question of self-reflexive institutional analysis is actually a little difficult to plot out. On the one hand, he makes his name around "microstudies" of laboratory practice, offering keen-eyed ethnographic reports on what "was happening inside the sacred walls of these temples," reports that are finely attuned to the inextricable imbrication of knowledge production and institutional design (Latour and Woolgar, 141). On the other hand, as he struggles to establish an initial niche for laboratory studies, he argues that he is constantly forced to resist the territorial claims of a contesting group of scholars, all "preoccupied by larger problems such as science policy, history of science, or more broadly, what is known as Science Technology and Society (STS) ("Give" 141). These are, it should be noted, scholars working more in the manner of Mandel, plotting out how large-scale policy initiatives shape the orientation of $R \& D$ hubs (and university curriculums) in relation to the projected needs and objectives of industry and big business.

To return to the language of Noys' critique, what we thus find, in the earliest days of Latour's intellectual project, is a sociologist designing modes of institutional analysis that pre-emptively resist Noys' invitation to "traverse abstraction." Instead, as Latour makes his name, and founds the field that secures his reputation, he initiates a form of inquiry that is explicitly constituted by parenthesizing, or cordoning off, the question of how policymaking orients the research objectives of the state's R\&D institutes. The legacies and limitations of this outlook are evident in the bulk of his subsequent projects, through the mid-career development of Actor Network Theory (ANT) to his more recent work on the ambitious EU-sponsored research platform, An Inquiry into Modes of Existence (AIME). 
Latour's record on the question of policy is admittedly a little more complex than this brief gloss can fully convey. And it must be acknowledged that his efforts to resist synoptic accounts of scientific development have not been without substantial analytical yield. His exacting attention to the material praxis of scientific and technical research has succeeded in bringing features of the world to brighter light. We see more thanks to Latour, rather than less. But only in so far as we refuse to make that definitive choice between old and new materialisms that he continually forces upon us. For if we accept the more dogmatic features of his argument - if we allow him, for instance, to drive discussion of totality into the hinterlands of academic debate - then knowing what Latour knows comes at too high a price.

In navigating these foundational methodological and political tensions, this chapter explores a variety of different routes into the core conundrums that Latour's research presents for the historical materialist. In so doing it distinguishes between his case studies of the material praxis of scientific research, which seem entirely compatible with Marx's methods, and his political opposition to "traversing abstraction," which proves wholly inimical to them. These tendencies - which appear somewhat contradictory from the vantage of an "old" materialist - see his work exerting a strangely magnetic combination of attraction and repulsion over the reader who attempts to engages it in depth while hewing close to the central insights of Marx's critique of political economy.

We get a general idea of the lines of inquiry that Latour opened up via early controversies within STS, if we take a moment to turn to his appraisal of Henry Collins and Trevor Pinches' historical analysis of the propagation of the humble air pump. In the 
following extract, we find Robert Boyles' deduction of the inverse relationship between air pressure and air volume serving as a theoretical framework for a whole of network of technical laboratories. These are labs whose "networks of standardized practices" serve to see a "cumbersome prototype" rapidly transformed into a widely-disseminated array of "cheap black boxes":

By following the reproduction of each prototype air pump throughout Europe, and the progressive transformation of a piece of costly, not very reliable and quite cumbersome equipment, into a cheap black box that gradually becomes standard equipment in every laboratory, the authors bring the universal application of a law of physics back within a network of standardized practices. Unquestionably, Boyle's interpretation of the air's spring is propagated - but its speed of propagation is exactly equivalent to the rate at which the community of experimenters and their equipment develop. No science can exit from the network of its practice. The weight of air is indeed always a universal, but a universal in a network. Owing to the extension of this network, competences and equipment can become sufficiently routine for production of the vacuum to become as invisible as the air we breathe. ("Never" 24)

Here, it is the iterative and amplificatory process of recursive and networked refinement that leads us, rapidly, from a handful of costly and unstable prototypes to a widelydisseminated array of standardized, reliable black boxes. This interaction of standardized practices and network effects proves so critical, as it is their combination that allows for thousands of work-hours to be channeled into the same technical problem within an intensely condensed period. What Latour maps out here is essentially an account of how the networking of a proceduralized practice facilitates the concentration of tremendous reserves of deductive effort at the resolution of a single technical problem. 
The clarity with which this central insight is formulated proves especially useful when applied to the unbearably acute technical and political quandaries that the onset of anthropogenic climate change compels us to confront today. For it is only in becoming more invested in understanding, tracking, and promoting iterations of precisely these kinds of dynamics that we can hope to become active participants in any process of "transition" that has a prospect of beginning in time to forestall the planet's passage toward the most extreme climate change scenarios.

Andreas Malm parses the central issues at stake here, before going on to unfold a political vision articulated in relation to these excruciatingly narrow timelines:

According to the latest scientific consensus, global emissions would have to peak before 2020 and then decrease by at least 3 percent per year - the same rate at which they currently increase, the explosion inverted into a flood of cuts, business-as-usual completely reversed... At this moment in time, the purpose of an inquiry into the climatic destructivity of capitalist property relations can only be a realistic assessment of the obstacles to the transition. They grow higher by the day. If the temporality of climate change compels revolutionaries to be a little pragmatic, it obliges others to start pondering revolutionary measures. (383)

Faced with this situation, and given the conclusion that Latour draws in asserting that the "speed of a [new technology's] propagation is exactly equivalent to the rate at which the community of experimenters and their equipment develop," those that stand outside of the "private space of the experimental community" are presented with a relatively simple strategic question: What can be done to see that these networks of practice are growing densest around the most vital technical questions and the most promising lines of inquiry and experimentation? 


\section{TRIALS OF STRENGTH}

One might wonder what humanists and social scientists can really hope to contribute to such a process. But here again I think Latour's work points us in useful directions. Consider, for example, his now classic contribution to the field of science studies, The Pasteurization of France. Latour's stated goal in this account of Pasteur's rise to prominence is to rebut the "great man" theory of scientific "revolutions." And as he begins this effort to reconstruct scientific practice in situ, we find ourselves in unlikely proximity to literary matters of concern, as he goes on to explain the logic of his intervention via reference to one of Russian literature's most celebrated scenes. The scene in question is taken from the prolonged digression in War and Peace where Tolstoy's narrator reflects on the profound limitations of individual agency.

Tolstoy's narrator takes issue with the prevailing historiographic tendency to attribute the outcome of key events to the strategic genius of a single individual. And in the revisionist account of the battle that he provides, we find Tolstoy drawing on the extensive archival research he had conducted into Kutuzov's correspondence. In the course of this work, Tolstoy discovers that Kutuzov had been somewhat unwillingly carried along by the course of events. Far from exerting a comprehensive mastery over the field of combat, he is instead forced to rubberstamp a course of action that he remains fundamentally disinclined to take. Left with little other option, Kutuzov finally concedes to engaging the French army on terms he considers disadvantageous:

Despite all his imaginary power, his intelligence, experience, and knowledge of people, Kutuzov ... could no longer hold back the inevitable movement, and gave 
the order to do that which he considered useless and harmful — he blessed the accomplished fact. (Tolstoy, 1084)

To Kutuzov's surprise, the Russians actually prevail at Tarutino, a result which sees contemporary chroniclers retroactively according him the status of master tactician. Latour glosses the lessons that science studies can draw from the novelist's probing of military events:

In [War and Peace], Tolstoy summons up hundreds of characters to give depth to what for him is the essential question: What can one man do? What does a great man like Napoleon or Kutuzov really do? It takes Tolstoy some eight hundred pages to give back to the multitude the effectiveness that the historians of his century placed in the virtue or genius of a few men. Tolstoy succeeded, and the whole of recent history supports his theories as to the relative importance of great men in relation to the overall movements that are represented or appropriated by a few eponymous figures. ("Pasteurization” 13)

Arguing in this vein, Latour begins his survey of Pasteur's rise to prominence by suggesting that our reliance on the tropes of scientific "revolutions" and individual genius has likewise served to distract us from paying more fine-grained and detailed attention to the host of unacknowledged factors and "agents" that attended and promoted Pasteur's rise.

In contrast to the then prevailing accounts of scientific and technological innovation - accounts that were preoccupied with the question of how new ideas were constituted in the first place - Latour instead works to foreground the means by which newly-constructed ideas and research protocols are materially publicized and propagated. He stresses that Pasteur's original claim concerning the microbial origins of infectious disease - and the spread of the particular prophylactic and diagnostic technologies that 
accordingly developed - did not proceed by way of some pseudo-physical chain reaction in which "genius" simply radiated its influence into the world. It was instead mediated by a host of discreet but interrelated parties. Latour sums up his hypothesis in the simplest of terms: "To convince someone that an experiment has succeeded, that a technique is effective, that a proof is truly decisive, there must be more than one actor" (15).

Though this line is written some years prior to his development of ANT, we clearly see Latour thinking along similar lines in this passage. And it is with the notion of multiple networked agents in mind that he will turn to describe the historical phenomenon of the hygienist movement in some detail. This finds Latour burrowing back into the historical annals, digging through a mass of journals and private correspondence, in an effort to demonstrate how pre-existing social networks provide Pasteur's theories of microbial agency both the discursive conduits through which public knowledge of them was channeled, and the financial nexus of fundraisers and investors that would subsequently bankroll the nationwide rollout of his laboratories.

Working in the latter half of the nineteen century, Pasteur's laboratory research responded to the then pressing question of "health and wealth" that had begun to preoccupy European elites during the concerted onset of urbanization (16). Simply put, the increasing concentration of human bodies in densely-populated urban centers was proving good for business, and bad for human health. The same concentration of bodies that secured industrializing capital its city-dwelling reserve armies of labour was also resulting in intensifying occurrences of contagious disease. Contemporaries of these events were equipped to identify the correlation, but until Pasteur's intervention they were not able to single out the microbe as the key casual factor. In the interim, responses 
developed along multiple lines, as countervailing explanations and putative remedies vied for credibility. And as the laboring classes were packed closer and closer together in stingy quarters, the concept of "hygiene" became a catchall term for the dominant class's philanthropic and disciplinary response to a state of affairs that threatened to derail the steady march of profit and progress altogether. A host of conferences, associations, publishing venues, and funding networks coalesced to address the issue, which was then - by necessity - understood in the broadest and most sweeping of terms:

Scientific rhetoric often channels the reader's attention in a single central direction, like a valley cutting through mountains. But the rhetoric of the hygienists does not possess this great flow. It has no central argument. It is made up of an accumulation of advice, precautions, recipes, opinions, statistics, remedies, regulations, anecdotes, case studies... Illness, as defined by the hygienists, can be caused by almost anything. Typhus may be due to a contagion, but it may also be due to the soil, the air, overcrowding ... To make fun of this style would be to fail to understand the nature of an all-round combat. If anything can cause illness, nothing can be ignored ... Many of the characteristics of socalled pre-Pasteur hygiene are to be explained by this situation. The hygiene congresses were, like Bouchardat's style, an attic in which everything was kept because sometime it might come in handy. In 1876, for instance, the subjects under discussion included water, lifesavers, gymnastics, women's work, "methods of developing among the laboring classes a spirit of thrift and the saving habit," alcoholism, and working-class housing. These congresses were a catchall, because illness could be caused by anything and because scientists had to be ready to set off enthusiastically in any direction. (20)

Though unable to narrow in on the critical factor, the hygienists succeeded in assembling a powerful network of players and vested interests, one that was especially well-primed 
to receive, celebrate, and promote the methods of diagnosis, disinfection, and inoculation that Pasteur's theory of the "germ" equipped him to provide.

Their response to the scientific controversies that subsequently erupted as Pasteur began to publish his findings was chauvinistic, partisan, and effective. The prominent hygienist Charles Richet was then the editor of the influential Revue Scientifique, and he did not hesitate to throw the full weight of his position behind Pasteur:

The Pasteur of the Revue Scientifique was not an obscure hero who was fighting alone against all and who had to convince his irremediably skeptical adversaries step by step. No, he had only to open his mouth, and others would turn his results into generalizations about every disease... [O]nce Richet became its editor, the Revue was on Pasteur's side and defended him "beyond the limit of all scientific prudence," one might say. When a timid challenge is raised, Richet, his flank guard, writes with condescension: "It is no bad thing if a discordant voice is raised amid a concert of praise. Perhaps it will encourage M. Pasteur to provide us with a few new discoveries as fruitful as the previous ones." That the Revue and all its authors should be so partial, so chauvinistic, so imprudent, shows the extent to which trust was placed in Pasteur, exactly as money is placed in a trust fund.... Generally "science" is never to be explained by itself. It is an ill-composed entity which excludes most of the elements that allow it to exist. The social movement into which Pasteur inserted himself is a large part of the efficacy attributed to Pasteur's demonstrations. (28)

In sum, the hygienist movement was soon deeply involved in the forceful promotion of Pasteur's work. They would go on to assist Pasteur in staging the famous demonstration at Pouilly-le-Fort, an event that then became emblematic of their broader efforts to publicise the veracity and social utility of his theories concerning microbial agency. 
In returning to events at Pouilly-le-Fort, Latour positions his own case study as one designed to evince a general claim concerning the means by which a theory manages to "become indisputable" (41). In accord with a tendency that he has stuck with for the bulk of his career, he defines the process of "becoming indisputable" as one that entails surviving an intensifying sequence of "trials of strength," trials in which proponents of differing theories vie with each other in their efforts to establish the indisputability of their own accounts. In accounting for Pasteur and the hygienists' successes, Latour highlights Pasteur's uncanny knack for devising scenarios that could stage the results of his research in the form of dramatic public spectacles, spectacles that Latour latter describes as "theaters of proof" (87).

The case of Pouilly-le-Fort provides Latour a particularly potent example, as it sees Pasteur and his allies staging a bold demonstration of his inoculation techniques before a throng of assembled agriculturalists, politicians, and newspaper correspondents. So that they might witness a dramatic display of the effectiveness of his anthrax vaccine, an assembled group was asked to look on as two discrete groups of livestock were injected with the bacterium Bacillus anthracis. Prior to the animals' exposure, Pasteur addressed his audience with an almost biblical prediction concerning the fate of the two experimental groups: to the one side, death; to the other, life. His research had left him with little doubt as to the outcome of this public trial. But to those exposed to such a dramatic scene for the first time, the tangible effects of his vaccine seemed almost miraculous in nature. The presses exploded with enthusiasm, and Pasteur soon found himself squarely in the public eye, with Revue Scientifique publishing weekly dispatches from his spreading network of laboratories, updating a riveted reading public on the 
increasingly rapid development of medical science. The combination of publicity with the formidable statistic strike rate of Pasteurian methods resulted in investors funnelling money into his institutes and laboratories. A "virtuous circle" was established that saw medical practice rapidly transformed from Hippocratic art to exact science.

Before long the hygienist movement had effectively morphed into Pasteur's movement, as the celebrated scientist became the totemic figurehead of the bourgeoisie's enlightened war on disease and ill health. Yet in identifying the networks that undergirded this process, Latour argues that he is not attempting to diminish our understanding of Pasteur's contribution. What Latour's account instead claims to add to the picture is a fuller understanding of how the theory and praxis of Pasteur was culturally and institutionally mediated. And in tackling this question, we have seen Latour analyzing the activities of a network of what we might today refer to today as "media players," lobbyists, and investors, who worked in concert with the experimental science of Pasteur's laboratory. The combined influence and cooperation of these different agents equipped Pasteur to turn the quietly painstaking activities of his private lab into a loudly-lauded national program. Summing up the hygienists' successful efforts to fascinate their contemporaries and so shift the fundamental structures of the social imaginary, Latour draws attention to the words of one of Pasteur's contemporaries, who suggests that the staging of Pasteur's experimental research had convinced a nation, and later a continent, that "[t]here are more of us than we thought" (35).

We have here a convincing account of the initial incorporation of "the lab" into the urban infrastructures of the industrializing metropolis, where it worked to regulate and readjust human and microbial relations, effectively defusing the so-called conflict 
between "health and wealth." The result of Latour's study is to return us to the initial imbrication of microbial and human bodies that Pasteur uncovers, before tracking the countervailing development of new analytical and technical procedures that are then used to introduce strategic "splits" in their interaction. Pasteur's laboratory practice essentially structures and manages the development and operation of a vast series of microbial sensors and gates that are diffused - via network effects - over a large territory with great speed, through a process that has distinct technical, discursive, and financial wings.

This theory's potential strategic utility with regard to the question of climate change is worth emphasizing. Latour's account of the "theater of proof" offers some precise indication of a key area where political efforts to initiate substantive climate change mitigation and adaption strategies are currently falling down. For though the argument for anthropogenic climate change has already successfully prevailed within the trials of strength that are proper to the scientific community, it has yet do so decisively in the court of public and political opinion.

Indeed, commercial and political expediencies - expediencies that have their material roots in the gigantic allocations of industrial capital and R\&D funds that the energy industry has already committed to the extraction of fossil fuels - are instead opening up bitter controversies between science and industry. Scientists are now becoming accustomed to the unnerving experience of their longstanding allies in government and industry performing a disturbing series of about-faces regarding the veracity of scientific truth claims. Here is Latour describing an exemplary scene of the increasingly fractious relationship between science and industry: 
They're sitting around a table, some fifteen French industrialists responsible for sustainable development in various companies, facing a professor of climatology, a researcher from the Collège de France. It's the fall of 2010; a battle is raging about whether the current climate disturbances are of human origin or not. One of the industrialists asks the professor a question I find a little cavalier: "But why should we believe you, any more than the others?" I'm astonished. Why does he put them on the same footing, as if it were a simple difference of opinion between this climate specialist and those who are called climate skeptics (with a certain abuse of the fine word "skeptic")? Could the industrialist possibly have access to a measuring instrument superior to that of the specialist? How could this ordinary bureaucrat be in a position to weigh the positions of the experts according to a calculus of more and less? Really, I find the question almost shocking, especially coming from someone whose job it is to take particular interest in ecological matters. Has the controversy really degenerated to the point where people can talk about the fate of the planet as if they were on the stage of a televised jousting match, pretending that the two opposing positions are of equal merit? ("AIME" 23)

It is easy to see why Latour presents the dynamic described here as paradigmatic. Despite overwhelming evidence of the onset of anthropogenic climate change, we have yet to undergo the fully cultural and discursive process that Latour describes in terms of an idea "becoming indisputable." The main reason for this is simply that, from the vantage of key players in the energy industry, relations between research findings and strategic interests are the inverse of those that Latour describes in the case of Pasteur and the industrialists.

This is a contingency that Latour could afford to consider in more depth, as its full political implications seem to somewhat escape him. We will return to this point in our concluding appraisal of AIME's overarching concern with the "diplomatic" resolution of inter-institutional "misunderstandings." But for the time being I want simply to dwell on 
what can be gleaned from contrasting the relations between industry and science that define the two moments. In Pasteur's case, industry and philanthropists were happy to pour vast reverses of finance and support into his research, as its applications neatly aligned with their material interests, resolving the conflict between "health and wealth" that was then threatening to derail the steady march of industrial expansion. The reverse proves true for many of today's climate scientists. With the formidable media and financial resources of the fossil fuel industry turned against them, climate scientists are all too aware that their research will not simply radiate its influence into the world. It must be funded, promoted, and propagated via financial, discursive and diplomatic networks. And what we thus discover is that while industry and government gladly promote and venerate the authority of "capital S Science" in cases where research findings and industrial interests neatly overlap, in today's context they are equally prone to pull out the rug from under researchers whose conclusions present impediments to the ongoing expansion of their industries ("Gaia" 278). Knocked off the very pedestal that industry had once constructed for the genius Pasteur, scientists can no longer rely on the notion that their findings will be welcomed and promoted outside their immediate sphere of professional influence. And without the uniform and consistent backing of industry and government, appeals to the generalized authority of the scientific expert are no longer operating as effective rhetorical strategies. Indeed, with no other option to fall back upon, the scientist of Latour's anecdote is compelled to respond to the sophistry of his inquisitors by summoning up, ad hoc, the kind of ethnographic account of scientific and technological practice that has been Latour's stock in trade for over three decades: 
I wonder how the professor is going to respond. Will he put the meddler in his place by reminding him that it's not a matter of belief but of fact? Will he once again summarize the "indisputable data" that leave scarcely any room for doubt? But no, to my great surprise, he responds, after a long, drawn-out sigh: "If people don't trust the institution of science, we're in serious trouble." And he begins to lay out before his audience the large number of researchers involved in climate analysis, the complex system for verifying data, the articles and reports, the principle of peer evaluation, the vast network of weather stations, floating weather buoys, satellites, and computers that ensure the flow of information - and then, standing at the blackboard, he starts to explain the pitfalls of the models that are needed to correct the data as well as the series of doubts that have had to be addressed on each of these points. "And, in the other camp," he adds, "what do we find? No competent researcher in the field who has the appropriate equipment." To answer the question raised, the professor thus uses the notion of institution as the best instrument for measuring the respective weight of the positions. He sees no higher court of appeals. And this is why he adds that "losing trust" in this resource would be, for him, a very serious matter. ("AIME" 3 )

Latour allows himself a wry smile at these developments. After decades of controversies concerning his anthropological account of scientific practice - controversies that culminated, during the 1990s, in the so-called "science wars" that saw Latour and others bitterly accused of undercutting public trust in science - we now see scientists approximating key features of this approach, offering a more demystifying and pedagogical explanation of their work than was customary when Latour first began his fieldwork. 


\section{SCIENCE IS ORDINARY}

The powerful and disruptive claim that lies at the core of Latour's ethnographic account of scientific knowledge production is the contention that "[s]ituated knowledge is much more realistic than knowledge from nowhere," than knowledge that claims to dwell in the rarified air of "neutrality," transcending the vulgar, provincial concerns of "interested parties" ("Gaia" 265). And it is this enduring conviction that has gone on to shape Latour's climate change interventions, as he has avoided wielding the latest disembodied emissions figures as truncheons to marshal the ignorant into line. He has instead attempted to foreground the workaday operations of that planetary-scaled network of labs, sensors, instruments, and techniques within which our knowledge of the Earth System actually develops.

In the course of these interventions it is evident that Latour regards "situated knowledge" not only as more realistic, but also as the more persuasive form of political address. From the outset his work has characterized laboratory science as a suasion system, "a system of literary inscription," whose practical and conceptual rigor was designed to convince "others that something is a fact" (Latour and Woolgar, 105). In later years he has gone on to develop this claim around the portmanteau term "factish" - a concept which he uses as a shorthand for the strange phenomenon of the "fabricated fact" ("Pandora" 281). The concept of the factish is designed to point us beyond the almanacs toward the "ecology of practices" that actually produce scientific knowledge on a procedural plane (Stengers, "Notes"). It is this effort to understand the apparent paradox of the "fabricated fact" that has provided his work on laboratory science one of its key conceptual through lines. And this is an effort that has become especially useful under 
current conditions, as it is precisely the paradox of the "fabricated fact" that renders scientists vulnerable to the kind of rhetorical strategies that we saw French industrialists adopting earlier, in construing climate scientists as lobby-driven exponents of groundless conjecture.

Latour's central argument concerning climate science thus develops from his enduring claim that accurately documenting the lived experience of research will have, in the final analysis, a more powerful evidentiary force than epistemological discourses that invite the ignorant to keep their distance from science's inner sanctum, genuflecting in quiet deference before the pronouncements of the Method's priestly sages. At such moments, Latour's fieldwork actually works in a manner comparable to Marx's, drawing us into the "hidden abodes" of scientific knowledge production. Though noting this similarity, Latour is however attentive to the singular nature of the "scientific objects" the facts - that are produced in research laboratories:

It is easy to understand why houses and cars and baskets and mugs are at once both fabricated and real, but this is of no help in accounting for the mystery of scientific objects. It is not just that they are made up and real. Rather, it is precisely because they have been artificially made up that they gain a complete autonomy from any sort of production. ("Pandora" 127)

The paradox at stake here is crisply defined elsewhere by Bourdieu as "the problem posed by the historical genesis of supposedly trans-historical truths" ("Science of Science" 1). Yet in contrast to Bourdieu's characteristically structuralist attempt to resolve this riddle, Latour's efforts to decipher this "most puzzling phenomenon" always lead us back to the "empirical site" of the laboratory itself ("Pandora" 127). Writing in Pandora's Hope, Latour argues that "[ $[\mathrm{t}] \mathrm{echnical}$ or industrial metaphors are not going to 
help us grasp" a "puzzling phenomenon" that "has taxed the patience of science studies" (127). Indeed, it is his contention that "the only solution when faced with difficult philosophical questions is to dive even deeper into some empirical sites to see how scientists themselves get out of the difficulty" (127). With this dictum in view, he then returns to another of Pasteur's key experiments, describing in some detail the distinct set of procedures and apparatuses that Pasteur devised to demonstrate that the "grey matter that sometimes appear[ed] on the top of vessels" was in fact yeast, "a plantlike, fullblown substance endowed with nutritional needs and rather peculiar tastes" (127):

The experiment creates two planes: one in which the narrator is active, and a second in which the action is delegated to another actor, a nonhuman one. An experiment shifts out action from one frame of reference to another. Who is the active force in this experiment? Both Pasteur and his yeast. More precisely, Pasteur acts so that the yeast acts alone. We understand why it is difficult for Pasteur to choose between a constructivist epistemology and a realist one. Pasteur creates a stage in which he does not have to create anything. He develops gestures, glassware, protocols, so that the entity, once shifted out, becomes independent and autonomous. According to which of these two contradictory features is stressed, the same text becomes either constructivist or realist. Am I, Pasteur, making up this entity because I am projecting my prejudices onto it, or am I being made up and forced to act in this way because of its properties? Am I, the analyst of Pasteur, explaining the closure of the controversy by appealing to his human, cultural, historic interests, or will I be forced to add to the balance the active role of the nonhumans he did so much to shape? These questions are not philosophical problems confined to the pages of journals in the philosophy of science ... they are the very questions tackled over and over by scientific papers, and by which they sink or swim. (130) 
Read in reference to the earlier anecdote, we see that - far from alien to the practice of scientific research - the objections that the industrialists direct to their scientific opponent are in fact "the very questions tackled over and over by scientific papers, and by which they sink or swim." To create a successful experiment, researchers must develop control procedures that operate as material instantiations of the very objections that the climate skeptic would pretend to address to the researcher for the first time. In the case of successful experiments, these questions are addressed beyond human interlocutors to the world, creating a "stage" by which the foregrounded behaviour of "independent and autonomous" entities serves as its own answer.

We will misunderstand the impetus of this approach entirely - and overlook the suggestive points of overlap with Marx's methods - if we allow critics such as Andreas Malm to convince us that Latour's work can be so easily conflated with the most facile and reductive forms of social constructivism. ${ }^{9}$ Instead, we should see Latour's study of scientific methods for what they actually are - efforts to allow an audience of nonspecialists fuller access to the distinct evidentiary procedures, technological means, and conceptual rationales that different branches of scientific research employ in their efforts to understand the world. And thus despite the indignation that continues to surround Latour's account, and despite the suggestion that this particular form of "realist constructivism" has actually served to undercut the authority of "Science," I think that there is much to recommend this effort to bring science down to Earth. The grounded, explanatory impetus of Latour's approach offers a welcome corrective to those implicitly

\footnotetext{
${ }^{9}$ Such is the view taken by Andreas Malm, in The Progress of This Storm. Positioned as a tract on climate change, Malm's book is probably more accurately read as a sustained polemic against Latour, in which he charges Latour with acting as a proponent of "epistemological nihilism" (105).
} 
authoritarian discourses that would have us position Science and Nature as courts of last appeal before which every ignorant knee must bow. For in contrast to such approaches, Latour's effort is to pull up the hood, to show us the gears, needles, and "daisy wheels" in motion:

It is fascinating to study, as I did for two years, the needles that scratch the drums of physiographs; to see how traps are set to make the things that are talked about write and speak directly to those whom one wishes to convince. These bizarre texts, which are not sacred writings but inscriptions produced by rat viscera or the open hearts of dogs, are strangely alluring. They are all very beautiful, I agree. They represent a lot of work and much dexterity, but they are not miraculous. There is nothing immaterial in the endless breaking of bindings, clicking of pens, clattering of daisy wheels, and scratching of styli. ("Pasteurization" 219)

Science, Latour seems to say, is ordinary.

Even practicing scientists are beginning to see the merits of Latour's approach, both in appealing to Latour as a mediator, and in feeling themselves drawn back, irresistibly, into the contentious mesh of politics and polemics. In the following excerpt from a recent interview we see Latour explaining the proximate cause of his recent work on climate change in relation to the beleaguered appeals of another cornered climate scientist:

It happened in 2009 at a cocktail party. A famous climate scientist came up to me and said: "Can you help us? We are being attacked unfairly." Claude Allègre, a French scientist and former minister of education, was running a very efficient ideological campaign against climate science. It symbolized a turnaround. People who had never really understood what we as science studies scholars were doing suddenly realized they needed us. They were not equipped, intellectually, 
politically, and philosophically, to resist the attack of colleagues accusing them of being nothing more than a lobby. ("Veteran")

The attitude of this unnamed scientist is in marked contrast to those that typified scientific communities during the early days of Latour's fieldwork. In those days it was more usual for scientists to express a general sense of "aversion to what nonscientists $\mathrm{sa}[\mathrm{id}]$ about science" (Latour and Woolgar, 12). Indeed, as Jonas Salk - then Director of the Salk Institute for Biological Studies - writes in his preface to Laboratory Life, exposure to journalistic and sociological commentary on science had led many practicing scientists to draw the fatefully conceited conclusion that "outsiders" were little capable of grasping the "substance of scientific thought" (11). Little wonder that as Latour and Woolgar began their fieldwork at the Salk Institute, they were conscious of being cast in a "strange" light by the subjects of their study:

When an outside observer first expresses interest in the activities of working scientists, he can expect one of a variety of different reactions. If he is a fellow professional scientist working in a different field, or if he is a student working towards final admission into the scientific profession, the outsider will usually find that his interest is easily accommodated ... However, for outsiders who are completely ignorant of science and do not aspire to join the ranks of professional scientists, the situation is rather different. The most naive (and perhaps least common) reaction is that nonscientific outsiders simply have no business probing the activities of science. (19)

But what then has conspired to transform a figure once regarded as a barely tolerable interloper into an ally and would-be champion? Why are "prominent" scientists now asking for the intercession of a humanist and social scientist, a purveyor of that "soft knowledge" that many in the hard sciences have long looked on with candidly aloof 
dismissiveness? Well, on the most fundamental level, it seems that whereas in the early days of Latour's fieldwork scientists were able to completely dismiss "what outsiders ha[d] to say about science" current circumstances no longer afford them this dubious luxury (11). Indeed, as they find themselves at loggerheads with their longstanding patrons in government and industry, we instead discover a narrow but profound fissure opening up between the twin pillars of the postwar modernization effort: applied science and monopoly capital.

It is within this fissure that I think we must begin to search for ways beyond the political and technical impasses that characterise our moment. Latour's enduring challenges to the original STS's concern with policy can make substantial contributions to this work. For without working theories of scientific practice beyond those offered from the perspective of contemporary policy documents we would find ourselves in an especially grim political situation. We need to be able to distinguish between the "fragmented" science that we know - the one "subjected to the capitalist division of labour," and "subordinated to profit maximalization by the monopolies" (Mandel, 262) from the one that is, in a sense, already struggling to break free from the grip of these conditions. Latour's work can help us to do this. And in this respect, it offers us an important complement and counterpart to an entirely activist-driven approach to climate politics, one that would focus its energies solely on opposing the rollout out of new fossil fuel infrastructures and extractive apparatuses. For alongside this vital effort to thwart the ongoing expansion of the fossil fuel industries, we need also to ensure the ongoing, unhindered development of those sciences and technologies that are committed to fathoming the behaviour, properties, and carrying capacities of the world we exist within, 
allowing them to guide our own infrastructures and modes of subsistence into more intelligent forms.

Under current conditions this cannot but initially entail encouraging and sustaining massive financial investment in renewable energy technologies, a goal that could easily see proponents of energy transition relegated to the position of cheer leaders for a rebranded energy industry. How then to square this circle? How do we operate within existing networks to try and forestall and mitigate the most extreme forms of climatic blowback without at one and the same time becoming complicit in the indefinite perpetuation and legitimation of prevailing power and property relations? There are no easy answers to this question, and indeed it is already evident that governments are often succeeding in stimulating investment in untried, financially-risky renewable energy initiates by underwriting them with the promise of tax payer bailouts in the event of project failure (IEA, 9; Bell). This creates a situation in which the taxpayer takes the hit for failed projects, while investors reap the rewards from successful ones. Given how pervasive oligarchic taxation regimes and corporate tax evasion practices have become under conditions of secular stagnation, this means that the ongoing raid on public coffers will continue apace, as the taxpayer foots much of the transition bill while sharing little in the transition profits (Srnicek, 24-26; 39; 52). Overall, this confluence of factors is set to see us implementing climate change response through a sublimed version of the trickleup dynamics that saw subprime mortgage holders turfed out of their homes, and banks bailed out, while CEOs looked on from penthouse suites exchanging golden handshakes. How many more rounds of dispossession, exclusion, and forcible appropriation will we tolerate before deciding, pace Thatcher, that there must be an alternative? 
In the meantime, given the zero-sum game that currently prevails in a global economy subject to stagnant growth and declining dynamism, gains in the area of infrastructural adaption seem likely be offset with the ongoing implementation of welfare state austerity - that is "modernization" of the welfare state as we saw it defined in current EU social innovation policy documents. And thus I think it is here, at the tipping point between the critique of private property and enclosure, and the necessary initiation of infrastructural adaption and renewable energy transition, that we need to target our interventions.

\section{ACTOR NETWORK THEORY}

Yet to understand what has brought us to this narrow pass in the first place, we must ultimately part company with key features of Latour's approach to political economy. And it is to such questions that we now turn, to highlight features of Latour's political theory that hinder rather than help us to grasp the nature of our situation. Having covered what Latour won by resisting the claims of his early antagonists in STS, we now turn to the question of what he lost. As we do so, we begin to explore how the logic of private property continues to trammel the development not just of the sciences, but of disciplines and discourses of every kind.

Our first concern is Latour's conceptualization of the state, which fails to countenance how fully and foundationally its role in maintaining the capitalist mode of production demarks and defines its signature modes of agency, including the kinds of influence it exerts over academic practice and scientific research. In this regard, 
Bourdieu's characteristically comprehensive theory of the state offers an instructive point of contrast. Writing in The Social Structures of the Economy, Bourdieu argues that it is in practice impossible to tease apart the strands of interrelation that tie state, industry, and economy into a self-reflexive and self-responsive whole:

[T] he economic field is, more than any other, inhabited by the state, which contributes at every moment to its existence and persistence ... This it does mainly through the different, more or less circumstantial 'policies' it implements as and when it sees fit (for example, its "family policies" which, through inheritance laws, the tax regime, family allowances and social assistance, have their effect on consumption - particularly on the consumption of houses - and standards of living) and, at a deeper level, through the structural effects produced through budgets, expenditure on infrastructure $\ldots$ and the definition and imposition of the rules of the economic game ... [A]11 these [represent] so many political interventions which make the bureaucratic field a macroeconomic stimulator, playing its part in ensuring the stability and predictability of the economic field. (12-13)

Adding to Bourdieu's analysis, we would do well to understand the university as entirely imbricated in, and instrumental to, the state's attempts to "ensur[e] the stability and predictability of the economic field." The pressures that governments exert upon universities - in the form of funding initiatives, policymaking directives, and (when they deem it necessary) their monopoly on violence - amount to another form of the "circumstantially" implemented policies that Bourdieu describes above. According to this account, the modern nation state's various R\&D departments represent key sites at which the technocratic theorists and administrators of the economy attempt to gain and apply purchase on the system's overall functionality. In so far as a nation state's key policymaking initiatives remain circumscribed by goals such as securing the ongoing 
expansion of GDP, increasing national competitiveness, and stimulating investment, the structure and mandates of its educational institutions remain subordinated to the same set of concerns.

Yet this kind of understanding of the relationship of state, economy, and academic research would likely be defined by Latour as an unduly "critical" product of a now outmoded form of sociology. In Reassembling the Social, Latour outlines ANT's key complaints against conventional sociological method. He argued that sociologists' willingness to "jump straight ahead to connect vast arrays of life and history, to mobilize gigantic forces, to detect dramatic patterns emerging out of confusing interactions" (22), have distracted them the from the humbler (and nobler) task of "tracing" the unpredictable and idiosyncratic "associations" that define sociality in all its puzzling "distributed, variegated, multiple, dislocated" forms (60). He proposes that the totalizing tendencies of the "sociology of the social" have actually served to delimit and constrain human and nonhuman agency. Indeed, sociologists' paranoiac vision, their determination "to reveal behind the scenes some dark powers pulling the strings" (22) is said to have repeatedly hindered "social actors" from "unfold[ing] their own differing cosmos[es]" (23). In view of this diagnosis, Latour argues that the new goal of sociology should be to leave "the task of defining and ordering the social ... to the actors themselves" (23). He outlines his new vision in the following terms: "It is almost as if we were saying to the actors: 'We won't try and discipline you, to make you fit into out categories; we will let you deploy your own worlds, and only later will we ask you to explain how you came about settling them"” (23). 
The particular cluster of stances that are outlined here - a focus on "variegated" and multiple assemblages rather than encompassing totalities; a preference for ethnographic description rather than systematic explanation; and a postural affinity for constructive reassembling rather than critical deconstructing - are now widely-regarded as the signal hallmarks of Latour's "postcritical" method. Here there are many telling points of contrast that we could establish with Bourdieu's commensurably forceful challenges to conventional sociological method. Yet there is one key distinction to which I want to draw particular attention. While the logic of Bourdieu's self-reflexive account of sociological praxis invites sociologists and cultural critics to foreground their practices' inextricable enmeshment in the state's attempts to stabilize and regulate the economic field, Latour's "dislocative" (46) ANT offers us the option of treating the disciplines as discrete networks, as assemblages of shifting associations whose development can be analyzed and explicated in isolation from the influence of overarching systems.

This logic will return with some frequency in the course of Latour's work. We might for instance look to the famous essay "Why Has Critique Run Out of Steam?" as an example roughly contemporaneous with Reassembling the Social. Latour argues here that, to explain the current humanist malaise, one need not factor in the creeping influence of post-1960s social state austerity, nor the university's attempts to cater to the needs of industry and investors. One can instead focus on the malign influence of a network of entrenched academics - the so-called "critical barbarians" (240) - who have reduced the humanities to a morass of bad faith and will to power, a "sordid pawnshop" (241) of stale and outmoded ideas. Indeed, in a characteristically pithy assessment of the 
increasingly abject institutional position of the academic humanist, Latour embarks on a style of commentary and a method of self-appraisal that has since become foundational to Felski's branch of postcritical literary scholarship:

Is it so surprising, after all, that with such [critical] positions given to the object, the humanities have lost the hearts of their fellow citizens, that they have had to retreat year after year, entrenching themselves always further in the narrow barracks left to them by more and more stingy deans? The Zeus of Critique rules absolutely, to be sure, but over a desert. (239)

Although one could doubtless dig up a host of risible "critical" projects to justify some of Latour's polemical ire, the idea that that devotion to the "Zeus of Critique" has rendered humanists such boorish company that "stingy deans" have reluctantly - and for the apparent sake of propriety - been forced to usher them into the "narrow barracks" where they now conduct their seminars surely taxes credulity to its limit. Are humanists really best characterized as the naughty children of the contemporary academy, deserving of a sobering "timeout" until such a juncture as they come to their senses and desist from repeating their critical tantrums? This is the kind of argument that is being made here, and it is one that seems to suggest that given a little more pragmatic good humor, a more "eudaimonic" attitude (Felski, "Limits" 151), the deans would relent, and spring would return to the humanities.

We might imagine that, over a decade after Latour first launched his widely cited salvo against critique, this kind of argument - and the implicit hope of a New Jerusalem that it extends to the inhabitants of the humanist "desert" - might itself have begun to run out of a little steam. Despite humanism's increasingly showy eschewals of the critical spirit there is as yet no end to the funding drought in sight. The longer this situation 
persists, the nearer comes the hour when we may be forced to return to Latour's original intervention with a more critical eye. In the meantime - while humanism's newly affirmative disposition has done little to turn the tide on funding and student flight (Delany; Nietzel; Nisen) - the prospect of a new spring continues to amplify Latour's interdisciplinary influence. And in the context of the literary academy, the key concepts and stratagems that we saw Latour outlining above have now been imported wholescale into the discipline in the form of Felski's widely lauded postcritical hermeneutics.

Writing in The Limits of Critique, Felski is candid about her debt to Latour. As she outlines the nature of her intervention, it is evident that - allusions to Ricœur notwithstanding - Latour's ANT serves as the conceptual bedrock of her new projects. Felski's fidelity to Latour's vision is especially evident in the introduction to The Limits of Critique where she reproduces the core tactics of Latour's ANT to the letter, making use of Latour's signature concepts and phrasing, while leavening them with a significantly larger measure of tact and diplomacy. Felski sets the tone by noting that "literary studies is currently facing a legitimation crisis" (5). Then, mirroring the logic if not the tone of Latour's "Zeus of Critique" passage, she goes on to confront literary humanists with the consequences of our attachment to critique, asking us to recognize how our "sadly depleted language of value" has left us "struggling to find reasons why students should care about Beowulf or Baudelaire" (5).

One could offer a number of objections to this line of argument. We can begin by reiterating Mandel's observation that since the inception of the postwar university educational policymaking has been attempting to marshal postsecondary students away from the study of the humanities. This is, once again, Mandel writing in 1968, 
The hallmark of this growth of scientific labour - elicited by the cumulative growth of scientific knowledge, research and development, and ultimately determined by accelerated technological innovation - is the massive reunification of intellectual and productive activity, and the entry of intellectual labour into the sphere of production. Since this reintroduction of intellectual labour into the process of production corresponds to the immediate needs of late capitalist technology, the education of intellectual workers must likewise be strictly subordinated to these needs. The result is the crisis of the classical humanist university, rendered anachronistic not only for formal reasons (excessive number of students, backwardness of material infrastructure, changes in social background of students, which demands an above-average expenditure in the university sector, and so on) and not only for overall social reasons (attempts to avoid the emergence of an unemployed intelligentsia; attempts to restrain student revolt, and to step up the ideologization of science for the purpose of manipulating the masses) but also and above all for directly economic reasons specific to the nature of intellectual labour in late capitalism; the constraint to adapt the structure of the university, the selection of students and the choice of syllabuses to accelerated technological innovation under capitalist conditions (260-1)

During the exuberant decades prior to the financial crisis, the decisive impact of these strategies became, admittedly, a little harder to discern. As the student loan industry boomed in the context of the FIRE sector's expansion, and as administrators accordingly began to sheath their sheers, literary humanists could look to the future and quite plausibly imagine that Baudelaire and Beowulf would have their votaries for as far as the eye could see.

Yet in today's climate it is both difficult to see beyond the next corner, and harder to ignore the increasingly stern summons of the technocrats. As the mirages of fictitious capital begin to dissipate, we are being returned to the more sobering perspective that was 
available to Mandel as the world-system teetered on the brink of its last great systemic crisis. The bulk of higher education policymaking is shaped with capitalist geopolitical strategy in view. We now feel this in our bones. And far from indulging in conspiracy theories to justify this reading of events - a favourite charge of the new materialist against the old - one simply has to consult higher education policies to see nations deliberately striving to outcompete each other in their attempts to anticipate and supply the intellectual and technical needs of a real economy in thrall to the demands of private capital. Search as one might amid the thickets of this literature, there is scarcely a reference to Baudelaire or Beowulf to be found. But there is really no need to "search." As the edicts come down the pipeline, it is enough just to say what you see.

This is perhaps a cheap point, and one finds it difficult to imagine that Felski or Latour are entirely unversed in this history. In fact, this course of events seems to be something that Felski is poised to address - if not head on then at least obliquely - at the outset of Limits to Critique. I quote from its opening passage at a little length, in order to give a flavor of the overall tone and tenor of this increasingly influential argument:

Our students, meanwhile, are migrating in droves toward vocationally oriented degrees in the hope of guaranteeing future incomes to offset sky-rocketing college bills. The institutional fiefdoms of the natural and social sciences pull in ever heftier sums of grant money and increasingly call the shots in the micro-dramas of university politics. In the media and public life, what counts as knowledge is equated with a piling up of data and graphs, questionnaires and pie charts, inputoutput ratios and feedback loops. Old-school beliefs that exposure to literature and art was a sure path to moral improvement and cultural refinement have fallen by the wayside, to no one's great regret. In such an austere and reverting to the canon-worship of the past? According to one line of thought, literary studies is 
entirely to blame for its own state of malaise. The rise of theory led to the death of literature, as works of art were buried under an avalanche of sociological sermons and portentous French prose. The logic of this particular accusation, however, is difficult to discern. Theory simply is the process of reflecting on the underlying frameworks, principles, and assumptions that shape our individual acts of interpretation. Championing literature against theory turns out to be a contradiction in terms, for those who leap to literature's defense must resort to their own generalities, conjectures, and speculative claims. Even as he sulks and pouts at theory's baleful effects, Harold Bloom's assertion that we read "in order to strengthen the self and learn its authentic interests" is a quintessential theoretical statement. ("Uses"1-2)

What never entirely emerges into view in this otherwise bracing account of literary study's contemporary travails, and this qualified defense of theory, is an explanation of why these changes have overtaken us in the first place. Student debt has increased, government and administrators have placed a premium on quantitative analysis, policymakers and students have grown more skeptical about humanism's social significance, and a new cybernetic logic of "input-output ratios and feedback loops" has reshaped the humanist's working environment. Yet while we are led to understand that the discipline must learn to adapt to this new and forbidding environment, the question of what has driven these changes never fully enters the picture.

My first chapter attempted a systematic explanation of the same phenomena, interpreting them as the results, in part, of social innovation policy frameworks. These frameworks, by their own admission, represent a programmatic response to the financialcrisis-catalysed onset of secular stagnation, and to the more dimly-apprehended prospect of catabolic collapse. They are designed to target scarce funds toward preciselydesignated areas of strategic concern, and they generally entail a withdrawal of the state's 
commitments to the old disciplinary dispensations, in favour of sponsoring research that addresses specific "target areas." I suggest that it these very frameworks that have led to the rise of phenomena as apparently distinct as the medical, digital, energy, and environmental humanities. They have led, also to Felski's own interest in the uses - one is tempted to say "impacts" - of literature.

That said, despite Felski's evident debt to Latour, there are a number of key differences between their critiques of the "critical spirit." In distinguishing their approaches, it might be helpful to return to Latour's influential essay, where we find Latour situating his original takedown of critique in the context of the US "culture wars." Latour begins by reappraising the legacies of his own ethnographic account of scientific knowledge production against the backdrop of mounting climate change skepticism. I quote at length as the fine detail strikes me as significant:

What has become of critique, I wonder, when an editorial in the New York Times contains the following quote?

Most scientists believe that [global] warming is caused largely by manmade pollutants that require strict regulation. Mr. Luntz [a Republican strategist] seems to acknowledge as much when he says that "the scientific debate is closing against us."

His advice, however, is to emphasize that the evidence is not complete. "Should the public come to believe that the scientific issues are settled," he writes, "their views about global warming will change accordingly. Therefore, you need to continue to make the lack of scientific certainty a primary issue." ... Do you see why I am worried? I myself have spent some time in the past trying to show "the lack of scientific certainty" inherent in the construction of facts. I too made it a "primary issue." But I did not exactly aim at fooling the public by obscuring the certainty of a closed argument - or did I? After all, I have been accused of just 
that $\sin$. Still, I'd like to believe that, on the contrary, I intended to emancipate the public from prematurely naturalized objectified facts. Was I foolishly mistaken? Have things changed so fast? ("Steam" 226-227)

Read from today's vantage one has to acknowledge the foresight of this argument. We see Latour tracking the initial crystallization of the "post-truth" sensibility that would help to define both the course of the last US electoral cycle, and the current direction of its energy and climate policy. Mobilizing the propagandistic concept of "fake news" in an ideological context defined by the fallout of a widely-reported verification crisis, the Trump administration has since made a kleptocractic dash to dismember the US's major climate science institutions and environmental watchdogs, under the cover provided by this "debunking impetus." Identifying these dynamics in a much earlier stage of development - and construing them as the pigeons of the Enlightenment coming home to roost - Latour's essay attempts to shift the terms of engagement by insisting that we need now to devise new "descriptive tools" capable of adding reality to matters of fact rather than subtracting it from them:

To indicate the direction of the argument, I want to show that while the Enlightenment profited largely from the disposition of a very powerful descriptive tool, that of matters of fact, which were excellent for debunking quite a lot of beliefs, powers, and illusions, it found itself totally disarmed once matters of fact, in turn, were eaten up by the same debunking impetus. My question is thus: Can we devise another powerful descriptive tool that deals this time with matters of concern and whose import then will no longer be to debunk but to protect and to care, as Donna Haraway would put it? Is it really possible to transform the critical 
urge in the ethos of someone who adds reality to matters of fact and not subtract reality? ${ }^{10}(232)$

The principal strategic goal at stake in this passage is clearly one of making climate change "real," of "bringing it home," of giving the data tangible and suasive cultural form, in a context where popular faith in the veracity of scientific truth claims - and trust in the institution of science itself - seemed to have undergone a surprising amount of erosion. Felski and her allies make analogous arguments concerning literature. But what will not surface in the course of these Latourian riffs is much evidence of the more foundational objectives that Latour's interventions here are actually designed to address. Indeed, among the eleven essays showcased in Felski and Anker's collection, Critique and Postcritique, the ostensible spear tip of a new movement in literary studies, there is not a single entry that takes the question of climate change as a point of focus. And it is the absence of this foundational concern - one that otherwise defines the new materialist approach in general - that really distinguishes literary study's critique of critique from those that stem more directly from science studies itself.

\section{THE MERITS OF CRITIQUE}

In all its guises, new materialism has tended to gain its ground and make its headway by relying on somewhat offhand and doctrinaire dismals of "old" materialism. I would suggest that we have now reached the point where a more rigorous exchange needs to be

\footnotetext{
${ }^{10}$ The Latour of The Pasteurization of France would have some questions to raise about this passage's tendency to position faulty concepts, rather that social networks, as the material drivers of this confusion. In attributing the whole mess entirely to the conceptual legacies of the enlightenment, rather than the propagandistic devices of the fossil fuel industry, we risk overlooking some very significant factors.
} 
staged between proponents of the two schools of thought. What is at stake here is the question of method. Critics of critique suggest it leads to a Cartesian quagmire of doubt and thwarted agency, I argue in contrast that it can actually lead to a firmer grasp on the contours of the world we inhabit, and of the political choices that lie before us.

A critique of political economy asks us to consider the socioeconomic conditions under which the modern university's fractal array of disciplines were first hatched, and under which their problem-focused and site-specific synthesis is now being directed. There are, admittedly, certain junctures where Latour appears partly open to this kind of outlook. In the opening pages of Reassembling the Social, he offers a sweeping appraisal of the historical development of sociological practice, proposing that "the views of society offered by sociologists of the social were mainly a way of insuring civil peace when modernism was underway" (16). This kind of argument seems set to explore how state and industry have actively shaped and deployed sociology as a means of understanding and pre-empting the "systemic" causes of poverty, civil unrest, and political disquiet, or as a means of ensuring - in the manner of Taylor - a measurable increase in workplace productivity.

Indeed, as Latour opens up this line of inquiry, he seems primed to offer an account of sociology's complex imbrication in the state-managed execution of postwar modernization programs. Yet in accord with the anti-totalizing character of his thought, he actually makes relatively few gestures in this direction. Instead, anticipating the logic of Felski's account of contemporary conditions in the literary academy, we are led to believe that a "surface" reading of a discipline's historical development might suffice. Given that in interpreting social phenomena one need not look for the influence of 
"shadowy puppeteers," while "context" itself is actually sometimes said to "stink" (148), it is perhaps not surprising that as Latour prosecutes his case against the architects of conventional method, the culprits turn out to be sociologists themselves:

[S]ome sociologists, tired of the revolutionary period, found a way to shortcut the slow and painful process of composition and decided to sort out by themselves what were the most relevant units of society. The simplest way was to get rid of the most extravagant and unpredictable ways in which actors themselves defined their own 'social context'. Social theorists began to play legislator, strongly encouraged in this endeavor by the state that was engaged in the ruthless task of modernizing. Without this strong obligation to play the legislating role, sociologists would not have limited the first obvious source of uncertainty, cutting all the links with the explicit and reflexive labor of the actors' own methods. Anthropologists, who had to deal with premoderns and were not requested as much to imitate natural sciences, were more fortunate and allowed their actors to deploy a much richer world. (41)

The language of this passage offers some telling insights into the characteristic blind spots of Latourian method. When Latour writes that "social theorists begin to play legislator, strongly encouraged in this endeavor by the state," one wants to ask what form this "encouragement" takes. Our social theory has likely already gotten off on the wrong foot when we begin by characterizing the state as a supportive cheerleader to sociology, the world's true unacknowledged legislator.

Indeed, to explain the overall arc of postwar humanism and the social sciences' historical development one need not go burrowing back into the conceptual hardware of the disciplines, imputing their regulative social function - or manifest decline - to an infelicitous association of concepts and methods. It is perhaps unwise to attribute systemic social maladies and negative funding trends entirely to the zeal of misguided 
academics, but this is the trajectory that our thought will tend to take if we opt to dismiss the question of context out of hand. The postwar proliferation of sociological fieldwork and theory that Latour professes to be amazed by need not be a matter of "astonishment" (34). It can be simply explained by positioning the discipline's practitioners in relation to the broader constellation of governmental and commercial institutions that have housed, solicited, and funded their work. The recent history of sociology - including the "attachment" of its "instruments" to every "social group" in the "developed world" (34) is best understood, after scholars like Clover and Mandel, in relation to the postwar expansion of a global university system oriented by the shifting needs and strategic interests of private capital.

The administrative aims and intents that have shaped the overall development of the social sciences and humanities have differed from those of capital's other R\&D units only to the extent that they have generally been more concerned with exploring, rationalizing, and regulating social reproduction than with refining and intensifying productivity and accelerating technological turnover time. To the extent that sociology has functioned as a means of understanding and governing dense urban populations (as well as securing workplace compliance and productivity), its repressive functions must surely be said to be contingent on its role in maintaining and policing the social disparities, and the cyclical rounds of dispossession and appropriation, that capital's combined and uneven development has continued to generate.

These basic principles remain operative, or even intensify, under conditions of dynamism or decline. And this is a consideration that asks us to emphasize a second feature of Latour's thought, one that is also evident in the quote above: his characteristic 
championing of a descriptive and anthropologically-informed method. This is one of those occasions where Latour appears to intimate, without necessarily defining, a significant set of contemporary tendencies. "Anthropologists," he writes, "who had to deal with premoderns and were not requested as much to imitate natural sciences, were more fortunate and allowed their actors to deploy a much richer world" (41). I want to weigh the possibility that Latour's preference for a more ethnographic approach to sociological method might actually have gained in appeal precisely in relation to the kinds of socioeconomic "contexts" that he suggests we need not attend to. I have in mind the interrelated phenomena of economic stagnation, digital conglomeration, and social state retreat.

Relevant here are the different structural positions that anthropology and sociology have historically occupied vis- à-vis what world-systems theory refers to as the "core" and "periphery" of the capitalist world-system. By Latour's own account, in the early days of the modernization effort, sociologists operated primarily within the economic "core," in those areas of advanced economic development that were home to large industrial manufacturers, dense urban populations, robust central governments, powerful bureaucracies, and sophisticated and highly-organized armies and police forces. Operating in this context - and in uneasy alignment with the strategic interests of the dominant parties (industry, investors, and government) - sociology is said to have worked to "insure civil peace" while the "ruthless task of modernizing" was underway (41). Sociology is thus, by implication, positioned as a discipline that is principally concerned with the regulation and reproduction of what Marx would define as "labour power," which is to say with the management of what was once referred to as "the 
masses." In contrast, anthropology was first devised to operate on the periphery of the world-system, in the "frontier" zones where capital was as yet merely prospecting with a view to resource extraction and eventual expansion, and where its principal strategic concern was with the acquisition of local knowledge rather than with the reproduction and regulation of labour power.

Now, in turn, anthropology's more descriptive, ethnographic approaches are proliferating in the aging economic "core" at the very moment when the interrelated effects of secular stagnation and automation have seen demand for industrial labour wane, and when an underfunded social state is concurrently tempted to "detach" itself from many of its old commitments. Global population numbers now drastically exceed what the labour market seems able to functionally accommodate, a phenomenon that lies behind the ongoing development of what Mike Davis famously defines as a "planet of slums," and that has also led to the new wave of anti-immigration policy and sentiment, and the increasingly serious discussion of Universal Basic Income (UBI) schemes. We should not be too surprised that, with the retreat of what Clover refers to as "absorptive capital," the state's social theorists are now just as prone to play at reconnaissance as disciplinary legislation (“Causality"). Increasingly large numbers of the world's people now subsist outside of the wage relationship via "informal economic activity," and as they do so the peripheries of the world's mega cities are becoming - from the vantage of state bureaucracies - something of an unknown country:

The U.N. Slum Almanac puts the number in writing within the first couple of sentences: around one billion people live in slums worldwide. In other words, one in every eight men, women and children currently live in slums, and that number is growing. Since 1990, over 200 million people have been added to the number 
of "slum-dwellers" (the term used to denote people who live in slums) across the globe. In fact, the report goes on to state that slums, in their rapidly growing numbers, are "emerging as a dominant and distinct type of settlement," especially in developing nations. (Praytor)

In view of these broader trends, sociology's turn toward an investigative and ethnographic mode arguably has as much to do with retooling "social theory" to play its part in the "ruthless" business of de-development as with turning the discipline toward more enlightened ends.

By Latour's own account we "moderns" are considerably less sure of where we are headed than we were in the days when the postwar modernization program was unfolding at full tilt, and we should probably not be too surprised that the prospecting, exploratory logic of ethnography is seen to have a special utility at precisely this juncture. Along the same lines, one might also add that the ramifying - and related - process of "digital conglomeration" has now unfolded to such an extensive degree that many of today's corporate giants have resorted to employing in-house ethnographers in order to render their acquisitions less of a mystery to top brass, and to help - in the convoluted terms of corporate anthropology - to "synthesiz[e] internal social group view[s] with the external effects-producing agentive view” (Dasyn; Urban and Kyung-Nan Koh, 139).

More crucially still, in the context of what Nick Srnicek refers to as the rise of "platform capitalism," the new strategic centrality of the User Interface (UI) is also leading to the formation of in-house research teams tasked with producing working theories of user experience (UX). Scott Stiner, CEO and President of UM Technologies, explains why ethnographers have led the charge on this research: 
Stemming from anthropology, ethnographic research is the study of a something in this case a business - in its own environment. My company uses it to meet with clients face-to-face and observe them in their normal environment. This allows us to view the real relationships between the business and its own clients, and as a byproduct, what the products or services they're providing need to succeed. Ethnographic research is without a doubt the largest part of achieving our user experience (UX) goals. (Stiner)

Needless to say, the observational methods and approaches described here could have cribbed directly from the pages of Reassembling the Social. And faced with the combination of prospects I identify here, one does wonder if what we are seeing taking place here is actually a case of freedom being handed over to social actors.

Although this line of argument frames ANT in a relatively harsh light - and though it somewhat overlooks the useful role that ANT is concurrently playing in mapping out urban infrastructures and "late industrial" ecologies (Fortun) - these are at least questions that deserve a hearing. And they are questions that we will only arrive at by challenging ANT with claims and concepts that it has yet to reach by its own devices. Indeed, in accord with the position that he first adopted in his early controversies in STS, ANT often seems deliberately designed to bracket off such questions entirely. The limitations of Latour's methods thus appear most stark the further we travel from laboratory studies and the closer we come the questions of political economy. And it is with these latter considerations in mind that we turn now to assess the strengths and limitations of Latour's work within today's social innovation frameworks, looking at particular at his EU-sponsored AIME project. 


\section{ROSE-TINTED SPECTACLES}

Latour's politics have become especially difficult to define of late. In the most recent phase of his work, it can sometimes seem that we do not need to put on rose-tinted spectacles to detect a slight reddish blush creeping into his political rhetoric. It is now not that unusual to encounter the strange prospect of this longstanding critic of utopias and revolutions offering offhand allusions to the abolition of the nation state ("Facing Gaia" 279), or insisting on the wholescale transformation of "our mode of production" (8):

As we hear one piece of bad news after another, you might expect us to feel that we had shifted from a mere ecological crisis into what should instead be called a profound mutation in our relation to the world. And yet this is surely not the case. For we receive all this news with astonishing calm, even with an admirable form of stoicism. If a radical mutation were really at issue we would already have modified the bases of existence from top to bottom. We would have begun to change our food, our habitats, our means of transportation, our cultural technologies, in short, our mode of production. Every time we heard the sirens we would have rushed out of our shelters to invent new technologies equal to the threat... In any case, we would already have acted. (8; emphasis added)

What Latour's vision of a transformation of "our mode of production" actually entails in practice is something of a moot point, and there is as yet little evidence - beyond occasional references to out-of-touch "elites" ("New Climate") - that his version of this objective presents any direct threat to established class and property relations. Yet however insufficient and partial Latour's theory of political economy may appear from the vantage of the anarcho-communist critique of private property, when situated in relation to much of the humanistic work that is developing within social innovation 
frameworks, one is still often struck by how bold Latour's political objectives can seem in comparison.

The EU-sponsored research platform AIME makes for an appropriately ambivalent case study in this respect. AIME was the recipient one of the European Research Commission's flagship Advanced Grants (2011-2015), and even as AIME's website - the ostensible core of the project - has latterly begun to drift into disuse, it still reads like a prototype for a new wave of state-sponsored knowledge production platforms. To access the bulk of the site's content, and to make use of its key interfaces, one has to agree to the stipulated terms and conditions. Once "connected," the user is met with a detailed breakdown of the project's protocols and presumptive norms. In exchange for trading in AIME's signature clutch of terms and concepts - henceforth the domain's lingua franca - the user is offered interactive access to its extensive networks, bibliographies, and databases.

By Latour's own admission, AIME's ambitions tend toward the grandiose, targeting no lesser an aim than the wholescale "renewal" of modern institutions, a project that has since been described as an effort to "reset modernity." What this seems to entail, in practice, is the attempt to expand a recalibrated and modified ANT into an open-ended multi-user research project, in an effort to facilitate and coordinate an immense crowdsourced ethnography of contemporary institutions, one that has ultimately synthetic objectives. This modified version of ANT is characterized by the addition of a couple of key concepts, designed to transform ANT from a diagnostic tool into a therapeutic device. In addition to ANT's central concepts of the network and the agent, AIME adds 
into the picture the new concept of the "domain" and the governing metaphor of "diplomacy."

It is the latter term that Latour leans into hardest as he frames the project. Taking this concept of "diplomacy" as its lodestar, AIME invites "coinvestigators" to identify sites at which conflicting "domains" or truth regimes - science, politics, law, and religion are among the stated cases - address themselves to shared, or contested, objects of analysis or concern (12). AIME's "coinvestigators" are positioned in a mediating role, tasked with incrementally and "diplomatically" resolving these conflicts to the mutual satisfaction of the warring parties. The stated goal here is to thereby undo the condition of baffling discordance that Latour famously satirized at the outset of We Have Never Been Modern:

Our intellectual life is out of kilter. Epistemology, the social sciences, the sciences of texts - all have their privileged vantage point, provided that they remain separate. If the creatures we are pursuing cross all three spaces, we are no longer understood. Offer the established disciplines some fine sociotechnological network, some lovely translations, and the first group will extract our concepts and pull out all the roots that might connect them to society or to rhetoric; the second group will erase the social and political dimensions, and purify our network of any object; the third group, finally, will retain our discourse and rhetoric but purge our work of any undue adherence to reality - horresco referens - or to power plays. In the eyes of our critics the ozone hole above our heads, the moral law in our hearts, the autonomous text, may each be of interest, but only separately. (5)

As AIME attempts to intervene in this state of affairs, representatives of different "modes of existence" are asked to respect the felicity conditions that are proper to other domains, 
employing a kind of negative capacity that is designed to facilitate the emergence of common ground.

Because the guiding metaphor of diplomacy is ultimately grounded in this effort to reconcile conflicting and institutionally-mediated felicity conditions, Latour is obliged - for consistency's sake - to describe these "domains" in terms that are compatible with his work to date. Consequently, as Latour speculates about the paths that his coinvestigators might take in conducting their research, he begins by discussing their trajectories in the language of ANT. Tracing out the patterns of "association" that link together "heterogeneous" entities, researchers are said to find themselves pulling on threads of connection that traverse ostensibly distinct knowledge regimes. Moving along these threads, the reader is asked to anticipate that despite each domain's air of selfcontained self-referentiality researchers will actually discover no hard and fast boundaries between them. Law is "not made up 'of' or 'in' law" any more than science is made up of and in science (38). Both domains take the things of the world as their object, and are mediated in and through them, and in and through each other. Yet as Latour's ethnographers observe how exponents of a particular regime navigate its claims and apply them to the world, it is thought that they will uncover patterns of association that are proper to each, patterns that are, in the final analysis, the result of domain-specific "means" and "procedures." Latour is extremely taken with this model of "comparative anthropology" and later goes so far as to position it as "the philosopher's stone of the anthropology of the Moderns" (40), one that will allow researchers to overcome the fractious compartmentalization that, for him, lies at the root of the modern condition. 
However this rebooted Babel understands itself, and whatever its stated goals, its functional architecture cannot but serve as a solid index to the intermeshed objectives and effects of current international higher education policy initiatives. Planners have demanded problem-focused and site-specific interdisciplinary knowledge exchange, and here is a theory and a program equipped to deliver it. ${ }^{11}$

Latour is more inclined to read AIME as the apotheosis of his own intellectual development, and yet, by the lights of his own study of Pasteur, it cannot be solely through the force of its own gravitational field that all these "coinvestigators" and resources have been drawn into its orbit. To understand why AIME looks like it does we have to return to our account of the systemic forces and policymaking initiatives that produced the funding frameworks within which AIME has emerged. At a time when international R\&D policymaking is insistently prioritizing the development of interdisciplinary networks and research hubs, AIME's overriding efforts to facilitate "diplomatic" transactions between different branches of knowledge answers directly to the needs of a diverse array of researchers.

When AIME turns to "the economy," the reasons for the project's appeal within the current conjuncture are perhaps especially clear. We are told that, once liberated from our mistaken belief in this grand abstraction, "the economy," our instruments and interactions will be free to adapt according to their own inner impetus, succeeding where

\footnotetext{
${ }^{11}$ Here, as a case in point, is a description of the procedure that "co-investigators" should employ if they find themselves confronting the conflicting felicity conditions of different "domains": "To establish these differences, we have prepared a very simple little protocol that begins with the experience produced when there is a clash between two values. This clash is felt each time one value is judged using the instrumentation coming from another value. We will make a collection of such incidents by creating a database of what we will call 'crossings' because they will allow two types of judgement to emerge" (“Crossings").
} 
attempts to overthrow the phantasm of "capitalism" have consistently failed. Turning our eyes from the prevailing macro and micro models, and their dubious claims to objectivity, Latour asks us to focus instead on the multi-branched web of embedded practices and discursive "scripts" that purportedly constitute our economic practices on an "immanent" level. According to this schema, better maps and better accounting will result in better practices, while a correspondingly painstaking recalibration of apparatuses and patterns of association will - by dint of some kind of cascade effect - ultimately result in the cumulative renewal of modern economic institutions. The key words are gradual and cumulative. Nothing too dramatic or startling. Nothing lost.

For those of us with little innate appetite for the upheaval that we associate with revolutionary goals such as "overthrow" or "seizure," one can see the affective appeal of the frictionless quasi-revolution that Latour seeks to initiate. Yet as he stakes out his theory of complex systems change, he is constantly forced to skirt issues that seem rather more intractable than his analysis will allow. Kim Fortun offers some incisive commentary as to why Latour's governing concept of diplomacy seems somewhat illequipped to tackle the task at hand:

Consider, for example, Baytown, Texas, home of one of the world's largest oil refineries, on the Gulf of Mexico near Houston - where my father grew up and I spent childhood Sundays and summers. Without a hint of irony, Baytown promotes itself as the town "where oil and water really do mix." In Baytown, Bayer Corporation proudly provides science curricula to public schools - striving to cement the science of interpretation of chemical toxicity at all levels. Social theory and our anthropological projects need to engage with this. Can AIME work in these conditions? Can diplomacy work out the differences and interests in play? I fear not. ("From Latour" 320) 
It seems hard to debate that Fortun hits the mark in this respect, and this is a state of affairs that is borne out in the political trajectory that Latour has subsequently followed in his post-AIME period. In the work since AIME, especially in his tract on Gaia theory, Latour seems inclined to adopt Fortun's more confrontational approach, identifying fissures rather that resolving disputes, and drawing on metaphors of combat and struggle that harken back to his Pasteurian work on "trials of strength":

The phenomena being debated bear upon the near future; they oblige us to rethink the entire past, but above all they entail a frontal attack on the decisions of many pressure groups, and they bear upon questions of direct interest to billions of humans obliged to change their mode of life down to the smallest details of their existence. How can we hope that the scientists will be heard without a fight? ("Facing Gaia" 30-31)

Which course of action will Latour ultimately decide to follow through on? We might be forgiven for hesitating over this question; for although he uses a similarly fractious scene as the framing context for AIME, as the argument itself unfolds these oppositional images are quickly displaced by the "diplomatic" concerns that characterize the project as a whole. Indeed, the developmental course of AIME's argument generally proves consistent with Latour's more conservative political tendencies. As he unfolds the full dimensions of the project, Latour gradually discloses that AIME's approach was patterned after the Roman Catholic Church's longstanding debates on the tension between the reforming "Spirit" and the governing "Institution." Pointing to the Church's capacity to incorporate new reform movements into its established governmental structures, Latour appears to believe that the old wineskins of modern institutions can be retrofitted to accommodate the new wine of "ecologization" $(8 ; 482)$. 
The question that goes mostly unaddressed in the course of this particular argument, is of which institutions are in fact worthy of trust in the first place. Indeed, as AIME develops, Latour constructs a chain of association that leads us from a conflict between climatology and industry, to the prospect of establishing diplomatic accords between warring institutions. In its full form, the arc of this argument thus invites us to conclude that the ongoing conflict between climatology and the fossil fuel industry is the result of a misunderstanding, rather than a simple case of the fossil fuel industry's strategically-motivated bad faith. In arguing in this fashion, AIME risks doing more to obscure than to disclose the nature of the problems at hand.

\section{TAKING AIME: ON THE LIMITS OF ANT}

The bulk of my remarks on AIME have thus far focused on the content of Latour's book. But given that the project itself actually oversaw a larger cluster of different initiatives, I want now to offer a slightly more developed account of its full scope. Given that AIME's online platform is positioned as the functional hub of the project, this seems the logical place to start. By the standards of most humanistic research the platform itself is a relatively large-scale project, one that is carried off with considerable flair, offering its users a much more attractive and ambitious user interface than most publicly-funded ventures can hope to provide.

Yet in relation to the standards that exposure to the work of the major tech companies daily habituates us, AIME's UI still proves relatively cumbersome. Navigating the site can prove challenging, and this is likely the result of the fact that - in 
contrast to the ever-evolving character of the major Silicon Valley UIs - the AIME platform itself is cast more in the mold of a onetime event. The relatively static character of the platform reflects the institutional constraints that it developed within. Given the five-year funding spans currently imposed by EU directives, and left without other sources of revenue, there was never much prospect of AIME enjoying the same kind of data-driven capital-intensive recursive refinement that the major social networks have accustomed us to think of as "normal." In the context of the "austere" penny-pinching social state that has developed in the face of declining tax revenues and austerity responses, the gap between the public and private sectors' technical resources continue to grow apace. And this presents public sector platforms such as AIME real impediments to their ongoing development. Without substantially-larger commitments of funds there is no prospect of publicly-developed platforms conducting the kind of ongoing exploration and refinement of user interfaces that we saw Stiner, CEO of UM Technologies, describing in his comments on ethnographic research into user experience (UX). Here we see a fairly simple example of how a particular venture's specific position within the shifting and uneven mesh of prevailing private property relations does much to determine its scope and scale from the outset. Private sector giants have incommensurably larger resources to pour into their UIs than even the most affluent of private schools or public ministries can hope to marshal, and their platforms are accordingly far more intuitive and sophisticated.

The point, here, is to underscore the concentration of decision-making capacity in the hands of a handful of major digital conglomerates, and to stress that under such conditions networks of technical practice, research, and innovation continue to grow 
densest, not around the vital objectives of energy system transition or "ecologization," but rather around whatever commercial and technical expediencies currently preoccupy the boardrooms of the Big 5. A self-reflexive account of AIME's institutional positional would need to incorporate these kinds of considerations, and would thus be forced to question whether the project of "resetting modernity" can actually hope to be accomplished from within institutional confines that are as yet drawn this narrowly. Indeed, as things stand, it is clear that the prevailing developmental course of research and innovation will be governed not by the "free play of passionate interests," nor by the transition from modernisation to "ecologization," but rather by the strategic interests of late capital's major conglomerates.

Though such prospects occasionally rear their head in the course of Latour's climate change interventions, he generally tiptoes around such issues in his work on political economy. To fill in the details that Latour's account of political economy tends to omit we need to ask what forms of politics, what organisation strategies, and what modes of address and intervention could contribute to establishing a break with the prevailing drift of things. Yet Latour's theoretical work on trials of strength and theaters of proof, can point us in useful directions in this respect. And summing up my overall appraisal of Latour's climate change interventions I would suggest that it moves in the wrong direction when it leans into the course adopted in much of AIME, where the emphasis is laid on working behind the scenes, running envoys between established institutions, in an effort to launch from within them a technocratically-governed transition from modernization to ecologization. Conversely, I would suggest that his work is at its 
most valuable when it is working in a more extroverted manner, attempting to theorize and meditate a new set of relations between science and the commons.

Indeed, in reviewing the full scale of the enterprise one is often struck by how much has been done with how little. For in addition to the initial rollout of the platform and the accompanying book, during its five years of operation AIME also hosted a variety of lecture series, exhibitions, and curatorial projects. Of this work, the curatorial project, Reset Modernity!, is the most singularly significant.

Reset Modernity!'s first installment was a major exhibition hosted by the ZKM Center for Art and Media Karlsruhe. This event was followed by an MIT-published print anthology, which served as a print remediation of the ZKM exhibition. The book itself is a compelling volume, one that sees Latour anthologizing the work of architects, physicists, dramatists, and conceptual artists, alongside essays in science studies and the environmental humanities. It represents an early example of the work of "meta-curation" that social innovation frameworks are creating as they funnel humanists into closer contact with science and engineering projects. Yet while a number of the collected essays and entries take the original AIME project as a touchstone, the overall effect is thankfully - less that of a diplomatically-maintained consensus and more that of what Latour will elsewhere refer to as a "parliament of things." Harkening back to concepts that he first explored in We Have Never Been Modern, each of the book's entries attempts to reveal distinct facets of the vast "quasi-object that we have all created," allowing the reader multiple lines of sight into that unstable planetary-scaled "thing" that we collectively compose and subsist within: 
Let one of the representatives talk, for instance, about the ozone hole, another represent the Monsanto chemical industry, a third the workers of the same chemical industry, another the voters of New Hampshire, a fifth the meteorology of the polar regions; let still another speak in the name of the State; what does it matter, so long as they are all talking about the same thing, about a quasi-object they have all created, the object-discourse-nature-society whose new properties astound us all and whose network extends from my refrigerator to the Antarctic by way of chemistry, law, the State, the economy, and satellites. The imbroglios and networks that had no place now have the whole place to themselves. ("Never" 144)

These efforts to make the contours of the social totality legible - and, really, what else to call this "thing" that we have "all created"? - are useful ones. However mixed AIME's results have been, and however questionable the governing metaphors, the execution of this initiative has still seen Latour situated at the heart of an extensive interdisciplinary network that has succeeded in drawing technicians, scientists, policymakers, artists, anthropologists, and political scientists, into conversation around the politics of climate change response. Although these developments are deeply-rooted in policymaking's current efforts to see every branch of inquiry and research delivering measurable socioeconomic "impacts," we should still note that these frameworks are all the while reshaping both the terms of our debates and the nature of our audiences. And building on the initial inroads that Latour has made into these new forums, while redressing the limitations of his approach to them, we might begin by clearly and candidly foregrounding the role that prevailing private property regimes have played in shaping the vertiginous contours of our geohistorical moment. If we recall, this is exactly the kind of task that EU policymakers appear to be inviting humanists to undertake, as they summon us to deliver our "contribution[s] where they are most needed" ("Integrating" 3). 
In underscoring this point, it might prove clarifying to return to a passage that we first encountered in the previous chapter's discussion of the EU's Horizon 2020 initiative:

Instead of programmes dedicated to particular research disciplines, Horizon 2020 seeks to solve, through research and innovation, our biggest challenges, such as climate change, an ageing population, and/or energy security. Horizon 2020 defines six major societal challenges - soon to be seven, at the request of the European Parliament. The Social Sciences and Humanities, in all their various disciplinary guises, will be firmly embedded in all the challenges. "Embedding" means that the Social Sciences and Humanities can make their contribution where they are most needed. It means that they can provide the necessary knowledge and understanding to tackle the challenges. It means that the social, political and human aspects are not forgotten alongside the technological aspects.

(“Integrating" 3)

Obviously, it would be a mistake to take this proposal solely at face value, imagining that government was intentionally giving humanists and social scientists license to question policymaking's abject subordination to the interests of private capital. We can however simply make use of strategic naivety in seeing that the critique of private property finds itself an awkward hearing in the interdisciplinary forums toward which we are now being actively funneled, and in the public domain to which they are ostensibly answerable.

Yet given the authoritarian drift of prevailing knowledge production regimes, and given the increasingly precarious nature of academic work, we should anticipate that committing to such courses of action may well come at professional cost. Such contingencies are little addressed in the benign research universe described in AIME. Indeed, in declining to ask questions about what roles "embedded" humanists will actually be tasked with fulfilling, Latour's calls to social and intellectual agency can often 
thus seem - from the vantage of us old materialists - somewhat prone to miss the mark. For in the absence of a working theory of research's tighter and tighter imbrication in the logics of monopoly capital, expansive invitations to begin "reassembling the social" risk seeming somewhat toothless. In so far as the modern nation state is in possession of a monopoly on violence and is at one and the same time positioned in a dependent and custodial relationship to economic growth and capital investment, it will continue to be private capital that offers the last word on how and when the social is reassembled. And should the structuring logic of private property be allowed to prevail indefinitely, we should anticipate that social innovation frameworks will oversee - not the "resetting of modernity," nor the move from "modernization to ecologization" - but rather the onset of urban "resiliency" and "sustainability" strategies that prove every bit as combined and uneven as the global development program that preceded them.

There is doubtless something deeply alluring about the prospect of reassembling social life as if its constitutive elements offered as little resistance to the intentions of the "collective" as a large box of Lego to a group of equitably-minded children. One can only look at our cat's cradle of socioecological impasses and wish that this were the case. The world, our world, offers resistance to us, and among the stubborn and determinative structures that define its current form, the institution of private property ranks as one of the most significant. Failure to understand this is failure to understand the depth and vintage of one of the principal political problems that confronts us. The technical, ecological, and demographic composition of the real economy has changed in ways that the originators of political economy could scarcely have imagined. Yet in so far as the dominant continue to demonstrate a robust appetite for dominance - and in so far as the 
maintenance of this dominance entails the reproduction of a bureaucracy that "speak[s] to the rulers of their interests and not of justice and duty" (Tarde qtd in Latour and Lépinay, 31) - we should expect that efforts to "reset modernity" will run into an-all-too-familiar set of obstacles. Refusing to speak the system's name, will not change its nature. Indeed, as the superrich fortify their islands, and circle the yachts, it seems naive to imagine that they will fail to go on enlisting technocratic emissaries willing to struggle against the introduction of whatever new "instruments" or discursive "scripts" threaten to tip the balance of power in a more equitable direction. 


\section{CHAPTER THREE: THERE ARE NO PURELY TECHNICAL SOLOUTIONS}

In the previous chapter I offered a case study in the research trajectory of Bruno Latour. One of its core concerns was to illustrate how a new wave of late capitalist policy initiatives has begun reshaping the humanist's working environment, and with it our objects of analysis, and our prevailing sense of audience. In reviewing Latour's career, we began by discussing his early efforts at establishing a foothold for his own ethnographic branch of laboratory studies, before following the development of his thought up until the present - through the mid-stage development of ANT, to his more recent work as one of the doyens of this new practice of "meta-curation." Interpreting Latour's multimedia AIME project in relation to the funding frameworks that fostered its emergence, I began to characterize the rise of lab-affiliated "meta-curators" as one of the early, signal cultural instantiations of policymaking's current attempts at "integrating" the sciences and the humanities.

As this argument unfolded, I proposed that critique's would-be torchbearers best respond to "postcritical" attempts at barring them from these spaces, by conceiving of themselves, less as the embattled defenders of the humanist citadel, and more as "raiding parties," intent on penetrating the new labs and knowledge production platforms, to seed their hopes and antagonisms within them. For reasons that this chapter will explore in more depth, many of these flagship social innovation hubs are positioned on the frontlines of late capitalist climate change response. And in understanding the systemic logic that shapes their approach, this chapter attempt to fill in the gaps left by a Latourian analysis of political economy. In contrast to Latour's longstanding tendency to cordon off the question of private property, or to blot the image of totality from theory's horizon, 
this chapter returns to Mandel's synoptic study of the late capitalist world-system. It highlights how late capital's moving contradiction continues to propel the planet toward a variety of critical climatic and ecological tipping points, even as a fresh wave of policy initiatives attempts to inaugurate a new age of "sustainable" development.

My key case study in defining the governmental logic that is driving the development of this new wave of interdisciplinary social innovation initiatives has been the EU's Horizon 2020 framework program. I stick with this case study in this chapter, as the extensive and public nature of the EU's archives, and the complexity of their interstate economic frameworks, afford comprehensive insights into a policy paradigm that has enjoyed a wide reach. In what I think is accurately categorized as the most comprehensive and influential example of social innovation policymaking to date, we see the European Commission (EC) acknowledging that it has become "increasingly selective when it comes to supporting research projects" (EC, "Testing" 9-10). In practice this "selectivity" now plays out in a handful of key ways:

1) We see funding allotted on the basis of "challenges to tackle rather than disciplines to be financed" (Geoghegan-Quinn, 2), such that researchersregardless of discipline - are expected to shape their research in relation to a precisely defined list of "social challenges." These include such pressing issues as climate change, an ageing population, energy "security," food "security", and natural resource depletion.

2) We see policymaking placing an especially strong emphasis on "results orientation." In practice, this usually plays out in demands for "Proof of Concept" - i.e., evidence from an experiment or pilot project that 
demonstrates the feasibility or scalability of a new initiative - or for a "Theory of Change" that clearly defines organizational strategy and/or research objectives in terms of measurable "impacts" and outcomes. This process is thought to narrow the gap between research and implementation while enabling funders to assess and monitor "investment returns."

3) Across the board, the EC actively prioritizes research programs that promise to help it secure "smart, sustainable, inclusive growth" (Potočnik, 3). This emphasis reflects a desire to speed up the velocity of the innovation cycle, while at the same time pre-emptively anticipating and mitigating the worst forms of socio-ecological blowback. Among the key concepts that the EC relies upon in this respect are "natural capital," "ecosystem services," and "circular economy," which all attempt in some fashion to map out and mitigate the problem of externalization by rendering it legible in accounting terms (Badura, Ferrini, Agarwala, and Turner).

4) Along the same lines, current policies also prize interdisciplinarity and promote lab-based team research that bridges disciplinary divides, synthesizing knowledge across a diverse array of "inputs." This effort takes various forms, including the EC's goal of "integrating" the social sciences and humanities with the STEM disciplines, a goal that is ultimately a facet of the broader effort to stimulate economic growth while fending off the encroaching prospect of catabolic collapse. 
5) Lastly, in view of constrained budgets and stagnant growth that has characterized economic planning in the wake of 2008 , the EC is keen to "close the gap" between research and market, such that it prizes publicprivate partnerships, the generation of intellectual property rights, and any other mode of market-facing or cost-cutting research that promises to deliver "increase[s] in inclusion and employment, reduction[s] in cost of service at same quality level" or "contribution[s] to the economy" (EC, "Testing" 4). (In the Ontarian context we have just seen this strategy implemented in an especially aggressive form, in Premier Ford's attempts to see 60 percent of higher education tied to performance targets by the year 2024 (CBC, “Funding for Ontario")).

It is admittedly hard to project what contribution advocates for literary culture can make in this kind of domain. Yet for my own part, and despite my better judgment, I confess to cultivating a secret hope that among those literary humanists that do make it aboard the new programs, one or two of them might bring along copies of Kim Stanley Robinson's Mars Trilogy, to circulate there as a kind of gateway drug to the anarcho-communist critique of private property. The concluding chapter of this thesis argues that the narrative arc that Robinson develops around his anarchistic trickster figure, Arkady Bogdanov, offers us a tantalizing "thought experiment" concerning the unpredictable, and to some extent "unmanageable," cascade effects that might be precipitated within the new lab networks, given the right circumstances.

This chapter prepares the groundwork for this final turn in my argument, by running reconnaissance. Rather than just repudiating these new funding frameworks and 
initiatives as neoliberal corruptions of a pastoral Keynesian campus - itself an expression of, and ideological bulwark to, the disastrous postwar modernization project - I ask how we might explore them as a new terrain of struggle, one whose characteristic constraints and dangers we need to foreground together, self-reflexively. These are, after all, the kinds of questions that early stage researchers across the board will have to address in practice, as they navigate $\mathrm{R} \& \mathrm{D}$ platforms and lab networks that more and more clearly subsist at the fraught intersection of a diverse array of conflicting "stakeholder" interests and political commitments.

\section{HISTORICIZING SOCIAL INNOVATION}

In the course of the introduction I began to introduce the concept of social innovation, tracking its rise to prominence in the aftermath of the financial crisis. Yet despite the term's current ubiquity, putting one's finger on what "social innovation" means in practice, turns out to be a slightly more changeling task than one might imagine. Prevailing definitions of the concept prove remarkably hazy. Indeed, it has become surprisingly common for social science primers on "social innovation" to begin by awkwardly acknowledging the somewhat amorphous nature of the concept they discuss. Frank Moulaert, Diana MacCallum and Jean Hiller open their contribution to The International Handbook on Social Innovation with the admission that "reading and talking about social innovation [does] not necessarily mak[e] its scientific meaning unambiguously clear" (13). Frances Westley and Sam Laban follow suit at the outset of the Social Innovation Lab Guide, admitting that "[t]here is as yet no established orthodoxy about what a [Social] Lab is" and stress that the term is currently "applied to a 
plethora of processes and organizations, often with markedly different goals and employing distinct methods and approaches" (1). Faced with this broad-based categorical confusion, this chapter attempts to account for the sudden ubiquity and questionable utility of a concept that is all the while reshaping academic practice in quite profound ways.

Attempting to track the idea's genealogical development provides mixed results. Bob Jessop, Frank Moulaert, Lars Hulgard, and Abdelillah Hamdouch offer an account that is thus far pretty widely accepted. They point to two key branches of social innovation theory, a Francophone and an Anglophone, identifying management theorists Peter Drucker and Michael Young, and French sociologists Pierre Rosanvallon, Jacques Fournier, and Jacques Attali as the idea's earliest proponents.

Comparing the differing stances adopted in these early theoretical statements, we can uncover at least one common claim: All the parties position their version of social innovation as a decentralizing alternative to the statist culture of command that the war years passed on to the architects of reconstruction. The French branch of social innovation theory develops in the immediate aftermath of 1968 , as contributors to the journal Autrement ask what enduring lessons sociology can draw from that era's groundswell of anti-establishment politics. This strain of social innovation theory is informed by a latently anarcho-communist vision, one that privileges the role that "collective initiative" can play in satisfying community needs, and that maintains a wariness concerning the social state's more autocratic and rigidifying tendencies.

Working in the UK's rather different political context, Young - a one-time member of Prime Minster Clement Attlee's brain trust - had grown disenchanted with 
party politics. During the active academic and political career that followed his departure from the Labour Party, Young promoted a political vision that was informed by a distrust of established institutions and hierarchies, and that sought to facilitate the political empowerment of non-state actors and local communities. In the course of this work he identified the rising profile of the NGO and drew on the entrepreneurial theory of Joseph Schumpeter in coining the term "social entrepreneurship," seeing the third sector as a potential cradle of the "non-statist, decentralist, participatory forms of public intervention" that he had long sought to promote (Meredith, 273).

The New York-based Austrian management theorist Drucker operated in a somewhat different vein, lending the concept more of a business emphasis. As a forerunner to today's "critical management theory," he argued that the profit motive did not absolve companies of the "need to make a social contribution" and welcomed the challenges that the environmental movement was then beginning to pose to prevailing industrial practices. Drucker pre-emptively rebutted Thatcher's assertion that there was "no such thing as society," insisting, instead, that industries and enterprises actually existed only on political "sufferance," and should "exis[t] only as long as the society and the economy believe that [they do] a necessary, useful, and productive job" (Drucker).

Contemporary social lab facilitator, Zaid Hassan, echoes the tone of this early work in positioning his own approach as an alternative to the "Soviet" planning models that characterized the immediate postwar period, and the "neoliberal" financializing models that rose to dominance as the older approach faltered and failed. In so doing, Hassan champions the "prototyping" practices of the technical laboratory as a solution to the world's most vexing social problems, arguing that that recursive flexibility of a 
testing bed approach, might equip them to steer a course beyond the longsighted rigidity of planning paradigms (xiii-xiv).

Yet despite the breezy confidence with which Hassan makes these claims, it is doubtful that the relationship between central planning and an R\&D lab can ever accurately be portrayed in terms of a simple dichotomy. Indeed, the cozy relationship between the strategic objectives of central planners and the practical orientation of today's social lab research is all too evident. For in lieu of Young's or the Autrement group's attempts to secure local communities some autonomy vis-à-vis an intrusive and autocratic state, facilitators of today's social labs are more likely to stress the goal of “integration." Here, for instance, are Frances Westley and Sam Laban of the Waterloo Institute for Social Innovation and Resilience (WISIR) sketching out their understanding of why "re-engag[ing] vulnerable populations" in the economic, social and cultural "mainstream" has come to represent "one of the principal goals" of social innovation (83):

On the one hand, better integrating excluded groups (such as the poor, mentally ill, or physically disabled) helps build a system's resilience as the stress of supporting the excluded (or defending against them) reduces the resilience of the whole. On the other, their inclusion in the social innovation cycle may actually help create novelty, bringing different viewpoints into the process of innovation, which is largely the result of recombining elements (bricolage) in new ways. Therefore, we exclude these voices at our own peril, losing the diversity of their experiences, expertise and perspectives on the system. The social innovation process benefits and is benefited by the inclusion of marginalized or vulnerable groups. (83-4)

This effort to cater to the strategic interests of state planners concerned with quelling unrest and shoring up fragile hegemony in the face of stark economic disparities, 
underscores how little today's "social labs" can have in common with the antiestablishment sympathies that informed the original schools of social innovation theory.

Although mainstream debates on social innovation have yet to look this issue fully in the face, we do still encounter a significant amount of discussion concerning policymaking's promotion of the term. And as Moulaert, MacCullum and Hiller draw on Gilles Deleuze and Félix Guattari in describing "social innovation" as an "order word" (18), they help us take a step closer to understanding why a term first promoted by critics of authoritarian statitism and corporate absolutism has suddenly emerged as one of central planning's favorite concepts. But to get to the heart of the matter we have to extend the logic of Moulaert, MacCullum and Hiller's claim further, to focus attention less on debating which kinds of social initiatives are accurately categorized as "innovative" in nature (an approach often favored in contemporary social science discussions of the subject) and more on attending to the policy program for which the term itself serves as a metonym. As we parse the evolving logic of this program from the vantage of Mandel's account of late capital, we will see the social innovation policy paradigm developing at the interstices of longstanding R\&D policy directives, tightening state budgets and austerity discourses, and the kind of "planet management" systems theory that was last in vogue in the early 1970s.

\section{INNOVATION AND LATE CAPITAL}

In a recent internal document, the EU offers a retrospective synopsis of the history of their "framework programs for research and innovation," tracing their initial 
crystallization back to economic and political objectives "linked to the control of energy sources" (Reillon, 3). And looking back on the energy sector initiatives that would go on to provide the template for all of the EU's subsequent intergovernmental research coordination programs, we find that by the beginning of the 1960s European governments are becoming actively concerned by the growing "technological gap" that was then seen to separate Europe and the United States (4).

The anxiety bears out Mandel's argument concerning the role that "applied science" now played in driving economic growth. In his use of the term, "late capital" was a periodizing device designed to identify the distinctive features of the postcolonial, postwar economy. In Mandel's estimation, what distinguished "late" capital from the "freely competitive" and "classical imperialist" periods that preceded it, was the extent to which the "monopolization of the technical process" had now emerged as the critical strategic high ground of inter-state and inter-capitalist competition. While acknowledging that technological innovation "played a key role in the growth of capital ... from the outset of industrial revolution," Mandel would still insist that the depth of late capitalism's dependence on applied science marked a departure from earlier norms (103). Anticipating Joseph Schumpeter's account of creative destruction, Mandel defined the newly central significance of technical innovation in the following terms:

[A] lthough the capitalist world system is an integrated and hierarchized whole of development on the international, reginal, and sectoral level, the main weight of this ramified and uneven and combined development takes different forms in different epochs. In the age of freely competitive capitalism its predominant weight lay in the regional juxtaposition of development and underdevelopment. In the age of classical imperialism it lay in the international juxtaposition of development in the imperialist states and underdevelopment in the colonial and 
semi-colonial countries. In the age of late capitalism it lies in the overall industrial juxtaposition of development in growth sectors and underdevelopment in others, primarily in imperialist countries but also in the semi-colonies in a secondary way. (103)

Whereas, during the colonial period, interstate rivalry led to the formation of competing trade empires, in the wake of the wars - and the dramatic mobilization of applied science that characterized them - states and industries were instead now on a "constant hunt" for new "discoveries and inventions" (192). In a context where the industrialization of the productive process was becoming all but universal, and where the closure of the world market had exhausted the imperial dynamics that Lenin and Rosa Luxemburg defined in depth, the mutually-reinforcing interaction of technological innovation and intellectual property right now served as capital's principal means of perpetuating the conditions of combined and uneven development on which the valorization process relied. Technical innovation played such a critical role here because of the extent to which it could both lower the "cost-price of commodities" and resist being immediately "generalized through a given branch of production and applied by all competitors" (192). Mandel found that both factors were critical, for new technologies could only operate in a "cost-cutting" and "labor-saving" (and therefore investment-spurring) fashion to the extent that their use represented a genuine departure from prevailing industry norms. As soon as a technology became universally-adopted, it ceased offering its user a competitive advantage, and became instead a general operating cost. It was thus essential to be at the forefront of technological change, for it was there that one stood to recoup the highest rates of return on investment: 
A significant period of time separates the first moment that a technological discovery is given a productive application (i.e. the moment of technological innovation) from the moment there is an equalization of the rate of profit. The cheaper commodity, manufactured with more modern technology, is first produced and sold at the average rate social price of production. It thus yields the owner a surplus-profit. This only gradually - through information in business reports and so forth - penetrates the consciousness of the generality of the owners of capital. (93)

In their efforts to secure themselves what management strategists today refer to as "firstmover advantage," companies poured larger and larger reserves of funds into R\&D. These dynamics were self-reinforcing, for as new technologies "penetrated" a sector, competitors in a given industry were compelled to follow suit, in search of whatever surplus-profits still remained. All the while, however, as the wave of "technological renewal" rippled through a sector, first-movers continued to enjoy an enduring structural advantage. Their production costs would remain lower than average, right up until the moment when all their competitors had either adopted the new innovation or been forced out of operation. At this point, competition would have succeeded in "lower[ing] the profit of the innovating firm" back "to the social average" (93).

The whole process would accordingly need to be repeated. And it was. For although a given innovation would not allow its user to evade the "equalization" of rates of profit indefinitely, during "the entire intermediate period" it all but guaranteed early adopters a higher share in surplus-profits (93). The velocity of the innovation cycle was thus primed to undergo constant acceleration, for it was through these cycles of technological renewal that industry kept at bay the entropic tendency toward the equalization of profit rates. The net effect of these dynamics was that leading technical 
innovators were drawn deeper and deeper into capital-intensive scientific and technical research. For as each new innovation permeated a sector, the technological sophistication of that entire industry increased dramatically. This in turn drove the proliferation of yet more capital-intensive research laboratories, as investors and companies raced to broach new scientific and technical frontiers. Meanwhile, as the automation of the productive process intensified with each new wave of technological renewal, labour was being steadily expelled from the manufacturing sector, and reincorporated, where possible, in the burgeoning "service sector." Midway through the twentieth century's postwar decades, "[t]he burly, "blue collared' line worker" seems to "blur," in the words of George Caffentzis, "diffracted into the female service worker and the abstracted computer programmer" (26):

And it all feels so different! Your wages go up but they evaporate before you spend them, you confront your boss but he cries that "he has bills to pay," and even more deeply, you don't see your exploitation any more. On the line, you literally could observe the crystallization of your labor power into the commodity, you could see your life vanishing down the line, you could feel the materialization of your alienation. But in the service industries, your surplus labor seems to be non-existent, even "non-productive," just a paid form of "housework," cleaning bedpans, massaging jogger's muscles, scrambling eggs. (26-27)

As labour struggles to reorganize itself in the context of these unfamiliar confines, the global economy undergoes a process that Jeff Diamante has referred to as "energy deepening," as the ongoing automation of the means of production and spread of consumer appliances, substitutes machinic for manual labour, driving up late capital's energic appetite. 
Nation states were no bystanders in this process. Given how critical the innovation cycle had become to the capitalist mode of production as whole, states policed the unsanctioned reproduction or reverse engineering of new technologies stringently. The logic was simple, if "surplus-profits" were not returned to the point of innovation, the dynamism of the entire innovation cycle would be imperiled. Struggles over the control of patents and the orchestration of cartel arrangements thus emerged as critical strategic battlegrounds. Reassured by nation states' enthusiastic anti-piracy initiatives, investors and CEOs began throwing "enormous outlays of capital" into research and development, in search of "the commensurately higher than average surplus-profits" that would be "won" by those companies that were the first to "achieve a breakthrough" $(254) \cdot{ }^{12}$

Yet then, as now, the overriding impetus towards investment in innovation came with the caveat that although first-mover advantage promised sectoral innovators the highest rate of return, individual $R \& D$ initiatives themselves remained a gamble. In the context of an era of accelerated technological innovation, uncertainty over investment returns resulted in an "increasingly powerful incentive to plan research" (255). Little wonder then, that the nascent European Community had understood cooperation on R\&D as an area of acute strategic concern. The scale of the US's resources - financial, territorial, pedagogical, and technical - had led European nations to conclude that their own industries would have little hope of competing, unless they committed to

\footnotetext{
${ }^{12}$ Once again, Mandel is at pains to insist that this dynamic represents a significant reorganization of some of capitalism's perennial dynamics, rather than a completely unprecedented novelty: "This does not mean, of course, that 'technological rents' - surplus-profits originating form advances in productivity based on technical improvements, discoveries and patents - did not exist in the 19th century, or were exceptional even then. It only means that, in the absence of a high level of centralization of capital, they were of relatively short duration, and therefore had a lesser weight in overall surplus-profits than 'regional' surplusprofits, and later colonial surplus-profits" (103).
} 
coordinating their R\&D programs, thus cutting down on the unnecessary duplication of research, and allowing them to operate research ecologies of commensurately vast scale and scope.

\section{“FRAMEWORK PROGRAMMES” FOR RESEARCH AND INNOVATION}

Under the sway of this effort to increase "innovation capacity" (Reillon, 32), initial panEuropean exercises in intergovernmental research had by 1981 coalesced into the first of the European Community's Framework Programmes (FP1). In the decades following - as the European Community gradually morphs into the European Union - FP1 was followed by seven new iterations of the project, culminating in its latest manifestation, 2011's Horizon 2020 (FP8). The iterative development of the "Framework Programmes" was anticipated in the constitution of the first document, which imagined the FPs as a means of coordinating research objectives while adapting them to changing circumstances. Indeed, as the Framework's first authors spell out its operation principals, we learn that FP1 would "act as a concertation mechanism," one that was intended to be "revised regularly," such that "[i]t would define thematic priority areas" and conduct ongoing appraisals of the "efficacy" of funded research programs research (Reillon, 6).

It perhaps belabors the point to stress that the basic foundational features of today's social innovation frameworks are already in evidence here in their initial R\&D context. Yet in the early stages of the first European Framework Programmes these mechanisms were only designed to promote intergovernmental STEM research. Over the intervening decades this picture gradually changes. In the words of the EU's Vincent Reillon, the FP slowly evolves from "a flexible shell within which the specific programs 
remained the most important components" to "a financial instrument whose structure and budget would constrain the content and budget of the specific programmes" (23). And as the scope and scale of this financial instrument develops, it begins to stretch its influence far beyond the STEM disciplines.

A crucial step in the development of the program occurs in 1995 as the EU begins planning FP5. It is at this point that we see the EU first beginning to flirt with a programmatic promotion of social innovation theory, as they attempt to supplement the FP's "historic focus on technical achievement" with the complementary aim of "mak[ing] research more efficient and increasingly directed towards meeting basic social and economic needs"" (14). FP5 is thus "guided by the idea of extending the scope of Community research policy and its main instrument" to the resolution of "social problems" (14). From this point on the EU takes gradual if intermittent steps in this direction.

Yet as the EU begins, in 2000, to plan the sixth iteration of the program, the dominant focus undergoes a pronounced shift back toward the kind of concerns that typified FP1. Facing stubbornly low productivity and stagnant growth, the EU is again concerned that "fragmentation" and duplication of research is serving as a major impediment to successful competition with the United States. FP6 is accordingly the site of a major "revamping" effort that is designed to make the EU "the most competitive and dynamic knowledge-based economy in the world capable of sustainable economic growth with more and better jobs and greater social cohesion" (12). With a new Commissioner for Research, Philippe Busquin, at the helm, and under the intellectual influence of 
Portuguese economist Maria João Rodrigues, the EU's Lisbon Strategy effectively takes the entrepreneurial theory of Joseph Schumpeter as its lodestar. ${ }^{13}$

With the onset of FP7 we see the EU returning to some of the social innovation theory that characterized FP5, while at the same time dramatically increasing the overall financial scale and scope of the program (Figure 1):

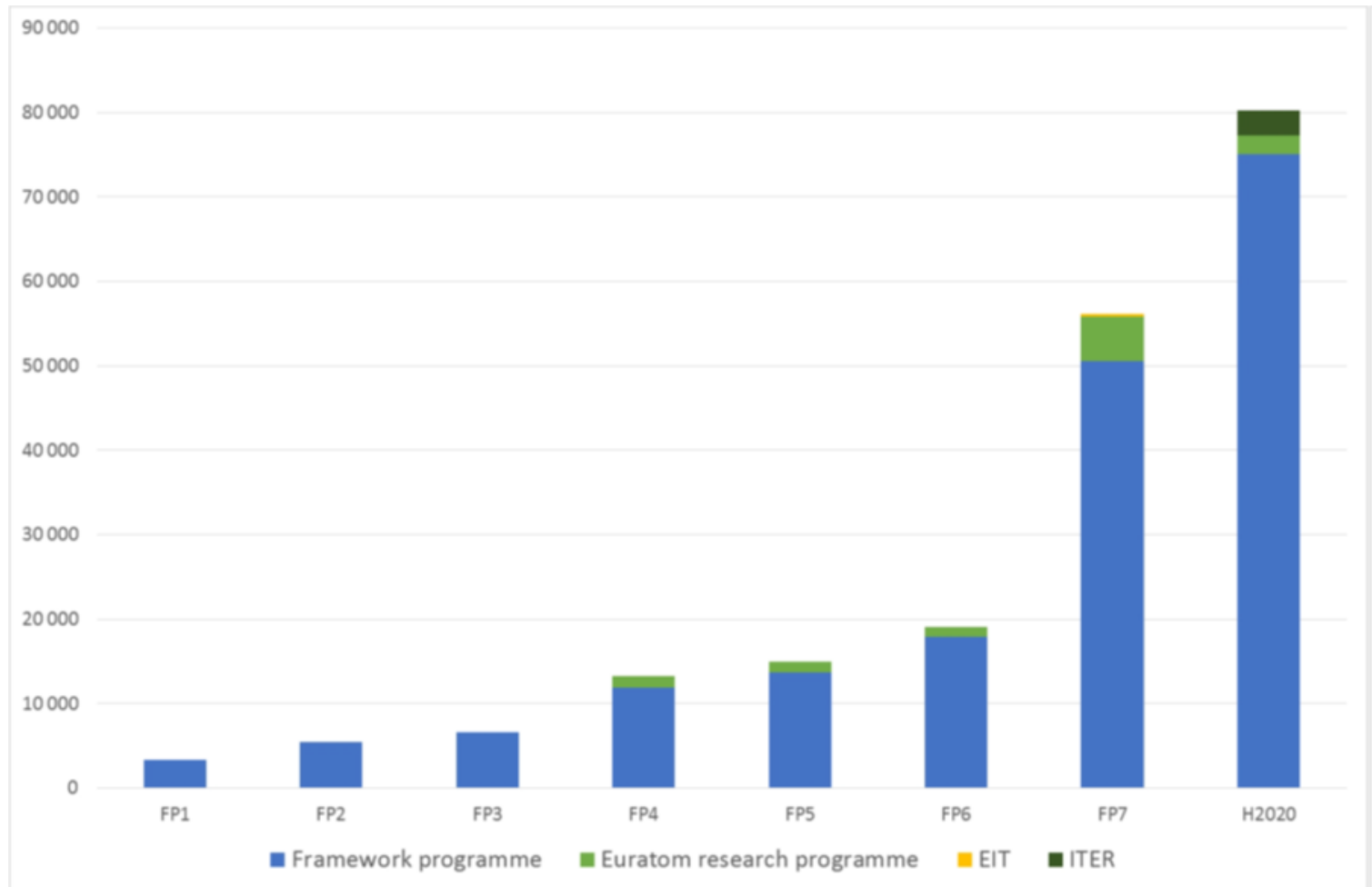

Figure 1: "Evolution of the budget of the EU framework programme for research (in million ECU/€)." From "EU framework programmes for research and innovation: Evolution and key data from FP1 to Horizon 2020 in view of FP9," figure in 24.

In accord with this dramatic expansion of committed funds, FP7 places an intensifying focus on the promotion and cultivation of public-private partnerships, which are designed to defray the state's financial commitments, while at the same time expanding and

\footnotetext{
${ }^{13}$ As something of a footnote to these dominant overarching objectives, FP6 begins to register the burgeoning climate crisis, such that the concept of "sustainable growth" gains some traction. This is also the juncture at which the now ubiquitous "research excellence frameworks" begin to make their initial inroads.
} 
securing investment in both technical innovation and social services. Highlighting eight strategically-central areas of scientific and technical research, FP7 complements six straight-ahead STEM invites - Health; Food, Agriculture and Fisheries, Biotechnology; Information and Communication Technologies; Nanosciences, Nanotechnologies, Materials and new Production Technologies; Energy; Environment; Transport; Space with two more novel additions, the so-called "Socio-economic Sciences and Humanities" and "Security."

The addition of these last two categories prepares that way for the more radical changes that would characterize Horizon 2020 (FP8), which comes online in 2011. Responding to the tightening budgets and political instability that followed the financial crisis, and unable, or unwilling, to completely ignore the evident threats now posed by a destabilizing planetary climate, FP8 now centers on seven areas of strategic concern: "health, food security, energy, transport, climate and environment, inclusive societies and secured societies" (222). Though the number of thematic areas has been whittled down from those adopted in FP7, the scope of the program itself has again been extended. Reaching beyond the management of the pre-productive sphere, FP8 now attempts to encompass and steer the management of the social state and, with it, social reproduction at large. And thus in lieu of FP7's experimental promotion of "Socio-economic Sciences and Humanities," ten years later Horizon 2020 is charged with funding and overseeing all social science and humanities research. Meanwhile, no longer an addendum, the concept of "security" tellingly structures the orientation of food and social research, while the innervating figure of "climate" begins to eclipse discussion of the environment. In sum, extended beyond the typical concerns of industrial $R \& D$, the eighth iteration of the EU's 
FP is clearly tasked with ensuring an "inclusive, "secure" and "sustainable" social order in the face of an increasing complex set of fiscal, technical, and environmental conundrums.

\section{THE RAD LAB: CYBERNETICS AND SYSTEMS THEORY}

On the ground, as the logic of this R\&D policy framework begins to exert its influence over the development of social policy at large, we see late capitalist policymakers beginning to position the city itself as a "living laboratory" (Schneider; EC, "Citylab"). This is a concept fraught with troubling ethical implications, to which we will return in the final chapter, as we explore what is being experiment on, and to what end. Yet it should be underscored that this is by no means a new question. For although onsite facilitators such as Hassan have a tendency to position their "labs" as somewhat unprecedent initiatives, the notion that urban and social planning could be made the object of the technical laboratory's iterative "testing bed" approach represents the culmination of a project that first began to coalesce back in the research laboratories of the war era.

In searching for this program's initial point of origin we could do worse than to return to the work of the widely-acknowledged founder of cybernetics, Norbert Wiener. Wiener began his career as a mathematician working in MIT's newly-founded Radiation Laboratory. Convened in response to the "Battle of Britain," the so-called "Rad Lab" was established in 1940 with a half-million-dollar grant from the National Defense Research Committee and tasked with "develop[ing] more effective ways to track and shoot down 
the bombers then plaguing" the embattled Island (Turner, 18). In line with the objectives of this broader initiative, the problem that occupied Wiener as he arrived at the key concepts of cybernetics was "devis[ing] statistical methods for determining the future course of an airplane based on its location and motion" (20). Working with engineer Julian Bigelow, the two developed a computational machine named "the predictor" which was designed to apply Wiener's predictive algorithms in real time, and under combat conditions.

In the early stages of this work Wiener and Bigelow realized that they needed to generate a conceptual language that was capable of grasping the human and mechanic components of their target phenomenon - the pilot and his plane, the gunner and his gun - as a single system. They elected to "find a mechanical analogue" for the gunner and the pilot for the simple reason that, as Wiener notes, "our understanding of the mechanical elements of gun pointing appeared to us to be far ahead of our psychological understanding" (qtd in Turner, 20-21). In grounding this approach they turned to the concept of the "servomechanism," and took the mechanical "governor" that James Watt first devised to regulate the speed of his steam engines as the basis of their model.

A major innovation in the history of mechanical engineering, Watt's fly ball governor made an elegant and ingenious use of centrifugal force in regulating engine speed (Figure 2). Its operational principles were disarmingly simple. At zero miles an hour the engine's steam valves would lie completely open, allowing for a rapid intake of steam. But as the engine's main drive shaft began to rotate at a higher pace, under the mounting pressure, it delivered force to a second speed-sensing valve drive. As this valve drive accelerated, centrifugal force caused the shaft's spinning "fly ball" weights to rise. 
The higher they rose, the narrower the intake valves became, ultimately cutting off the flow of steam altogether. As the engine slowed, the falloff in centrifugal force would cause the fly balls to descend, reopening the intake valves and returning energy to the system.

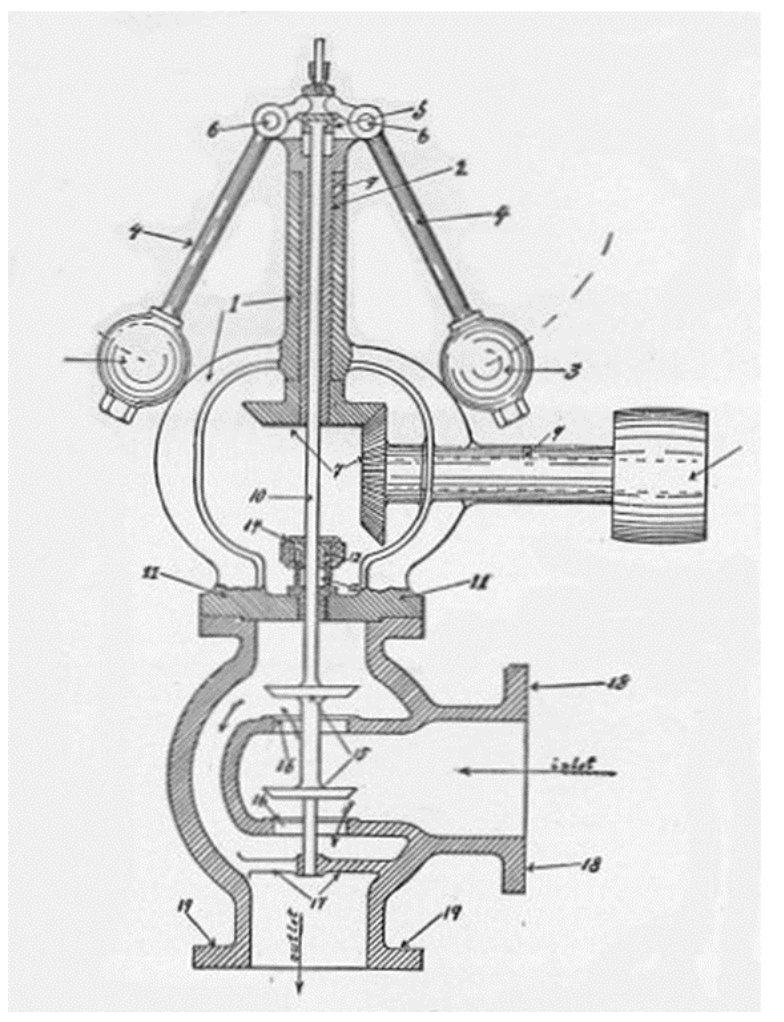

Figure 2: Nehmiah Hawkins. 1904. “The Governor.” Artist illustration. From The New Catechism of the Steam Engine, figure in 46.

Wiener and Bigelow defined the principal embodied in this recursive, self-regulating action as one of "negative feedback." They termed it such in identifying a form of "circular causality" that allowed a closed system to monitor and react to the buildup of critical variables, thereby regulating its internal conditions. They distinguished negative feedback from "positive feedback," which in lieu of activating a cut-off point, simply saw the buildup of a given variable exponentially increasing a system's demand for it. Operated according to the principal of "positive feedback" Watt's steam valves would have grown wider and wider as the engine increased its speed, leading the machine along 
a vector of constant acceleration that would ultimately see the buildup of heat and pressure tearing the engine's walls apart.

Many of the principals at stake here were already part of the conceptual bedrock of machine engineering, yet the key theoretical innovation at the heart of Wiener's intervention was that one could apply the conceptual architecture of machine engineering to understand the behavior of living things. One could, for instance, predict the behavior of pilots, or birds, in flight, as they reacted to changing aeronautical conditions, maintaining a line of flight via a series of counterbalancing correctional processes analogous to the activity of Watt's governor.

The conceptual implications of this theory were quickly extended beyond the relatively narrow confines of the problem that they were designed to model. As laboratory testing delivered Wiener and Bigelow a persuasive proof of concept, they "began almost immediately to generalize their vision of [the] self-directing system," applying it to other fields (22):

In early 1942, Wiener and Bigelow had begun to think about the biological realm and approached Arturo Rosenblueth. Their discussions led to the 1943 publication of a paper, 'Behavior, Purpose, and Teleology,' in which they suggested that behavior and purpose in biological systems proceeded according to the same feedback dynamics that governed the sorts of mechanical and biomechanical systems Wiener and Bigelow had been developing in the Rad Lab. But this was only the beginning. Within a year, Wiener began to imagine duplicating the human brain with electrical circuits. By 1948 he had transformed the computational metaphor into the basis of a new discipline. (22)

The ramifications of the research were grasped quickly by other researchers in the war era's growing network of technical laboratories, and as labs began to explore the heuristic 
implications of circular causality they would be led to the conclusion that informationfeedback system was all pervasive in nature. By the close of the war it seemed that one of the most intellectually generative aspects of this mode of thinking was its apparent capacity to serve as a universal conceptual architecture for modernity's increasingly labyrinthine array of scientific, humanistic, and managerial discourses. Anthropologist Gregory Bateson would go so far as to remark that cybernetics represented "the biggest bite out of the fruit of the Tree of Knowledge that mankind has taken in the last 2000 years" (476).

In accounting for the immense synthetic capacities of Wiener's theory, Fred Turner traces its structural logic back to the collaborative working environment in which it was devised. Read in this light, the discourse of cybernetics was one of a number of interdisciplinary "contact languages" then being developed, on the fly, as researchers from different disciplines were thrown together and asked to collaborate around the resolution of key technical problems (19). Turner suggests that the specific organizational structure of the Rad Lab made a significant contribution to the syncretic capacities of cybernetic theory, and to the subsequent character of postwar R\&D research in general. In contrast to the more monolithic and bureaucratic approaches of the major militaryindustrial projects that would develop "the atomic bomb, submarines, marines, aircraft, and even digital computers," the Rad Lab's working environment was instead defined by "nonhierarchical, interdisciplinary collaboration" (18). Indeed, in place of the "single laboratory room" that its name implies, the Rad Lab was in fact "a collection of interlinked research projects" that bought together MIT scientists and mathematicians with "engineers and designers from industry, and many different military and government 
planners" (19). Commenting on the professional dispositions that this environment promoted, Turner finds that "among the engineers and designers, entrepreneurship and collaboration were the norm, and independence of mind was strongly encouraged" (19). And read in relation to our discussion of the social innovation research paradigm, this interdisciplinary and entrepreneurial milieu appears disarmingly familiar. Indeed, in view of Turner's claims, it seems quite plausible that the Rad Lab itself served as the principal institutional incubator of that research paradigm that has since begun to lay claim to every facet of the modern university system. Looking back on the early days of this “collection of interlinked research projects" (19), we see the same prioritization of interdisciplinary knowledge exchange, and the same close working relationship between industry, research, and academia, that social innovation policy frameworks are now beginning to insist upon at every turn.

\section{SYSTEMS DYNAMICS, LIMITS TO GROWTH}

Yet in an irony intrinsic to the logic of the late capitalist world-system, it is this network of technical laboratories and prototyping hubs that provides both the developmental matrix for the planetary-scaled expansion of human infrastructures, and for the conceptual frameworks and instruments that will allow researchers to grasp and conceptualize the reverberating ecological repercussions of this expansion. These contradictions are especially well exemplified in the career of Jay Forrester, whose work at MIT would mirror Wiener's, building on wartime servomechanism research to develop a series of experimental policy initiatives, initiatives that provide today's social labs with many of their basic operational principles and conceptual underpinnings. 
Cutting his teeth in the same wartime technical labs that provided Wiener with his working environment, Forrester would later move on to MIT and bring his research on servomechanisms to the newly emerging field of digital computation. This work would culminate in the development of Random Access Memory (RAM), laying the foundations for modern computing. Yet Forrester's career was characterized throughout by a relentlessly linear development logic, such that by the time RAM itself was finally achieved, he had already moved on to other fields. Coming to the perhaps premature conclusion that "the pioneering days in computers were over," Forrester had by 1956 joined MIT's newly-founded Sloan Management School with the goal of figuring out what "contribution digital computation and control theory might make to management" (Lane and Sterman, 5-6). It was here that he helped to found the field of research that we know today as "supply chain management."

Forrester's first major project at the Sloan Management School was to assist General Electric Corporation managers, who were then puzzling over "large fluctuations in production, inventories, employment, and profit" (6). In attempting to identify their underlying causes, Forrester would follow Wiener's lead, conceiving of the corporation itself as a closed system, and modeling the "interaction of [its] physical structure, information flows, and decision processes," thereby mapping out complex "nonlinear" interactions between that "network of feedback loops that generate[d]" its core dynamics (8). In justifying this then-novel approach, Forrester insisted that the research methods of the technical laboratory could be applied to the analysis of diverse social phenomena, delivering managers a firmer grasp on the operation principals of commercial enterprises and social systems: 
Our social systems are far more complex and harder to understand than our technological systems. Why, then, do we not use the same approach of making models of social systems and conducting laboratory experiments on those models before we try new laws and government programs in real life? The answer is often stated that our knowledge of social systems is insufficient for constructing useful models. But what justification can there be for the apparent assumption that we do not know enough to construct models but believe we do know enough to directly design new social systems by passing laws and starting new social programs? (Forrester, "Counterintuitive" 52-53)

Half a century later, Forrester central proposal now supplies today’s social innovation labs with their fundamental raison d'être. Indeed, following the success of his work with GE, Forrester was invited to apply his Systems Dynamics (SD) theory to the study of urban development, heading up a pilot program at the request of the U.S. Department of Housing and Urban Development (HUD).

His subsequent work in "Urban Dynamics" responded to the early days of the long downturn by attempting to devise urban renewal strategies for American metropolitan centers bogged down in economic stagnation, chronic unemployment, and spiking civil unrest. At the heart of his approach was the notion that computer simulations could be used to project the unfolding interaction of critical variables - such as housing stock, local industrial trends, material resource flows, bylaws, and taxation regimes - and used to design and test "policies to improve the behavior of the systems within which we live" (Forrester, "Systems Analysis" 258). Regarded with ambivalence at the time, following a hostile assessment by HUD, interest in Urban Dynamics is now undergoing a major resurgence. In addition to a new batch of self-styled Urban Dynamics Labs, social lab facilitators in general are returning to Forrester's approach. 
Understanding cities as complex systems of feedback loops, many of today's urban labs use computer modeling in order to forecast the systemic consequences of prevailing trends, and the longer-term repercussions of proposed policy interventions. Here, for instance, are Westley and Laban, writing in their newly-published social innovation lab "handbook," defining the preparatory stages of a social lab intervention in precisely the terms that Forrester devised fifty years earlier:

The Social Innovation Lab emphasizes not only imagining high potential interventions but also gaining system sight, redefining problems, and identifying opportunities in the broader context with the potential to tip systems in positive directions. It is a three-step process of developing, testing and instigating innovation strategies. It requires the right starting conditions, an investment in research and skilled facilitators. It also makes use of computer modeling to prototype interventions in complex systems. Like other processes for convening multi-stakeholder groups working on complex challenges, it is best suited to the early stages of making-change. (1)

In Forrester's case, however, Urban Dynamics research turned out to be yet another waypoint. For having previously jumped scale from the machine, to the corporation, to the city, Forrester's next move was to take the process to its logical conclusion. And at the invitation of Aurelio Peccei of the Club of Rome, Forrester began applying Systems Dynamics to modeling the interaction of the world economy and the biosphere, treating the two as facets of a single, closed system.

This project resulted in the production of MIT's World3 simulator, which was designed to model and predict the systemic interaction of feedbacks loops "among population, natural resources, pollution, agricultural and industrial production, capital investment, and quality of life" (Lane and Sterman, 12). This line of inquiry found 
Forrester and his team arriving at some disquieting conclusions. Applying the core concepts of cybernetic systems theory to an analysis of global resource consumption, they discovered the destabilizing influence of positive feedback mechanisms at play in almost all the areas under discussion. The resulting research provided the theoretical underpinnings for the Club of Rome's widely-circulated The Limits to Growth. There, Forrester's students, Donella and Denis Meadows, would summarize the results of the World3 simulations in stark terms. They concluded that as modern systems sought to redress the fallout of exponential growth in four key areas - world population; industrialization; pollution; food production and resources depletion - they mobilized technologies that could postpone, but not evade, a final reckoning with the finitude of the planet's resources. As late capital's appetites exceeded its ingenuity, it was set to converge on a condition of "overshoot and collapse," one that that the study projected would arrive - should present trends continued unabated - in the mid to late 21 st century. They framed the core conundrum that decision-makers would have to face in the following terms:

The apparent goal of the present world system is to produce more people with more (food, material goods, clean air and water) for each person... [I]f society continues to strive for that goal, it will eventually reach one of many earthly limitations... [I]t is not possible to foretell exactly which limitation will occur first or what the consequences will be, because there are many conceivable, unpredictable human responses to such a situation. It is possible, however, to investigate what conditions and what changes in the world system might lead society to collision with or accommodation to the limits to growth in a finite world. (86-7) 
We now know, of course, which of these "earthly limitations" were among the first to be broached. Yet despite the fact that the onset of anthropogenic climate change and a sixth age of extinction have borne out the World3 simulators' core predictions on roughly the same timeline that it projected, we have yet to face up to the full political ramifications of this research. This is not for want of clarity on the part of Forrester or the Meadowes. In a move that has remained anathema to the axiomatic principals of global development, Forrester's team summed up the implications of their simulations in remarkably blunt terms. In summarizing their conclusions, David Lane and John Sterman observe that Forrester and the Meadowes cautioned decision-makers that "there [were] no purely technical solution[s] to the challenge of creating a sustainable society" (14). Criticizing the very strategy that continues to dominate climate change mitigation and adaption initiatives today - and that lies at the heart of the Paris Agreement itself - Forrester and his team described the nature of the prevailing approach, before going on to characterize it as facilely simple-minded:

Technological innovation, market forces, and government policies are all aimed at ameliorating the symptoms of stress - pushing back the limits to growth by finding more energy, reducing greenhouse gas emissions, irrigating marginal lands and designing new cultivars to boost food production, thus allowing growth to continue until another limit is reached. (14)

Here, in a nutshell, is our current response to climate change, anticipated at a distance of half a century. And identifying its "obvious and self-evident" flaws, Forrester argued that it represented an exemplary case "of attacking symptoms rather than underlying causes" (qtd in Lane and Sterman, 14). He regarded this approach as entirely "futile" (14). For pursued in the context of an overriding commitment to compound growth, the "treat[ment 
of] one symptom" would always tend to "unleash a different" and unanticipated "overwhelming reaction" elsewhere, for the simple reason that human infrastructures had now developed to such scale that they were at every turn "exceeding the carrying capacity of the Earth" (14).

In viewing the Paris Agreement in relation to this claim, it is important to stress that the Agreement itself is cast in the same mold as the very R\&D management devices that propelled us towards the planet's carrying capacity in the first place. The Agreement mandates the development of "a technology framework" meant "to provide overarching guidance to the work of the Technology Mechanism" (COP, 14). It defines its objectives in the following terms:

Accelerating, encouraging and enabling innovation is critical for an effective, long-term global response to climate change and promoting economic growth and sustainable development. Such effort shall be, as appropriate, supported, including by the Technology Mechanism and, through financial means, by the Financial Mechanism of the Convention, for collaborative approaches to research and development, and facilitating access to technology, in particular for early stages of the technology cycle, to developing country Parties. (15)

At such points the terms of the Agreement is all but indistinguishable from those that we found characterizing the EU's FP1.

For the sake of clarity, it is worth contrasting these policy proposals with those that Forrester and his team arrived at. For in place of the doom-mongering that has since been imputed to it, it should be noted that the overall thrust of The Limits to Growth was profoundly agential. In its own words, the report attempted to outline "an alternative to unchecked and disastrous growth and pu[t] forward some thoughts on the policy changes 
that could produce a stable equilibrium for mankind" (196). Indeed, although The Limits to Growth has been subject to much critique in the intervening decades - drawing fire from across the political spectrum - in today's context it is hard not to be somewhat charmed by the naïvely utopian largesse of the document's ambition:

It is possible to alter these growth trends and to establish a condition of ecological and economic stability that is sustainable far into the future. The state of global equilibrium could be designed so that the basic material needs of each person on earth are satisfied and each person has an equal opportunity to realize his individual human potential. (24)

Held up beside the Paris Agreement, or the objectives of today's social innovation labs this reads more like the language of Starfleet, than of any earthly advisory body. In 1972 The Limits to Growth would propose that averting civilizational collapse would require a wholescale transformation of our industrial and economic systems, one so profound that we would be required to jettison the growth imperative - a goal "so distant from our experience as to require a Copernican revolution of the mind" (197). But by 2016, global governance would instead insist that given the right calibration of subsidies, tax schemes, price points, and trade incentives, central planners would be able to direct "finance flows" in a manner that would provide "a pathway towards low greenhouse gas emissions and climate resilient development" (COP, 22).

This prevailing field of play points us toward the intensely contradictory nature of Forrester's intellectual legacy. We have seen that his Systems Dynamics work helped to pioneer the kinds of computational simulations that would become essential to the disciplines of global ecology and Earth System Science, while his work in Urban Dynamics mapped out the basic conceptual parameters of today's social innovation labs. 
Yet there is a case to be made that the practical implications of his research are still most keenly felt in the domain of Supply Chain Management (SCM), which would build on Forrester's early work, in developing his methods of "flow management" into the "lean" Just-In-Time (JIT) production models and logistics systems that undergirded the process of globalization.

In overcoming the condition of stagflation that began to beset the world economy in the late 1960s, corporate bureaucrats and central planners drew on SCM's methods to manage a concerted campaign of capital flight, as the world's industrial base was shifted from north to south in a remarkably short span of time. In the process - one which we should probably regard as one of the more significance logistical feats in human history industrial commodity production became a fully globalized phenomenon, distributed across immense intercontinental tracts of time and space. This was an economic movement that represented as profound a rejection of The Limits to Growth's proposals as could possibly be imagined. And to understand the Janus-faced legacy of Forrester's work, one must ask why decision-makers would trust Forrester's research methods to oversee the next phase of the global markets' expansion - and the vast, risky transfers of fixed capital that this process entailed - while at the same time discounting and discrediting the alarming environmental forecasts that the same research methods were then generating. 


\section{THE IDEOLOGY OF TECHNOLOGICAL RATIONALITY}

In probing this question further, I want to return to Mandel's analysis of late capitalist institutions, as it offers us key insights into the nature of the bureaucracies and governmental structures to which Forrester and his team directed their appeals. If we understand these institutions from Mandel's vantage, we will be little surprised that Forrester's warnings fell on such deaf ears. Yet in order to provide Mandel with a foil, and to set his claims against others that were current at the time, I want to preface this return to Mandel by looking a little more closely at the work of James Lovelock. Lovelock makes for a useful foil to Mandel, as reviewing his core claims will allow us to delve a little more deeply into the contributions that cybernetics made to the development of climatology and Earth System Science, while at the time underscoring how vulnerable the postwar scientific community then was to a misplaced faith in the pragmatic rationality of the postwar era.

Alongside the Club of Rome's Limits to Growth, Lovelock's Gaia: A New Look at Life on Earth was a member of the first major wave of ecological systems theory that rose to public and policymaking notice throughout the 1970s. One of the boldest moves that Lovelock made in crafting his first iterations of Gaia theory, was to attempt to synthesize Wiener's cybernetic theory of negative feedback mechanisms with the early attempts that physicists had made at defining organic systems from the vantage of thermodynamic theory. Working independently, John Desmond Bernal, Erwin Schrodinger, and Eugene Winger had all arrived at the same basic conclusion, that life belonged to a "class of phenomena which are open or continuous systems able to decrease their internal entropy at the expense of substances or free energy taken in from 
the environment and subsequently rejected in degraded form" (Lovelock, "Gaia" 4). According to this line of thinking, life was "one of those processes which are found whenever there is an abundant flow of energy"; indeed, it was "characterized by a tendency to shape or form itself as it consumes," resisting entropy by "excret[ing] lowgrade products to its surroundings' (4). Though aware of the limitations of these initial accounts - noting that "this same definition would apply equally well to eddies in a flowing stream, to hurricanes, to flames or even to refrigerators and other man-made contrivances" (4) - Lovelock developed the work further. Drawing on Wiener's theory of the servomechanism, he posited that, in organic lifeforms, entropy reproduction relied on the use of negative feedback loops, through which a living system exercised "active control" over its internal conditions. By expelling waste and absorbing raw materials, organisms were able to maintain a "relatively constant" state, achieving a state of dynamic stability to which Walter Cannon had already given the name "homeostasis" (10).

Scaling up the claim, Lovelock proposed that pursued en masse and over immense tracts of time, life's struggle with entropy applied a slow but determinative influence over the geochemical composition of its host planet. As individual organisms conducted their metabolic appropriation of energy flows, they created "a boundary, or interface" between their inner "factory areas" - "where the flow of energy or raw materials [was] put to work" - and the outer "surrounding environment" that "receive[d the] discarded waste products" (5). In effect, the Earth's organisms used the planet's "fluid regions" - its waterways and airways - as "conveyor-belts for raw materials and waste products" (5). Lovelock argued that these dispersed exercises in entropy reduction 
actually exerted cumulative world-making effects, as the by-products of discrete metabolic processes "spilled over" into surrounding regions, incrementally changing their geochemical character (5).

Singling out "the persistent ... disequilibrium" of the Earth's atmospheric gases as "clear proof of life's activity," Lovelock arrived at his signature claim (6). Homing in on the statistically-anomalous chemical composition of the Earth's atmosphere - which bore no resemblance to a "steady state" of chemical equilibrium (9) - he proposed that "[d]isequilibria on this scale suggest that the atmosphere is not merely a biological product, but more probably a biological construction" (9). Seen in this light, Earth's lifebearing atmosphere was not exactly "living" but "like a cat's fur, a bird's feathers, or the paper of a wasp's nest," it was instead "an extension of a living system" (9). Scientific consensus at the time conceived of the atmosphere as the inert product of a passive process of off-gassing. Lovelock argued, instead, that its composition was actively shaped and influenced by the planet's scores of living beings.

Even in this highly speculative form, the hypothesis was just about capable of passing muster as a conventional scientific theory. Yet as far as many of his peers were concerned, Lovelock would take a step too far when insisting that "the entire range of living matter on Earth" - "from whales to viruses, and from oaks to algae" - could be seen to "constitut[e] a single living entity," one that was "endowed with faculties and powers far beyond those of its constituent parts" (9). Flirting with the idea of the macroorganism, these claims relied on a form of inductive, synthetic speculation that raised the hackles of a community of peers trained in fundamentally deductive, analytic methods. 
Following the publication of his first book, Lovelock was consequently embroiled in a series of hotly-contested controversies concerning the scientific status of his theory, the legacies of which continued to bedevil his scientific reputation up until very recent years. Zoologist (and polemist) Richard Dawkins leveled characteristically vehement charges against Lovelock, proposing that he had broken faith with Darwin's theory of natural selection. John Maynard Smith went further in categorizing the Gaia hypothesis as "an evil religion" (qtd in Ruse). Microbiologist and Fellow of the Royal Society, John Postgate, meanwhile reported "suffer[ing] a nasty twitch, a feeling of unreality" whenever journalists asked him to discuss the theory's veracity (qtd in Ruse). In the face of this widespread public derision from influential scientists, even those researchers most indebted to Lovelock's work tended to tactfully distance themselves from active association with his name.

Yet with the passing of the years, and the progress of the science, the prevailing assessment of Lovelock's scientific contribution has shifted. Following the 2001 Amsterdam Declaration on Earth System Science, it is now a basic tenet of the discipline of Earth System Science that "[t]he Earth System behaves as a single, self-regulating system" (Moore et al.). Comprised of "physical, chemical, biological and human components," this system is said to be defined by complex "interactions and feedbacks between the component parts," which "exhibit multi-scale temporal and spatial variability" (Moore et al). The debt to Lovelock, and to Wiener, is patent.

Indeed, one of the strengths of Lovelock's contribution to cybernetic and scientific theory was the extent to which it adopted the keenest insights of Wiener's research, modeling the behavior of organic life and industrial technology through the 
same consistent set of concepts. This was a perspective that allowed Lovelock to avoid some of the cruder positions that have since developed around phenomena such as pollution and industrial waste, providing industrial society a first full glimpse of the foundational affinities and systemic determinations that bound organic lifeforms and industrial technology together in a shared fate:

Pollution is not, as we are so often told, a product of moral turpitude. It is an inevitable consequence of life at work. The second law of thermodynamics clearly states that the low entropy and intricate, dynamic organization of a living system can only function through the excretion of low-grade products and low-grade energy to the environment. Criticism is only justified if we fail to find neat and satisfactory solutions which eliminate the problem while turning it to advantage. (25)

Yet although Lovelock's early work is defined by this consistent antipathy to moralizing or catastrophizing rhetoric, it remains the case that he did much to anticipate the contours of our current situation. Lovelock was one of the first scientists to devise instruments capable of detecting the atmospheric buildup of greenhouses gases. And in a text composed ten years before the formation of the UN's IPCC (Intergovernmental Panel on Climate Change), he cautioned his readers that the cumulative buildup of greenhouse gasses could proceeded unnoted, with little evident effect for many decades, until such a moment as the broaching of critical thresholds bought "non-linear effects ... into play" (41). Indeed, "in the absence of a biosphere[ic] fix" to carbon dioxide accumulation, Lovelock conceded that it was conceivable that carbon dioxide's atmospheric concertation could "exceed ... critical figure[s]," leading the Earth to heat up at great speed, to catastrophic effect (41). 
Lovelock kept abreast of developments across the field that he and Lynn Margulis helped to found, eventually revisiting his original thesis in a text entitled The Revenge of Gaia. Writing in 2001, Lovelock listed key ways in which climatologists had begun to identify the onset of positive feedback mechanisms in regions of acute geoecological significance. Lovelock's list begins with the ice albedo feedback effect then being observed in polar regions. In the face of the net trend toward global warming, icecaps and icebergs had begun to melt, taking with them their white, reflective surfaces of snow. Newly disclosed to the sun, these exposed tracts of darker land and water acted as heat banks, retaining solar energy that would formerly have been deflected back into space. The process offered a textbook example of the exponential logic of positive feedback; the warmer the polar regions became, the larger their newly-emerging heat banks grew.

Meanwhile, in more temperate equatorial zones, iterations of the same kind of dynamics were in play. As tropical regions became more arid under the pressure of rising temperatures, old growth died back, and woodlands retreated. As they did so, surrounding regions were deprived of the tropical forests' cooling effects. The fallback of forest life thus acted as an accelerant to the very dynamics that had driven it into retreat in the first place. Like the polar icecaps, tropical forests were, in Lovelock's distressing phrase, effectively "melting away," and as they did so they spurred on a process of retreat that was inherently self-reinforcing. In retreat, they took with them the carbon-storing capacities of their photosynthetic metabolisms, drastically reducing the planet's reserves of living carbon sinks.

Similar patterns were being observed at sea. As the oceans heated up, their surface waters underwent a marine version of the "desertification" process. In this case, 
the proximate cause of positive feedback effects was the strange and mercurial properties of water itself. As temperatures at the ocean's surface rose above about $12{ }^{\circ} \mathrm{C}$, surface waters expanded significantly, creating "a stable ... layer of warm water ... that stay[ed] unmixed with the cooler, nutrient-rich waters below" ("Revenge" 20). These dynamics effectively cut off ocean algae from their food supply, reducing their numbers, and with them the carbon-fixing properties of their photosynthetic metabolisms. The so-called carbon "pump down effect" - in which carbon-dioxide-saturated algae took their load of carbon with them as they died and sunk to deeper waters - was thus being diminished at precisely the moment where in it might have acted as a pressure valve for a system that was already taxed to its limits.

By the turn of the millennium, it was thus already apparent that temperatures were rising at the same time as the Earth System's old inhibitory feedback mechanisms had begun to fail. Seventeen years later, in a report that their own government commissioned and then attempted to bury beneath the Black Friday sales, US scientists would synthesize decades of climate research, marshaling evidence from a wide variety of ongoing studies. Their executive summary paints a grim picture of a climate fully in the grip of loop gain effects:

Observations from around the world show the widespread effects of increasing greenhouse gas concentrations on Earth's climate. High temperature extremes and heavy precipitation events are increasing. Glaciers and snow cover are shrinking, and sea ice is retreating. Seas are warming, rising, and becoming more acidic, and marine species are moving to new locations toward cooler waters. Flooding is becoming more frequent along the U.S. coastline. Growing seasons are lengthening, and wildfires are increasing. (Jay et al) 
These accounts of emerging conditions see us looking on as the Earth System slips out of its old rhythms and holding patterns, and begins cascading toward a new and as yet undermined state of dynamic stability, one that - in Lovelock's phrase - is likely to prove considerably less hospitable to human beings.

As it happens, these conditions would actually have somewhat surprised the Lovelock of 1979, as his first formulations of Gaia theory tended to dramatically overestimate the homeostatic resilience of the Earth System. Indeed, in his early work, Lovelock's conviction in Gaia's homeostatic resilience is such that he tends to frame global warming as an extreme "limit case" scenario rather than an imminent threat. He does, however, warn his readers that "there may be some regions of the world more vital to Gaia than others," and anticipates the current goals of mainstream environmental lobbies in insisting that "we should take special care not to disturb too drastically those regions where planetary control may be sited" ("Gaia" 107). In fact, prior to the rise of big tent conservationism in the 1980s, he was already arguing that the unchecked exploitation of "core" biogeographic regions - regions where the planet's carbon sinks and biodiversity were most intensely concentrated - could lead to outsized, unanticipated consequences.

Defining the core regions of Gaia as those that lay between "latitudes $45^{\circ}$ North and $45^{\circ}$ South," Lovelock proposed that it would be necessary "to keep a close eye on these areas" if we were to "guard against unpleasant surprises" (113). Here again, he identifies, while somewhat underestimating, one of the key drivers of anthropogenic climate change. In this case we find him criticizing the kind of slash-and-burn farming practices that the palm oil industry has since made infamous: 
It is well recognized that the agriculture of the tropical belt is often inefficient and that large stretches are already worked out or are being devastated through the same sort of primitive farming methods which led to the Bad Lands of the United States. What is less well known is that this bad farming is also disturbing the atmosphere on a global scale and to an extent at least comparable with the effects of urban industrial activity... Fires of this type inject into the air, in addition to carbon dioxide, a vast range of organic chemicals and a huge burden of aerosol particles. Some of the chlorine now in the atmosphere is in the form of the gas methyl chloride, a direct product of tropical agriculture. Grass and forest fires generate at least five million tons of this gas each year. (113)

Today, policymaking is belatedly recognizing the scale of this threat, as the UN and other global development agencies attempt to bring online a new set of pilot programs designed to incentivize systemically-sounder agricultural practices. In the example of "Payments for Ecosystem Services" we see social innovation funding frameworks and policy initiatives attempting to divert farmers away from emission-intensive cash crop practices, and toward the cultivation of "valuable" carbon sinks and biodiversity.

In theory, these experimental initiatives would eventually see major "downstream" resource-users and waste-producers induced to pay local communities for the "upstream" cultivation of carbon sinks and biodiversity. Yet the decidedly provisional and as yet experimental character of these interventions - there are few that have yet made it beyond the trial stage - underscores the extent to which Lovelock's confidence in late capitalism's technocratic rationality arguably proved even more misplaced than his faith in Gaia's homeostatic resilience.

Indeed, in his early publications, Lovelock tends to position himself as a firm believer in the "technological rationality" of the postwar order, espousing a faith that 
Mandel defines as "the specific form of bourgeois ideology in late capitalism" (500). In the following passage, for example, we see Lovelock projecting future trends on the basis of this faith, as he makes the fatal category error of equating late capital's monitoring capacity with what we might think of as its "capacity to respond":

National and international agencies are in the course of establishing monitoring stations equipped with sensors which will keep a record of the health of our planet. Satellites circling the Earth carry instruments to monitor the atmosphere, the oceans, and the land surface. So long as we can maintain a fairly high level of technology, this sensing programme is likely to continue and may even be extended. If the technology fails, then presumably other sectors of industry will also have failed and the potentially injurious effects of industrial pollution will diminish accordingly. In the end we may achieve a sensible and economic technology and be more in harmony with the rest of Gaia. (109-110)

This argument makes for poignant reading in today's context. In place of the "sensible" and "harmonic" futures that Lovelock anticipates, the intervening decades have instead driven us deeper and deeper into a now-familiar "Casandra Paradigm." Here, the vast climate-monitoring infrastructure that Lovelock describes, has developed in lockstep with a program of environmental exploitation that makes few meaningful concessions to the knowledge that this infrastructure generates, nor the threats it identifies.

As a youthful believer in late capitalism's technological rationality, this was a contingency that Lovelock struggled to imagine. Mandel, on the other hand, understood late capitalism's pretentions to technological "omnicompetence" as the idealized selfimage of a system that was, in reality, "a hybrid and bastardized combination of organization and anarchy" (502). Substantiating this line of argument, he insisted that "the objective overall irrationality of the capitalist mode of production" was made most 
evident in the ongoing "opposition between the profitability of individual firms" and the "balance-sheet" of general socioecological "costs and benefits" (577). Grounding his reading of late capitalism's development trajectory in this assessment, he offered the following prediction concerning the threat that business-as-usual now posed to life on Earth:

There is no need to expatiate on the brutal logic of market fanaticism here. Because companies pollute the atmosphere to maximize their profits, the simple right to fresh air is abolished: "access" to this "scarce commodity" must be purchased by a "tax." The real task, of course, is precisely to emancipate production from calculations of profitability related to either factory or company, from private ownership and commodity production, and to satisfy needs rationally, without gigantic wastage... For it is not science and contemporary technology "in themselves" but their capitalist organization and application which endanger the survival of humanity. The pursuit of technological rents creates conditions which collide directly with the protection of human health. For example, it obliges the chemical industry to throw new synthetic products onto the market every four or five years, before it has had time for any responsible study of the biological and ecological risks potentially involved in them. (577578)

There can be little doubt that the course of world events has since borne out this diagnosis on ever-increasing orders of magnitude. Indeed, nothing could better illustrate the ongoing "opposition between the profitability of individual firms" and the "balancesheet" of general socioecological "costs and benefits," than the campaigns of climate change misinformation currently waged by a fossil fuel industry intent on maintaining its market share. Meanwhile, in comparing Mandel's forecasts concerning the responsive capacity of late capitalist policymakers, to the those offered, contemporaneously, by the 
founders of Earth System Science, we see that Mandel's prove more reliable than the latter, for the simple reason that he had a much firmer grasp on how decision-making and resource allocation actually unfolds within the confines of the late capitalist worldsystem.

Faith in the technological omnicompetence of this ailing economic order seems set to fall on hard times in the coming years. Indeed, in Stenger's rereading of Lovelock, we are now fated to understand in hot practice what the "guardians" of the global development program long since failed to grasp in cold theory. The unremitting pursuit of growth-at-all-costs has pushed the Earth System over a variety of irreversible tipping points, such that the transformative and chaotic effects of positive feedback are now reverberating through the system. A destabilized Gaia has begun to "intrude" on the anthropocentric narrative of progress, confronting its custodians with a "forgotten ... form of transcendence" ("Catastrophic Times" 107). For Stengers, this forgotten form of transcendence reveals itself in the shape of "a ticklish assemblage of forces," one that is defined by its utter "indifference" to the claims and rationales of political ideology and economic "necessity" (47):

The intrusion of this type of transcendence, which I am calling Gaia, makes a major unknown, which is here to stay, exist at the heart of our lives. This is perhaps what is most difficult to conceptualize: no future can be foreseen in which she will give back to us the liberty of ignoring her. It is not a matter of a "bad moment that will pass," followed by any kind of happy ending - in the shoddy sense of a "problem solved." We are no longer authorized to forget her. 
But while no longer able to "forget" Gaia in the sense that Stengers defines here, there is another sense in which we remain strangers to her altogether. Politically and culturally speaking, we know that the findings of modern climate science remain the object of vehement partisan debate. Until they provide us, instead, a common sense - and the touchstone of our approach to industry, agriculture, and urban infrastructure - we would probably do best to regard ourselves as an older and wiser Lovelock has learned to, as "passengers on a small pleasure boat sailing quietly above the Niagara Falls, not knowing that the engines are about to fail" ("Revenge" 6-7).

\section{THE VIEW FROM THE GROUND: SOCIAL LABS IN SITU}

But what would it take, politically and culturally speaking, to at least begin catching sight of Lovelock's falls? To begin the vast upheaval of values, institutions, and infrastructures that "turning to face Gaia" would actually entail, we need a far keener cultural understanding of the nature, and the scale, of the threat that business-as-usual now poses to life on Earth. Reports from the first major wave of social lab "resiliency" initiatives make for interesting sites of analysis in this respect, as we know that these resiliency labs are being compelled to implement a contradictory policy program - one that was, in effect, pre-emptively disavowed by its founder. We have already looked at the conclusions that Forrester reached regarding the persistent claim that "technological innovation, market forces, and government policies" could indefinitely "ameliorat[e] the symptoms of stress" and "push... back the limits to growth" - he cautioned that it was a shell game, one that disguised the depth of the systemic contradictions in which the late capitalist political project was now inextricably enmeshed (Lane and Sterman, 14). 
Little wonder, then, that as social lab resiliency initiatives attempt to devise and prototype more "sustainable" systemic practices, we find iterations of Mandel's complaints about business-as-usual beginning to surface within these flagship programs. Yet it is not only facilitators and technicians that find themselves feeling the weight of tremendous systemic pressures. For one of the more interesting features of these new initiatives is the extent to which Theory-Of-Change protocols find many of today's labs undertaking extensive and ongoing "stakeholder" consultation. This is a tendency that distinguishes the current wave of social labs initiatives from the Urban Dynamics lab that Forrester first established. Rather than merely a briefing center for municipal officials and politicians, or a thinktank addressing policymakers, today's labs often serve as a staging ground for intense civic struggles over the form and content of municipal and climate change response.

Given that Zaid Hassan, a self-styled social lab guru, and jet-setting public policy advisor, has recently emerged as the self-appointed spokesperson of the "social labs revolution," we might look more closely at his thinking. He describes the kinds of conflicts that are apt to break out in these highly-networked environments, as proponents of differing schools of thought, or representatives of divergent branches of industry, local community, and government, clash over the fundamental orientation of their "social enterprises." As we consult Hassan's rueful account of his early experiences as a social lab facilitator, we can begin to anticipate the next chapter's turn to the work of Kim Stanley Robinson. For looking at Hassan's candid commentary on the struggles that take place within these forums, readers of Red Mars will find it difficult not to recall the kind of internecine conflicts and cloak-and-dagger power plays that inform the action as the 
Ares touches down on the surface of the red planet, as Robinson's cast of interplanetary colonists contest the unfolding shapes of their collective terraforming project. In one early passage, we find Maya Toitovna, the leader of the Russian cosmonauts, appraising group dynamics in the wake of a series of political provocations offered by the novel's anarchist trickster figure, Arkady Bogdanov:

Under the giant eye of Mars, all their disagreements became taut, clearly it was critical now, there was little time left. People argued, in the open or under the surface. So many groups now, keeping their own counsel ... What had happened to that brief moment of happiness? Maya blamed it mostly on Arkady. He had opened Pandora's box; if not for him and his talk, would the farm group have drawn so close to Hiroko? Would the medical team have kept such close counsel? Shed didn't think so. She and Frank worked hard to reconcile differences and forge a consensus, to give them a feeling they were still a single team. ("Red Mars" 85)

On the surface of things, this is hardly a desirable state of affairs. Yet the strange symmetries that play out between Robinson's speculative fiction, and Hassan's realworld experiences are, I think, quite suggestive. Looking back on Bhavishya Lab - a Maharashtra-based initiative designed to tackle child malnutrition - Hassan remarks on the kinds of stalemates that arose in the shadows, as powerful "stakeholders" covertly maneuvered for dominance:

The innovation process ... was profoundly and deeply distorted by opaque political processes. In the official learning history for the lab, we analyzed this dynamic by looking at hidden transcripts, or essential conversations that people deemed too risky to have in public. The power dynamics within the lab swung wildly. It is hard to appreciate how debilitating this was until one experienced it personally. (70-71) 
It is probably no accident that Robinson's speculative fiction so nearly anticipated Hassan's lived experience, as the social lab model is in many respects the attempt to apply NASA's technical-lab-based "mission" models to a taxing set of earthly quandaries. And in returning to Hassan's social lab memoirs with Maya's fictional complaints in mind, we might thus imagine that critical provocations are not especially welcome in the already fraught and unfamiliar social space of the innovation lab, one where there are ample occasions for territorial conflicts, and where social lab facilitators are structurally compelled to seek out and strengthen accords between representatives of historically antagonistic groups. Given this social complexity, one might reasonably assume that this is a milieu that proves relatively impermeable to the kind of naysayers and enfant terribles that thrived during humanism's high-finance-buoyed summer, and that Robinson's Arkady himself embodies.

Yet the picture is a little more complicated. Indeed, as Hassan outlines his understanding of the operational principles of the social lab, we find him characterizing these emerging nodes of the "lean," "agile" social state as a kind of "public" in microcosm, one where dissenting opinions and critical voices are actively solicited rather than surreptitiously suppressed and sidelined:

Myrna Lewis' work on Deep Democracy postulates a "terrorist line" which names the stages of disagreement that lead to all-out warfare. The "terrorist line" begins in the unspeakable. When power ensures that the consequences of speaking out are high, dissent begins in what James C Scott calls "the hidden transcript" - in jokes and innuendo, in comments that can be taken both ways, and then escalate as the conflict continues until it "storms the public stage" in the form of demonstrations or strikes, requiring security responses, which then give way to civil war, insurgency and battle responses. Myrna argues that "simply saying what 
needs to be said" can halt the terrorist line. The practice therefore of operating on contested terrain is to allow dissenting voices in. This dissent serves in multiple ways. The most fundamental is that what is being contested, via dissent, is the shape of our society. The social lab aspires to be a space where this negotiation can take place productively. (71)

Hassan's reformist and conciliatory approach is evident here, while Lewis's remarks on "hidden transcripts" and "jokes and innuendo" go a long way toward anticipating the kind of dynamics that propelled the "alt-right" to prominence during the US's last electoral cycle. Overall, we would probably not be mistaken in characterizing Hassan's vision of the social lab as a cybernetic recapitulation of John Stuart Mill's utilitarian account of the liberal public sphere. Here, as there, it is maintained that the collision of contrary views acts as a necessary aid to the disclosure of truth, to the mitigation of armed conflict, and to the collective negotiation of complex practical problems.

Yet despite these affinities with canonical liberal social theory, for Hassan it is also evident that the institutions we inherited from the era of programmatic modernization are now doing more to suppress than to facilitate the effective exercise of critique and conflict. Echoing Mandel's complaints against what he too refers to as business-as-usual (BAU), we see Hassan's critique cut in two directions, pushing back both against the residual forms of postwar modernization's bureaucratic culture of command - which he is all too apt to identify solely with "Soviet" planning models - and against the "neoliberal" financializing models that rose to dominance as the older approach faltered and failed.

The outlines of Hassan's complaints against the "Soviet" planning paradigm are familiar enough not to require too much recapitulation, but his pushback against Chicago 
rhetoric is substantially fresher and more novel. As Hassan introduces his critique of neoliberal policymaking he takes aim at one of the movement's arch-theorists, Fredrick Hayek. In a neat dialectical reversal of Hayek's signature claim, Hassan states that The Road to Serfdom's foundational insistence that we "need to let the market make decisions," has simply replaced one faulty and crisis-ridden planning model with another, substituting a "horizontal, state-driven, planning approach" with "a vertical, marketdriven, planning approach" (89). Hassan argues that this shift results in the promotion of organizations "that focus all their efforts on the production of [financial] capital" at the cost of depleting other forms of capital at the same time," such that - for example - "strip mining depletes natural capital in order to generate financial capital" (89). Arguing with potentially fatal optimism that such enterprises are "unnecessary" and a "dying breed" (89), Hassan advocates a Bourdieusean conceptualization of multiple "capitals," such that social labs are tasked with developing projects that "payout" in multiple registers:

Through examining these types of results we can see a particular class of outcomes emerging from each social lab. They are best understood as different forms of capital. The first results we sought to cocreate with labs were what we called prototypes and initiatives. When implemented, these provided a new set of services to stakeholders on the ground and are new forms of physical capital (infrastructure). The second set of results we sought to create, relationships, were a form of social capital. The third set of results, capacities, were a form of human capital. Finally, all the experience and formal lessons from both designing and implementing these labs were a form of intellectual capital. (83)

He grounds this theory, as he does much of his work in initiating systemic change, in Bourdieu's theory of habitus: "Bourdieu, in his explorations of habitus, makes the case for reclaiming the notion of capital from the economic and monetary spheres: 'It is 
impossible to account for the structure and function of the social world unless one reintroduces capital in all its forms and not solely in one form recognized in economic theory" (85). With John Michael Greer's theory of "catabolic collapse" also in view especially his core contention that historical societies have been repeatedly driven to collapse by producing more goods than they can afford to maintain - he argues that identifying and promoting multiple forms of "capital" will provide "strategic opportunities ... to deploy wisely what capital stocks we still possess in generating new forms of capital” (86). In Hassan's account, failure to move swiftly, failure to avert the ongoing depletion of "capital stocks," will result in Greer's worst-case scenario of "catabolic collapse" wherein "the rate of waste being produced outstrips the rate of capital being produced" leading to "ecological breakdown" (84).

Seen from Hassan's vantage, the rise of the social innovation lab is calibrated in relation to a condition of mounting "scarcity," scarcity that is imagined in a variety of registers that encompass everything from resource depletion, mass extinctions, dilapidated infrastructures, escalating energy demands, a rapidly encroaching emissions threshold, and a stalled or retreating social state development program. In this vein, and in an effort to allow governments and policymakers to better conceptualize conditions and needs on the ground, Hassan advocates for the development of "prototypes and initiatives" that can help break beyond prevailing practices, practices that are propelling a "cycle of collapse" wherein existing "stocks of capital" are being exhausted on every front (85).

In weighing the merits of Hassan relatively monumental ambitions, it is worth pointing out that this subordination of "natural" to "financial" capital - far from a 
neoliberal novelty - is a feature of dynamics that Marx knew to be fundamental to the capitalist mode of production from its inception. Here is Marx sketching out the core of his account of value's real movement:

But now, in the circulation of M-C-M, value suddenly presents itself as a selfmoving substance which passes through a process of its own, and for which commodities and money are both mere forms. But there is more to come: instead of simply representing the relations of commodities, it now enters into a private relationship with itself, as it were. It differentiates itself as original value from itself as surplus-value, just as God the Father differentiates himself from himself as God the Son, although both are of the same age and form, in fact one single person; for only by the surplus value of $£ 10$ does the $£ 100$ originally advanced become capital, and as soon as this has happened, as soon as the son has been created and, through the son, the father, their difference vanishes again, and both become one, $£ 110$. Value therefore now becomes value in process, money in process, and, as such, capital. It comes out of circulation, enters into it again, preserves and multiplies itself within circulation, emerges from it with an increased size, and starts the same cycle again and again. M-M, "money which begets money," such is the description of capital given by its first interpreters, the Mercantilists. (256)

According to Marx, there is more at stake in the destructive subordination of "natural" to "financial" capital than the mere activation of "faulty categories." The systemic subordinations that Hassan struggles to understand are precisely those produced by “money in process," as value's preservation-via-multiplication runs roughshod over other considerations. And yet although Marx and his world-systems heirs would likely meet Hassan halfway in agreeing that this system is ailing and perhaps even strained to breaking point - indeed, Immanuel Wallerstein today insists that the current worldsystem has entered into "terminal crisis" - they would also add that the historical 
evidence overwhelmingly suggests that that dominant class that currently reaps such benefits from this system, and exerts such profound sway over its political institutions, is unlikely to go gentle into the good night. For the selfsame movement of value that serves as the engine of growth at one and the same time reproduces the class divisions - and opposed interests - that characterize capitalism as a social form. As Marx's remarks on the Mercantilist class imply, it is only when one comes to enjoy the possession of a relatively high concertation of capital that the illusion of M-M' - "money betting money" - becomes operative. Below that threshold, the inner identity of labour and value is harder to ignore, as every working day brings with it the certain knowledge that one must sell one's labour in order to live.

Yet however naive Hassan's categorical interventions might seem to students of emancipatory struggle - especially the implicit suggestion that if social labs simply reconfigure how we conceive of "capital stocks," entrenched interests will fall compliantly into line - it remains the case that his insistence on identifying multiple forms of "capital" pushes planners and publics to conceive of wealth and economic praxis in a richer and more holistic register than has been conventional in recent years. Indeed, Hassan's vision of social innovation is one in which "capacity building" and the provision of public works and social infrastructures are given considerably more weight than was conventional under the Chicago School doxas that guided policymaking in the era of neoliberal hegemony, in those more innocent days when the market was imagined to have all the key contingencies in invisible hand.

Hassan's rise to prominence suggests that cracks continue to spread deep into the policymaking edifices that were constructed in the heyday of the Chicago school. For 
there can be little doubt that the lab-centered turn to social policy prototyping and infrastructural innovation has gained traction in the context of an ambient but encroaching sense of profound systemic crisis. As he makes his pitch for social labs, Hassan suggests that they have the "potential to become engines that generate enormous amounts of capital in a world that is running dangerously low" (Hassan, 91). Here and elsewhere we see hints of a sly effort to promote modes of R\&D, and forms of social relation and experimental exploration, that - though developing within the frameworks imposed by late capital's Silicon Valley-enamored policymakers - cannot always be characterized as exhaustively and uniformly "capitalistic" in nature. When Hassan writes that "[t]he challenge becomes one of ensuring that we do not fall into the habitus of BAU, producing single types of capital (i.e financial) that do little more than further entrench BAU” (Hassan 89), we see him - apparently somewhat unwittingly - locked into a struggle with the circuits of money capital, championing use values over exchange values.

That said, it is at the same time evident that venture capitalists see ample opportunities for appropriation and profit in those social lab ventures that do succeed in generating new capital stocks; and from the vantage of Marxist historiography it should certainly be anticipated that, even if successful, Hassan's attempts to build up new capital stocks will simply serve as a staging ground for a new round of what David Harvey refers to as "accumulation by dispossession" ("New Imperialism" 137). Indeed, urbanist Ashley Dawson has already coined the term "accumulation by adaptation" to describe the process whereby appeals to lauded goals such as "sustainability" and "resiliency" serve merely to mask the implantation of an all-too-familiar batch of greenwashing schemes, 
land grabs, and gentrification projects (Dawson, 57). Yet although Hassan considerably underestimates the tenaciousness of entrenched interests, it is as one on the same time clear that his emphasis on "capacity building" and "phronēsis" (practical reason) has gained enough institutional traction and policymaking support to trouble prevailing governance models with a keener sense of the unfolding consequences of business-asusual.

For promoters and on-site facilitators such as Hassan, social labs are being understood as spaces where existing systemic social antagonisms can find a dialogic expression, and where representatives of different interests are invited to challenge each other in a collective search for means and methods that better address common needs. Though Hassan's projects will, rightly, be critiqued for their fetishization of entrepreneurial "disruption" and "innovation," as well as their inherently incrementalist and reformist objectives, it remains hard to deny that these are potentially significant initiatives. This is especially so in so far as these are sites where systemic social antagonisms are being encouraged to surface around the effort to provide urban centers with foundational social necessities - public infrastructures, energy networks, climate change defenses, and food systems - and where the emphasis is laid on devising a richer and more complex account of late capitalist "ecologies" than the former Chicago school orthodoxies were ever designed to provide.

Indeed, what Hassan and other policymaking allies claim to promote in these spaces is a new knowledge production habitus, one that makes a definitive break with the foundational doxas of both the neoliberal and Keynesian R\&D frameworks: 
BAU strategies are unsuited to complex social challenges because they are not the product of what Bourdieu calls "genuine strategic orientation," oriented toward current realities and the emerging future. Rather, BAU stems from habitus that is “the source of all these strings of 'moves,' which are objectively organized as strategies without being the product of genuine strategic orientation - which would presuppose at least that they be apprehended as one among other possible strategies" .... Our reliance on the expert-planning paradigm is an example of Bourdieu's observation, "Practice has a logic which is not that of the logician." This means that when faced with a real need to adapt our behaviors to a new reality, we as a society are unable to do so. Decision-making power and the control of resources rests with a narrow class of technocrats occupying BAU spaces, characterized by habitus. In the face of increasingly complex social challenges, the result is a troubling strategic vacuum masked by frantic technocratic activity. (42-43)

It is probably not worth dwelling too long on the irony that the global initiation of the social lab program is of course indicative of the extent to which influential figures within this "narrow class of technocrats" are already aware of operating in a "strategic vacuum." For if Hassan is right, and if the success of the prototyping approach can be proven to rely on the functional autonomy and strategic adaptability of the labs themselves, then there is a potentially key devolution of political and technical power taking place here.

All the more reason, then, to pay attention to what is happening "inside the sacred walls of these temples" (Latour, "Give" 141); for who power devolves to is as yet in play. The vast majority of these initiatives take place at the fraught intersections of academia; federal, provincial, and municipal governance; local communities; and the private and third sectors. As Hassan's accounts illustrate, they are already the site of intense partisan struggle. In this respect, the early involvement of the tech giants is an acute concern. It 
thus seems that if Hassan's vision of breaking with "BAU" is to take flesh in a functionally egalitarian form - if we are to "reclaim the production of multiple forms of capital from the economic and monetary spheres, instead of locking capital in enclosures (benefiting a small class of people)" (Hassan, 89) - it will be necessary to produce a more thoroughgoing and comprehensive political taxonomy of the exiting social innovation labs than we have at present, in order that we can better understand how, when, and where to attempt tactical interventions in the course of their development. It is to such prospects that we now turn, as we explore the uncanny extent to which Robinson's speculative fiction has mapped out this new terrain of struggle in advance of our arrival there. 


\section{CHAPTER FOUR: LAB OF LABS, COMMUNE OF COMMUNES}

In this final chapter I draw on Kim Stanley Robinson's Mars Trilogy, using the three novels to develop a slightly more exacting set of political proposals than I suspect policymakers are asking for when they invite humanists to assist social labs in "solving our biggest societal challenges." Combining a keen Latourian eye for the nature of laboratory praxis, with a vividly-realized account of the new vision of life on Earth that Lovelock passed on to Earth System Science, Robinson makes key contributions to the anarcho-communist critique of private property - bringing a Marxian understanding of political economy into conversation with vital scientific and technical questions. In so doing, this hard-sci-fi trilogy, first published over two decades ago, can sometimes seem to have arrived at our current conjuncture ahead of us. The series provides a sustained thought experiment in how ideological "friction" and multipolar political struggle might stack up within today's interdisciplinary R\&D networks, shifting their parameters and priorities, influencing the kind of world-making that takes place within them (Wark, 177). Approaching today's social innovation frameworks with this perspective in hand, this chapter attempts to conceptualize them in Bourdieu's terms, as a "field of struggle." Leaning on Robinson's and Bourdieu's often uncannily compatible understandings of the politics of social change and collective world-making, I pick up on Bourdieu's argument concerning the "collective invention of the collective structures of invention," taking Michael Rubenstein's gloss of the concept as a key point of strategic orientation:

The crux of Bourdieu's formulation is that the utopian culturalist turn ("collective invention") - in order to be effective in the political sphere - must be grounded in realized social structures that must, in turn, be reinvented. His imperative is 
emphatically not to invent utopias outside currently existing political structures but to imagine those utopias from within. (48)

Building upon this theoretical proposition, this chapter begins by mapping Robinson's utopian narrative onto the social history that I sketched out in the last chapter. It concludes by locating a handful of sites at which "realized social structures" seem most primed for "utopian reinvention" - a project that also entails identifying initiatives where countervailing tendencies appear most deeply entrenched. The goal here is to use Robinson's fiction to pry away the uniformly vague and inoffensive public faces of different social lab initiatives, to get at their underlying stakes, affiliations, and political potentialities.

Here it must be acknowledged that there are many good reasons to remain acutely pessimistic about the political potential of today's social labs, not least because of their deep - and perhaps even inextricable - imbrication in the systemic logics and path dependencies of monopoly capital. Such was the charge leveled against an MITsponsored "Fab Lab" (Fabrication Laboratory), in a recent arson attack in southeastern France. Writing in a subsequent Solidarity post, "the group of Grenoble" claimed responsibility, offering the following justification of their actions:

City managers cater to start-ups greedy for money and the fashionably geek masses by opening fablabs in trendy neighborhoods. These extremely diverse measures on the surface all aim to accelerate the general social acceptance and usage of the technologies of our sinister era. (...) And we couldn't care less whether these fablabs came out of the stale imagination of a revered hacker, which isn't the case, or whether they're participating in fruitful scientific collaborations with one of the temples of technocracy, MIT (Massachusetts 
Institute of Technology), which is the case-because they are a nuisance, we destroyed one. (qtd in Rédaction)

Commenting in the aftermath of the fire, former General Secretary of the French National Digital Council, Jean-Baptiste Soufron, expressed "sadness" that the La Casemate lab was made the "victim" of this "discharge of hate and distress" (Soufron). He still insisted, however, that we will have failed to grasp the political implications of such events if we are not willing to understand them as iconoclastic acts of protest against a "religion of progress and technology that is being sold as an inescapable future for everyone." Some fifteen years after the first proponents of Web 2.0 promised that "digital technology would usher in a new era of transparency and democratization," we have watched as the Big 5 reproduced the general logic of late capitalism, consolidating tremendous influence over the levers of government, and monopolistic control over many key and emerging markets (Scholz). In a recent sign that the mask has slipped, that discontent with this situation has begun to broach the political mainstream, US Senator Elizabeth Warren launched her bid for the Democratic Party nomination by mooting a flagship antitrust policy initiative designed to break up the Big 5, in an attempt to erode some of the immense power that they now exert "over our economy, our society, and our democracy" (qtd in Provenzano).

Two years prior to Warren's campaign, and the concurrent rise of the French antiestablishment gilets jaunes movement, Soufron read the incident at La Casemate as a warning, both that "the negative impact of the digital industry [was] being felt harder and harder by citizens," and that the repercussions of this hardship would "not be limited to nice ex-big tech employees speaking [at] elite conferences," or to "smart social science 
researchers writing outraged papers." In Soufron's telling of events, the La Casemate Fab Lab provided a lightning rod for wider social resentments because of the extent to which it served, not just as a major hub for technical research, but also as a means of disseminating Silicon Valley ideology.

Though not a social lab in precisely the sense that we have seen Zaid Hassan and Frances Westley defining in previous chapters (little concerned with the effort to effect complex system change, nor reorient infrastructural practices to better anticipate an "emerging future"), Fab Labs can still be regarded as a forerunner to these initiatives, because of the extent to which they attempt to trammel untapped social energy back into the "innovation cycle." Like the social lab, Fab Labs are positioned as sites of community outreach. And in common with Sam Laban and Frances Westley's suggestion that social labs can build "systems resilience" by ensuring the "integration" of "marginalized" communities into the "mainstream," Fab Labs aim to induct "amateur inventors" into a global network of entrepreneurial "incubators" (S. Davis). What began in 2001 as a partnership between the MIT Media Lab and Grassroots Invention Group, has since grown into a roster of over 550 laboratories, each equipped with laser cutters, milling machines, advanced computer hardware, robotics, and electronic assembly tools. Open to public use, this comprehensive suite of resources - said to be able to "manufacture practically anything” (Building Change) - is designed to equip interested parties with technical expertise, and with the entrepreneurial impetus to capitalize upon it.

Yet despite the philanthropic tone in which these pedagogical initiatives are described, it is clear that there is more at stake in the programmatic promotion of these 
spaces than simple, open-hearted altruism. Indeed, in this respect, Althusser's remarks on the nature of the Ideological State Apparatus (ISA) remain as pertinent as ever:

[B]esides ... techniques and knowledges ... [the individual] learn[s] the "rules" of good behavior ... which actually means rules of respect for the socio-technical division of labour and ultimately the rules of the order established by class domination ... All the agents of production, exploitation and repression, not to speak of the "professionals of ideology," must in one way or another be "steeped" in this ideology in order to perform their tasks "conscientiously" - the tasks of the exploited (the proletarians), of the exploiters (the capitalists), of the exploiters' auxiliaries (the managers), or of the high priests of the ruling ideology (its "functionaries"). (88)

It is precisely the Fab Lab's efforts at "steeping" the general public in the ideological and practical habitus of a Silicon Valley technical laboratory that has made them the object of anarchistic ire. Indeed, the Grenoble group characterize Fab Labs as a social "nuisance" because of the extent to which they operate as a means of capture, designed to induct school children, college students, and the underemployed into the "maker" ideology of Silicon Valley, which valorizes coding, computer engineering, robotics, and industrial design as the building blocks of modernity's most politically and technologically progressive tendencies. Meanwhile, the same technologies continue to erode the labour share of income, while subjecting global populations to ever-more invasive forms of digital profiling and manipulation - diving up the energic appetite of the world-system in the process.

Yet while acknowledging that these performative acts of neo-luddite resistance are grounded in a robust systemic analysis, I think it also worth probing the possibility of a more anarcho-syndicalist approach to the social lab, one wherein the concepts of 
socialization and collectivization guide the incursions we make into these spaces and the pressures we exert on them from without. Such is the vision that Robinson asks us to entertain in the Mars Trilogy. And key to understanding the politics of Robinson's fiction, is the tension that his work explores between the open-ended - and, for him, incipiently utopian - experimental space of the laboratory, and the closed "certainties" and path dependencies of the commercial and governmental institutions that trammel the efforts of these laboratories down the destructive pathways of business-as-usual.

We have already seen these tensions foreshadowed in the historical case studies that we touched on in the last chapter. In Forrester's case, we saw MIT's World3 laboratory serving as the staging ground for a political vision so blue-skied in its outlook that Forrester and his team would anticipate a post-scarcity civilization-to-come, one in which the nonhuman world had been freed from the ravages of growth-at-all-costs, and in which "the basic material needs of each person on earth" had been "satisfied" (Meadows et al., 24). We know the realpolitikal rocks on which this vision floundered. As governments played handmaiden to monopoly capital, they doubled down on compound growth and the headlong charge toward "overshoot and collapse," drawing on Forrester's SCM research to stabilize this new phase of economic expansion.

Robinson situates his novels at the crux of these kind of contradictions. I categorized his vision of the lab as "incipiently utopian," but in key respects it might be more accurate to draw on Foucault's somewhat slipperier terminology, in characterizing Robinson's narratives as "heterotopian" in nature. Though this is a concept that has since inspired a significant body of research, it is one that Foucault seems to have tired of relatively quickly. Aside from a few brief references in the preface to The Order of 
Things, Foucault offers only one sustained theoretical statement on the subject - a 1967 lecture that was eventually published, almost two decades later, under the title "Of Other Spaces.”

The concepts at stake in this piece branch out from those which Foucault was developing contemporaneously in The Order of Things. In accord with that major work's influential account of "epistemic ruptures" and epochal "discontinuity," "Of Other Spaces" is initially positioned as an exercise in periodization, one that defines its eras and epochs, not via attention to the warp and woof of historical events, but through an "archeological" analysis of the a priori concepts that "define the possibilities of knowledge" in a given time and place ("Order" 168). Arguing in this vein, "Of Other Spaces" proposes that in contrast to the nineteenth century's "obsession" with time, with the crises and cycles of an "ever-accumulating" historical past, our own epoch was best defined as "the epoch of space" (22). In Foucault's telling of events, we increasingly experienced the social order less as "a long life developing through time" and more as a "network" of "connect[ed] points" continually "intersect[ing] with its own skein" (22).

Despite this concern with periodization, however, the lines of thought that Foucault begins to develop at the outset of "Of Other Spaces" actually seem to closely anticipate those that Latour would later go on to map out in his ANT. Interesting, then, that as Foucault opens his discussion of heterotopia, we find him brooding over the same of set of historical and institutional case studies that have since obsessed Latour:

[T] he real scandal of Galileo's work lay not so much in his discovery, or rediscovery, that the earth revolved around the sun, but in his constitution of an infinite, and infinitely open space. In such a space the place of the Middle Ages 
turned out to be dissolved, as it were; a thing's place was no longer anything but a point in its movement, just as the stability of a thing was only its movement indefinitely slowed down. In other words, starting with Galileo and the seventeenth century, extension was substituted for localization. Today the site has been substituted for extension which itself had replaced emplacement. The site is defined by relations of proximity between points or elements; formally, we can describe these relations as series, trees, or grids. Moreover, the importance of the site as a problem in contemporary technical work is well known: the storage of data or of the intermediate results of a calculation in the memory of a machine, the circulation of discrete elements with a random output (automobile traffic is a simple case, or indeed the sounds on a telephone line); the identification of marked or coded elements inside a set that may be randomly distributed, or may be arranged according to single or to multiple classifications. (23)

This is a dense passage, that also begins exploring the kind of conceptual terrain that Gilles Deleuze and Félix Guattari would go on to occupy in A Thousand Plateaus. Indeed, as the essay opens, Foucault seems set to offer a blueprint to Deleuze and Guattari's processual account of an "arboreal" capitalist system that "striate[s] the space over which it reigns," via the intervention of technical labs that function as sites of comparison, "introducing breaks and divisions into otherwise freeflowing phenomena" (Deleuze and Guattari, 385; Haggerty and Ericson, 608). Operating in concert, these sites of comparison are said to create centers of appropriation where energic, informational, and material flows can be documented, tracked, "captured" and "monetized" (Haggerty and Ericson, 608).

Yet rather that investigate the social practices that shape these sites, or push further into mapping out their systemic effects, Foucault instead swerves away from the figure of the laboratory, to seek out parenthetical spaces that appear to stand somewhat 
outside this "whole network of knowledge" (23). In so doing, he identifies a series of social "sites" that are said to be "nurtured by the hidden presence of the sacred" (23). As Foucault draws on anthropological accounts of the social function of sacral space, these spaces are seen to operate as "mirrors" and "counter-sites" to the larger networks of which they form a part (24). Set apart, heterotopias are defined by "the curious property of being in relation with all the other sites ... in such a way as to suspect, neutralize, or invent the set of relations that they happen to designate, mirror, or reflect" (24). In Foucault's estimation, utopias and heterotopias both share in this "general relation of direct or inverted analogy with the real space of Society" (24). Both prove capable either of representing society itself in a perfected form, or of recapitulating it in inverted or distorted shapes. Yet what distinguishes a heterotopia from a utopia, for Foucault, is the extent to which, in contrast to the fictional "no place" of the utopia, heterotopias are grounded in the known world, operating as "something like ... effectively enacted utopia[s]," anchored and expressed in realized social structures (24).

Although defined in implicit opposition to the space of the laboratory, it is noteworthy that the qualities that Foucault attributes to a heterotopia could just as easily be applied to the laboratory itself. As Latour demonstrates in his early ethnographic studies of laboratory praxis, there are few sites more apt to stand in "relation with all the other sites" - while at the same time "suspect[ing], neutraliz[ing], or invent[ing] the set of relations that they happen to designate, mirror, or reflect" (24) - than the site of the laboratory itself. Key to understanding what permits the lab to function in these diverse modes - as "mirror," investigator, and means of "invention" - are the translations in scale that the laboratory is designed to affect. Turning to a favourite example in Pasteur, Latour 
recalls that microorganisms proved hard to detect outside the laboratory, because they were "invisible and struck in the dark." But brought inside Pasteur's laboratory illuminated, isolated from other factors, and magnified under the lenses of the microscope - it becomes possible to make "a reversal of the actors' strengths":

Once a great many microbes are cultivated in pure forms in laboratories and submitted to numerous trials to make them accelerate their growth or die, a new practical know-how is developed. In a few years, experimenters acquire skills in manipulating sets of materials that never existed before. This is new but not miraculous. Training microbes and domesticating them is a craft like printing, electronics, blue-ribbon cooking or video art. Once these skills have accumulated inside laboratories, many cross-overs occur that had no reason to occur anywhere else before. This is not because of any new cognitive attitude, or because suddenly people become conscious of micro-organisms they were unaware of before. It is simply that they are manipulating new objects and so acquiring new skills in a new idiosyncratic setting. ("Give" 148)

Having cultivated microbes in the "purified" environment of a sterilized vessel, and having tracked their response to stimuli via a meticulous process of inscription and documentation, social practice learns how to "train" microorganic beings that were preciously inaccessible to its reach. Yet as Latour also begins to intimate here, in addition to facilitating interaction with new material strata, laboratories also permit us to do strange things to our experience of time, allowing us - in certain respects - to cheat its onward passage, to apparently turn back the clock and "return" to an earlier point in a developmental sequence. In Pasteur's case, we see that once microbes are cultivated and banked in a "purified" and stabilized form, microbial cultures begin to function as a kind of "baseline," to which researchers can return, beginning a new iteration of the experimental process. Mistakes prove less costly in this environment, as there is the 
option of hitting the "reset button," returning to a preestablished point in a sequence with new reserves of experience in hand. Indeed, Latour suggests that in contrast to the politician who exists in the "one shot" world of politics, and who must always operate at "full scale," the laboratory permits the scientist to take multiple passes at a miniaturized version of a larger problem, learning from every documented mistake that is made along the way (165):

'Accumulated knowledge' people say with admiration, but this acceleration [of the learning process] is made possible by a change of scale, which in turn makes possible the multiplication of trials and errors. Certainty does not increase in a laboratory because people in it are more honest, more rigorous, or more falsificationist. It is simply that they can make as many mistakes as they wish or simply more mistakes than the others 'outside' who cannot master the changes of scale. Each mistake is in turn archived, saved, recorded, and made easily readable again, whatever the specific field or topic may be. (164)

These observations have key ramifications for our discussion of heterotopia. For given the ways in which the laboratory thus seems to stand both "inside" and "outside" of the temporal and spatial "orders" that govern everyday life - and given the way in which it depends on the practice of "setting aside," cordoning off, and isolating - it seems strange to categorize the lab as the antithesis of a heterotopia rather than as a particular form of it.

For the case to be settled, however, laboratories also need to act as spaces capable of revealing the shape of the social order that produces them. In Foucault's discussion of heterotopia, we are presented with a series of "sites" - among them, the festival; the sacral initiation rites of premodern cultures; the cemeteries of Medieval and modern Europe; and the libraries and museums of the nineteenth century - that are all said to reveal the form of their "Society" in mirrored, idealized, or inverted from. We know from 
Mikhail Bakhtin and Charles Taylor how the carnival can be read as an inverted model of everyday life, as a world-reversed in which prevailing social hierarchies and prohibitions are temporarily turned upside down. Yet in searching for an example of heterotopias that offer site-specific realizations of their societies' perfected or idealized forms, Foucault points to the role that public libraries and museums played in modeling the nineteenth century's sense of a "glacially" cumulative historical past (22):

Museums and libraries have become heterotopias in which time never stops building up and topping its own summit, whereas in the seventeenth century, even at the end of the century, museums and libraries were the expression of an individual choice. By contrast, the idea of accumulating everything, of establishing a sort of general archive, the will to enclose in one place all times, all epochs, all forms, all tastes, the idea of constituting a place of all times that is itself outside of time and inaccessible to its ravages, the project of organizing in this way a sort of perpetual and indefinite accumulation of time in an immobile place, this whole idea belongs to our modernity. The museum and the library are heterotopias that are proper to western culture of the nineteenth century. (26)

Just as the public library and the museum concretized the conceptual lifeworld of the nineteenth century in site-specific form, we can also read the lab as a perfected or idealized expression of the modes of thought and practice that characterize of our own networked age. In accord with the definition that Foucault offers, these are sites that in certain key respects stand "outside of all places" and "outside of time," even "though it may be possible to indicate [their] location in reality" (24). And as we know from the example of Forrester and the Wolrd3 simulator these are also spaces that are capable of holding up an unwelcome "mirror" to the whole network of social relations to which they stand related. Indeed, in view of the following remarks from Foucault, it should not 
surprise us that The Limits to Growth's damning indictment of prevailing industrial practices came couched in the form of a speculative utopia:

The mirror is, after all, a utopia, since it is a placeless place. In the mirror, I see myself there where I am not, in an unreal, virtual space that opens up behind the surface; I am over there, there where I am not, a sort of shadow that gives my own visibility to myself, that enables me to see myself there where I am absent: such is the utopia of the mirror. But it is also a heterotopia in so far as the mirror does exist in reality, where it exerts a sort of counteraction on the position that I occupy. From the standpoint of the mirror I discover my absence from the place where I am since I see myself over there. Starting from this gaze that is, as it were, directed toward me, from the ground of this virtual space that is on the other side of the glass, I come back toward myself; I begin again to direct my eyes toward myself and to reconstitute myself there where I am. The mirror functions as a heterotopia in this respect: it makes this place that I occupy at the moment when I look at myself in the glass at once absolutely real, connected with all the space that surrounds it, and absolutely unreal, since in order to be perceived it has to pass through this virtual point which is over there. (24)

Seen in this light, the challenge posed by The Limits to Growth was a heterotopic one, in which late capitalism was offered - in the "virtual space" of the World3 simulator - a more unforgiving "reflection" of its prevailing systems dynamics than it was able to tolerate or acknowledge. Little wonder that so many attempts have since been made to blot out all memory of the image that it left behind.

\section{POST-CAPITALIST REALISM}

Robinson's speculative fiction mines these kinds of tensions and contradictions in depth. There are key respects in which the Mars Trilogy can be seen to operate in a similar 
fashion to Foucault's essay, teasing out the utopian tendencies that he finds concretized in existent social sites. Although the lab is the primary case in point, here, the novels can be interpreted, more broadly, as a compendium of heterotopic references. Indeed, as McKenzie Wark remarks in a perceptive study of the novels' overarching ambition, Robinson's primary concern in the Mars Trilogy is with puzzling out "forms of organization and belief for a post-bourgeois world," with "the invention of a grammar that might come after that of capitalist realism" (177). Attempting to put flesh on the bones of this ambition, Robinson's trilogy bristles with references to an assortment of "actually existing, contemporary or historical societies," all of which, in some fashion or other, "exude hints of utopian possibility" (178). Wark highlights Robinson's allusions to "Mondragon Co-ops, Yugoslav self-management, Red Bologna, the Israeli kibbutz, Sufi nomads, Swiss cantons, Minoan or Hopi matriarchies, Keralan matrilineal land tenure" as cases in point (178). But to round out the picture, we need also to acknowledge Robinson's countercultural and hedonistic inclinations, his frequent circling back to the site of the dance and the rave, to the image of bodies moving, together, to rhythms and psychotropic substances that exert their own utopic spell.

Yet despite this profusion of "other spaces," the heterotopia at the heart of this narrative is unmistakably that of "the lab." We can be more specific still, as we know that Robinson's preliminary research saw him stationed at the Antarctic scientific research outpost, at the invitation on the National Science Foundation's Artists and Writer's Program. Of this experience, Robinson remarks:

If you want an analogy for what a moon base will be like, think South Pole station. Don't think Plymouth Rock or Jamestown, that's wrong - hugely wrong. 
The South Pole's base is as close to a space station as we have on Earth. The International Space Station is another good analogy. It's going to be awkward and dangerous, and you'll always be indoors, except for occasional spacesuit ventures onto the surface. One thing I got out of my Antarctic trips was the feeling of what it would be like to be indoors in a very inhospitable place with a small group of scientists, and trips outdoors that were like EVAs. ("Good Anthropocene")

The simple conceit at the heart of the trilogy is thus to use the most extreme examples of currently existing scientific outposts as a guide to the conditions and institutions that interplanetary colonists would be forced to face and build, as they struggle to survive in an environment that is clearly, and repeatedly, imagined as a sublimed Antarctic.

Patterned after Robinson's experiences in the South Pole, life in the early days of Martian expedition is dangerous, precarious, and yet charged with a visceral survivalist intensity. Here is Arkady Bogdanov, the trilogy's political provocateur, expounding on the heterotopic nature of life at the Antarctic station:

When we first arrived, and for twenty years after that, Mars was like Antarctica but even purer. We were outside the world, we didn't even own things - some clothes, a lectern, and that was it! Now you know what I think, John. This arrangement resembles the prehistoric way to live, and it therefore feels right to us, because our brains recognize if from three million years of practicing it... So as a result people grow powerfully attached to that kind of life, when they get a chance to live it. It allows you to concentrate your attention on the real work, which means everything that is done to stay alive, or make things, or satisfy our curiosity, or play. That is utopia ... especially for primitives and scientists, which is to say everybody. So a scientific research station is actually a little model of prehistoric utopia, carved out of the international money economy by clever primates who want to live well. ("Red" 342) 
In this passage, Robinson asks us to discover, hidden in the recesses of the Antarctic scientific station, an unlikely "union of opposites" in which modern and premodern sensibilities appear to blend and intersect. At the crux of this vision is the notion that the research station forms a parenthetical space, one temporarily - if only partially bracketed off from the alienating logic of the commodity form. Indeed, for Robinson, scientific outposts are conceived as sites at which subsistence is secured, less through the direct mediation of the market, and more via the "real work" of what "is done to stay alive, [to] make things, [to] satisfy curiosity, or [to] play." Commenting on this dimension of the novels, Wark remarks,

Not everyone gets to live such a life, even at [Robinson's] Underhill, and so the scientific life isn't really a utopia. Scientists carve out refuges for themselves from other forms of organization and power rather than work on expanding them. The crux of the [political] position in the Mars Trilogy is making the near-utopian aspect of the most advanced forms of collaborative labor a general condition. (180)

What thus takes shape in the Mars Trilogy is a utopic inversion of the bad faith narrative that Fab Labs promote when claiming to put the most sophisticated forms of technical capacity at the disposal of the commons. In place of the photo ops, column inches, and tech industry recruitment drives that Fab Labs are clearly designed to promote and facilitate, Robinson's fiction asks what would happen should the laboratory "go rogue," should it slip its fetters, shake free from the grip of monopoly capital, and put itself at the service of an entirely different set of political objectives. What thus emerges in the course of the Mars Trilogy, is a fictive effort at "reclaim[ing] the production of multiple forms of capital from the economic and monetary spheres, instead of locking capital in enclosures 
... benefiting a small class of people" (Hassan 89), one that actually understands just how inimical such goals are to the systemic logic of capitalism.

Robinson uses a number of narrative devices to render this vision a little more plausible that it seems when stated in the flat, blank form of academic prose. The first is to introduce his post-bourgeois world via the jaded and Machiavellian perspective of political pragmatist, Frank Chalmers. Though the first book details some of the voyage from Earth to Mars, its opening chapter begins by jumping forward to a later stage in the narrative arc, as Frank offers a wry and weary commentary on "the usual ... Inspirational Address" that his friend and rival, John Boone, is then delivering to a new cohort of "Terran" migrants ("Red" 4). This perspectival device ensures that political cynicism arrives on Mars ahead of us, in order that Robinson can attempt to circumvent it on his own terms. This strategy is representative of Robinson's longstanding efforts at contesting the dominance that dystopian narratives now exert within the genre of speculative fiction. Discussing this history in a recent interview with Robinson, Adam Rogers situates Robinson's hard-sci-fi in relation to the cyberpunk genre that rose to pop cultural prominence as we began knocking on the door of the new millennium:

Books like William Gibson's Neuromancer and Bruce Sterling's Schismatrix played out a future dominated by corporations, where code and cybernetic body modification threaded through underworlds full of murderous gangsters. It wasn't to Robinson's taste. "Cyberpunk was an aberration," he says. "They were somewhat antifeminist, with their hard noir gals. It was defeatist. Or nonpolitical. Or collaborationist - like noir. So I hated them, and they hated me.” The tropes of film noir, he says, weren't up to the task of laying out a useful future. 
In the light of this exchange, it is clear that Red Mars' opening appeals to the hardboiled sensibility of film noir are designed to act as a kind of Trojan Horse, via which Robinson attempts to smuggle in his own perspective, pre-emptively buffered against the "defeatism" of a genre that has struggled to imagine an end to the dominance of capitalist social relations.

All the same, the most critical steps that Robinson takes in attempting to invent "a grammar that might come after that of capitalist realism," are the result of the political agitation of Arkady Bogdanov. In the course of the Ares' journey from Earth to Mars, Arkady undertakes a series of "situationist pranks" which are designed to pry open the Overton window, compelling the other colonists to acknowledge the abyss of freedom that becomes theirs as they touch down on the surface of Mars, with all of the most advance technical resources of late stage capitalism at their disposal, and with not a cop or a militia in sight for 34 million miles.

To grasp the full scope of the Mars Trilogy's political vision it is critical to note that the Ares is propelled out to Mars on the backdraft of ecological crisis. For even as Robinson's hundred-strong team of scientists and engineers begin their initial acts of exploration and settlement, their work is constantly dogged by the looming background figure of conditions on Earth. Details are scant, but the brief glimpses that we catch of our own planet are straight from the pages of The Limits to Growth:

"We now use about eighty percent of the net primary product of land-based photosynthesis," he said. "One hundred percent is probably impossible to reach, and our long-range carrying capacity has been estimated to be thirty percent, so we are massively overshot, as they say. We have been liquidating our natural capital as if it were disposable income, and are nearing depletion of certain capital 
stocks, like oil, wood, soil, metals, fresh water, fish, and animals. This makes continued economic expansion difficult." Difficult! Art wrote. Continued? (“Green" 76)

Indeed, in Robinson's "future history," it is precisely the imminent threat of "overshoot and collapse" that has propelled the Ares out toward Mars in the first place, where the colonists are meant to serve as a reconnaissance team for late capitalist extractive industries desperate for new resources. The passage to Mars is funded by transnational “metanats," who will eventually come looking, with police in tow, for a return on their investment. The UN, meanwhile, sees the Martian settlement as a potential safety-valve for a Terran population that is outstripping the Earth's carrying capacities, and the colonists are therefore tasked with "terraforming" a humanly habitable biosphere.

Regarding Robinson's representation of this terraforming project, Wark remarks that although Robinson does not "coin the term" he certainly succeeds in giving it "the richest expression of any writer" (177). For Wark, the "richness" of Robinson's account hinges on the extent to which its attention to "technical issues" ultimately operates as "a Brechtian estrangement device," one that "open[s] up a space for thinking about the organization of the Earth" (177). Robinson is not shy of signaling his ambitions on this score; indeed, at one juncture he will have Maya, the charismatic leader of the Russian team, bald-facedly state the trilogy's d'être in the most candid of terms: "We exist for Earth as a model or experiment. A thought experiment for humanity to learn from" ("Green" 376). Though the phrase resonates in an extradiegetic register, it also has distinct diegetic implications, as the Mars mission is the object of intense media scrutiny. There are journalists among the first cohort of engineers and scientists, and they transmit 
a steady stream of footage back to Earth - including a series of heated arguments between the leaders of emerging ideological factions.

Amid the four or five political schisms that develop in the early stages of the first novel, Red Mars, a handful of major fault lines emerge; they concern both the nature of the settlement's political autonomy, relative to earthly authorities, and the ethics of the terraforming project itself. In the former case, tensions first surface between Arkady and Maya, as Arkady questions the chain of command, and pushes the colonists to construe their mission as a political, as well as a scientific, experiment. This pressure has knock on effects, emboldening many of the other characters to tender their own scientific and political proposals. This leads to a protracted series of struggles over the terraforming initiative, as Ann Clayborn doggedly resists the effort to refashion Mars into a facsimile of Earth - insisting that it should be the sole prerogative of the sciences to understand this world, rather than to dominate and transform it. Sax Russel, meanwhile, makes the case that science is a means to an end and accordingly emerges as the driving force of the terraforming program. Hiroko Ai adopts the last of the three main theoretical stances, seeing "the altering of Mars' atmosphere and surface" as entailing a collaborative "process in which the planet and its inhabitants evolve together" (Leane, 94). In her semiSpinozan view, far from dominating Mars, the terraforming process merely catalyzes the release of the "creative self-designing" capacities that already inhere in matter itself (“Green” 13).

Seen from the vantage of Earth, the early days of the mission are thus transformed into an absurdly heightened form of "reality television," one that has been subject to such intense political and technological torque that the "society of the spectacle" seems to be 
collapsing in on itself. For as the audience on Earth begins to "root" for different members of the mission, they are drawn through the looking glass, into a world in which "questions of base and superstructure, nature and culture, economics and politics" become impossible to "treat in isolation" (Wark, 177). In the process, Robinson's characters begin plumbing the kind of conceptual waters that have since occupied Latour in his tracts on Gaia theory, as they confront the "same question [that] confronts all cosmologies: what does it mean, for a people, to measure, represent, and compose the form of the Earth to which they find themselves attached?" (Latour, "Gaia" 150-151). Yet what is never far from view in Robinson's take on such matters, is that this "cosmological question" will only emerge as an active and transformative political force in a context where the hegemony of capitalist social relations has been called into question. Indeed, for Robinson, it is clear that as long as capitalist social relations prevail, it will continue to be the real movement of value that utters the last word on what "it means to measure, represent, and compose the form of the Earth to which [we] find [our]selves attached."

As Wark notes, this facet of Robinson's politics is made especially evident in the way the trilogy extends the pedagogical logic of Brechtian theater, providing its readers with a means of grasping their own position in geohistory. In the estranging "mirror" of Robinson's "unreal" world, we catch clear sight of the manner in which the value form currently measures, represents, and composes our own. Here, Robinson combines Mandel's understanding of the "overall irrationality" of late capitalist systems dynamics, with a keenly realized account of the holistic vision of the Earth System that Lovelock passed on to Earth System Science. 
There are many rich historical ironies to be unpacked in treating the Mars Trilogy in relation to Lovelock's work. For it was actually as NASA began planning the Viking mission to Mars that Lovelock was first commissioned to begin the research that led him to the formulation of Gaia theory. The space agency had recruited Lovelock - a chemist and engineer - to devise instruments capable of remotely detecting extra-terrestrial life. As Lovelock and his collaborators probed different routes into the question, they gradually arrived at the hypothesis that chemically-complex atmospheres - such as our own - might be most accurately construed, less as the gaseous abiologic properties of an inert planetary body, and more as the cumulative consequences of the metabolic agency of the organisms that inhabited it. Absent the presence of living organisms, Lovelock hypothesized that entropic tendencies would see planetary atmospheres settling down into relatively uniform chemical states - a thesis that was supported by what was then known of those planets that were within the reach of our instruments. He concluded by proposing that the remote detection of anomalously-complex atmospheres might serve as a key indicator of the presence of life, in so far as this chemical complexity could be read as an environmental trace of life's metabolic struggle against entropy. In Lovelock's phrase, "the atmosphere of a life-bearing planet" should be "recognizably different from a dead planet” (“Gaia" 5).

Robinson's speculative fiction closes this conceptual loop, in finding us transported aboard the first days of a scientific expedition that will see the novel's resourceful cast of characters relying on the conceptual legacies of Lovelock's hypothesis as they attempt to reverse-engineer a humanely-habitable biosphere. This is a project that Robinson's scientists and engineers are incapable of accomplishing without successfully 
enlisting the agencies of other life forms. Unsurprising, and for reasons that Lovelock's

Gaia theory can explain to us, their efforts at "areophany" begin with the microbes:

That is one of the definitions of life: organism and environment change together in a reciprocal arrangement, as they are two manifestations of an ecology, two parts of a whole. And so: more oxygen and nitrogen in the air. Black fuzz on the polar ice. Black fuzz on the ragged surfaces of bubbled rock. Pale green patches on the ground. Bigger grains of frost in the air. Animalcules shoving through the depths of the regolith, like trillions of tiny moles, turning nitrites into nitrogen, oxides into oxygen. At first it was nearly invisible, and very slow. With a cold snap or a solar storm there would be massive die-offs, whole species extinct in a night. But the remains of the dead fed other creatures; conditions were thus easier for them, and the process picked up momentum. Bacteria reproduce quickly, doubling their mass many times a day if conditions are right; the mathematical possibilities for the speed of their growth are staggering, and although environmental constraints - especially on Mars - keep all actual growth far from the mathematical limits, still, the new organisms, the areophytes, quickly reproduced, sometimes mutated, always died, and the new life fed on the compost of their ancestors, and reproduced again. Lived and died; and the soil and air left behind were different than they were before these millions of brief generations. And so one morning the sun rises, shooting long rays through the ragged cloud cover, up the length of Valles Marineris. On the north walls are tiny traces of black and yellow and olive and gray and green. Specks of lichen dot the vertical faces of stone, which stand as they always have, stony, and cracked, and red; but now speckled, as if with mold. ("Red" 205-206)

To unpack passages such as this, and to grasp the earthly implications of the fictive Martian conflicts that Robinson stages, we need to operate at a long and salutary distance from a two-cultures approach to the study of science and culture. Indeed, the attraction of narratives such as Robinson's, is that like Gaia theory itself, they invite us to pass 
through the barrier that we once erected between humanity and nature, in searching for an understanding of interspecies interdependency that is "more active, more open, [and] more corrosive" in kind (Latour, "Gaia" 86).

Understating the terraforming of Mars in precisely these terms, Robinson's characters undertake a process of infra-ecological expansion that is, in a sense, the reverse of the one that late capital has overseen on Earth. In place of agribusiness models committed to the production of cash crop monocultures, or factory fishing "methods" that remorselessly drive ocean life into extinction, the goal of this new terraforming effort is to apply the knowledge derived from the Earth System Sciences, in generating a rich biodiverse planetary system from the ground up. As this process takes place over the span of three books, and the better part of two centuries, the reader is introduced to a mode storytelling that could be characterized as Gaian in nature.

To appreciate the novelty of this approach we might consider taking a brief detour through Michel Serres' influential contribution to the philosophy of science, The Natural Contract. In the opening pages of that book, Serres conducts an expressionistic reading of Goya's Fight with Cudgels, using the painting to provide an allegorical diagnosis of prevailing cultural tendencies and representational impasses (Figure 3): 


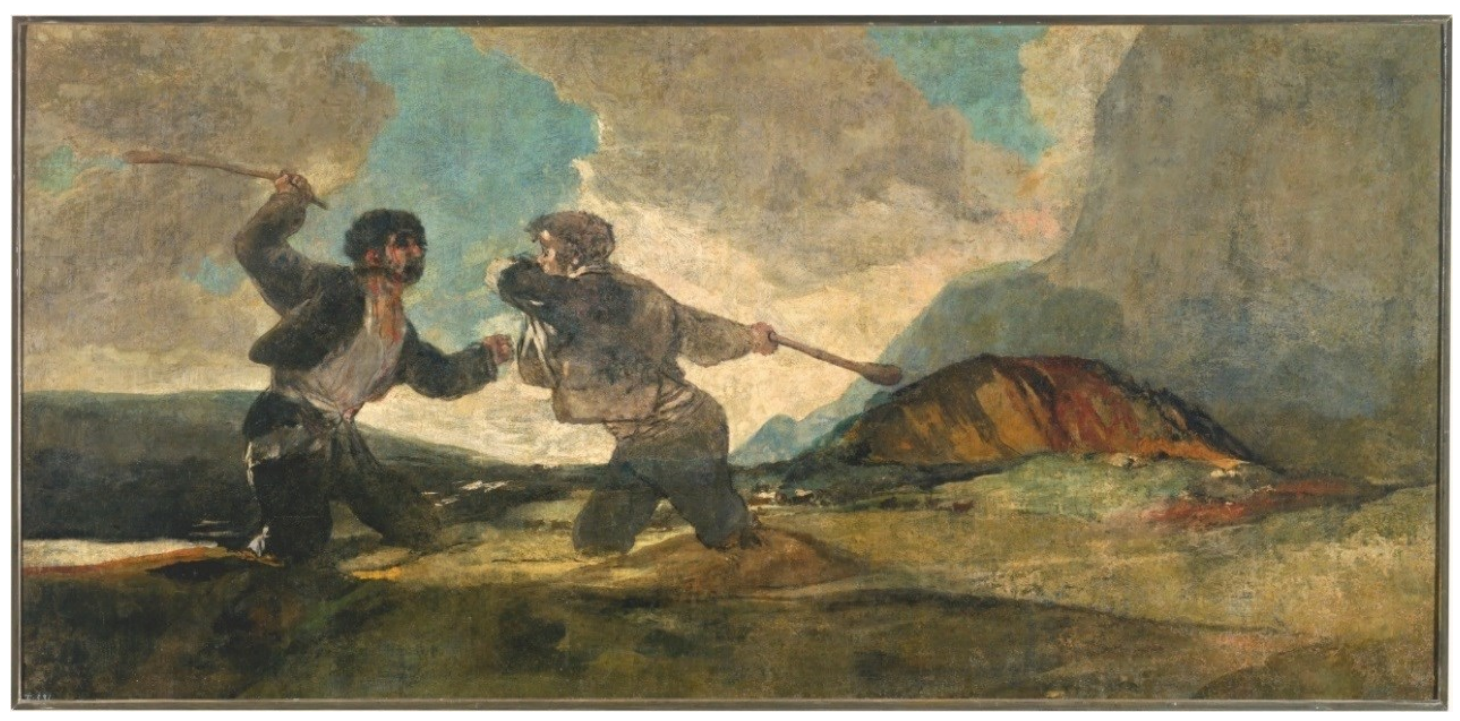

Figure 3. Goya. Fight with Cudgels. 1820-1823. Oil on canvas, $123 \mathrm{~cm} \times 266 \mathrm{~cm}$. Museo del Prado, Madrid. Museo del Prado, Madrid. Web. 30 May 2019. Digital Image.

A pair of enemies brandishing sticks is fighting in the midst of a patch of quicksand. Attentive to the other's tactics, each answers blow for blow, counterattacking and dodging. Outside the painting's frame, we spectators observe the symmetry of their gestures over time: what a magnificent spectacleand how banal! The painter, Goya, has plunged the duelists knee-deep in the mud. With every move they make, a slimy hole swallows them up, so that they are gradually burying themselves together. How quickly depends on how aggressive they are: the more heated the struggle, the more violent their movements become and the faster they sink in. The belligerents don't notice the abyss they're rushing into; from outside, however, we see it clearly. (1)

In Serres' somewhat moralizing terms, the fate of these floundering antagonists neatly encapsulated the logic of a neurotic, anthropocentric humanism that was still more concerned to gawp over aestheticized representations of intra-species bloodletting than to grasp its disruptive place within the broader web-of-life:

Nothing ever interests us but spilled blood, the manhunt, crime stories, the point at which politics turns into murder; we are enthralled only by the corpses of the 
battlefield, the power and glory of those who hunger for victory and thirst to humiliate the losers; thus entertainment mongers show us only corpses, the vile work of death that founds and traverses history, from the Iliad to Goya and from academic art to prime-time television. (2)

Riffing on the Enlightenment's obsessive interest in riddling out the relationship of "object" and "subject," Serres goes on to describe these internecine, intra-species conflicts as "subjective wars," distinguishing them from the "objective violence" that was meanwhile being inflicted on a planet that was all too often imagined as the empty vessel, the mere "theatre," of human conflict:

From now on, then, I will call subjective wars those, whether nuclear or conventional, that nations or states fight with the aim of temporary dominance ... I will call objective violence that in which all the enemies, unconsciously joined together, are in opposition to the objective world, which is called, in an astonishing metaphor, the "theater" of hostilities. Thus the real is reduced to a spectacle in which the debate stands out against a cardboard backdrop that can be displayed or dismantled at will. For the subjective wars, things didn't exist in themselves. (11)

Robinson's speculative fiction cuts a clean path out of this thicket of deeply-entrenched cultural tropes. Indeed, in the Mars Trilogy, the non-human world is no longer "a carboard theater" or "backdrop" against which human antagonists struggle, but is itself perceived as a network of living agencies and energic currents, of which the characters themselves form a conscious and active part. There are many conflicts, and even wars, in the "future history" that Robinson writes. Yet in contrast to a focus "on the vile work of death that founds and traverses history, from the Iliad to Goya and from academic art to prime-time television," the Mars Trilogy is far more deeply invested in exploring the inner life of a biospheric system that is patterned after our own "Gaia." Indeed, in key 
respects, the Mars Trilogy performs a similar kind of "cognitive mapping" function to the television documentaries of David Attenborough, drawing its audience, via narrative, through an immense body of scientific research. Like Attenborough and his team, Robinson employs multiple "camera angles," synthesizing knowledge drawn from a vast ecology of research practices. Inhabiting the scale-shifting imaginary of the lab, Robinson offers the reader everything from microscopic images of the complex cocktail of living biomatter that we know as soil, ${ }^{14}$ to the naked eye's view of spreading grasslands, ${ }^{15}$ to flyovers of Mars' rugged landmasses, ${ }^{16}$ to montages of water cycles in formation. $^{17}$

It would be poignant to offer a comparative study of the narrative that Attenborough's documentaries traces in six decades of documentation, to the one narrated in the Mars Trilogy. For the basic phenomenon that Attenborough maps out over

\footnotetext{
14 ' $[\mathrm{T}]$ hey were finding that manufacturing soil was one of the most difficult technical feats they had ever undertaken ... [S]oil was in fact very complex. About five percent of it by weight was made of living things, and this critical five percent consisted of dense populations of nematodes, worms, mollusks, arthropods, insects, arachnids, small mammals, fungi, protozoa, algae, and bacteria. The bacteria alone included several thousand different species, and could number as high as a hundred million individuals per gram of soil' ("Blue" 330).

15 'Who knew how plants felt? When you looked closely at them, glowing in all their detailed articulation like complex crystals, they were as mysterious as any other life. And now their presence here made the entire plain, everything he could see, into one great fellfield, spreading in a slow tapestry over the rock; breaking down the weathered minerals, melding with them to make the first soils. A very slow process. There was a vast complexity in pinch of soil; and the look of this fellfield was the loveliest thing he had ever seen' ("Blue" 66-67).

${ }^{16}$ 'From a hundred meters' height they could watch the shadowed landscape below turn to bronze as the terminator rolled by and clear daylight followed, illuminating a fantastic jumble of bright rocks and long shadows ... Then the land fell away below them, and they were over the first of the outflow channels they would pass, a sinuous unnamed valley west of Shalbatana Vallis. This little arroyo's S shape was unmistakably water-cut. Later that day they lofted out over the deeper and much wider canyon of Shalbatana, and the signs were even more obvious: tear-shaped islands, curving channels, alluvial plains, scablands; there were signs everywhere of a massive flood, a flood that had created a canyon so huge that the Arrowhead suddenly looked like a butterfly.' ("Red" 183).

17 ' $[\mathrm{T}]$ hey measured the hydrological cycle, with all its storms and variations in rain and snow, melting and seeping into the ground, running over the surface in creeks and rivers, down into lakes and then into the Hellas Sea, there to freeze in the winter, then evaporate in the summer and begin the whole round again.' ("Blue" 608).
} 
the course of his long career, is of course the inverse of the one described in the Mars Trilogy. In the latter case, the spread of human infrastructure brings with it biodiversity and the expansion of the territorial range of nonhuman life. In our own, the onward march of human industries spells retreat, diminishment, and extinction for an increasing number of the world's species.

This bleak pair of contrasting images returns us to that all-too-familiar "Casandra paradigm" in which we look on at the mounting devastation with a sickening sense of inevitability, reduced to petitioning stonewalling national governments to act on our behalf. And it is at moments such as this that I think Robinson's speculative fiction can serve as a useful stimulant to the political imagination, principally by insisting on this mutinous idea that the laboratory - which Latour has taught us to understand as first and foremost a social practice - can inherit other destinies than those assigned it by monopoly capital. Indeed, in Robinson's speculative fiction, the powers and potentialities of this unique social practice are deemed too rich and too precious to be ceded to the simpleminded cynicism of business-as-usual. Echoing claims that Murray Bookchin first began making back in the early 1960s, Robinson insists that the "the ecological crisis" is not the result of "technology" per se. Nor is it, as the moralizing tenets of liberal individualism insist, "a matter of misinformation, spiritual insensitivity, or lack of moral integrity" ("Ecological Crisis"). Aligning with Forrester, Mandel, and the Meadowes, Robinson and Bookchin instead understand "ecological crisis" as the all-too-predictable outcome of an economic system that permits no deviation from the pursuit of growth-atall-costs: 
The present social illness lies not only in the outlook that pervades the present society; it lies above all in the very structure and law of life in the system itself, in its imperative, which no entrepreneur or corporation can ignore without facing destruction: growth, more growth, and still more growth. Blaming technology for the ecological crisis serves, however unintentionally, to blind us to the ways technology could in fact play a creative role in a rational, ecological society. In such a society, the intelligent use of sophisticated technology would be direly needed to restore the vast ecological damage that has already been inflicted on the biosphere, much of which will not repair itself without creative human intervention. ("Ecological Crisis")

This is entirely the kind of diagnosis that Robinson's Mars Trilogy offers of our current situation. Yet this reading of events does not lead Robinson or Bookchin to advocate retreat to the embrace of an autocratic and hierarchical nation state - one given license, by climate crisis, to indefinitely invoke the state of exception. Both writers instead envision the emergence of a "post-scarcity anarchism" in which the city has emerged as the foundational unit of political organization. Indeed, as the Mars Trilogy unfolds, we see the scientific research outposts that Robinson patterned after the Antarctic science station, gradually morphing into a network of autonomous city-states that give iconographic form to political propositions that Bookchin began formulating back in 1963:

The absolute negation of the state is anarchism - a situation in which men liberate not only history, but all the immediate circumstances of their everyday lives. The absolute negation of the city is community - a community in which the social environment is decentralized into rounded, ecologically balanced communes. The absolute negation of bureaucracy is immediate as distinguished from mediated relations - a situation in which representation is replaced by face-to-face relations in a general assembly of free individuals. The absolute negation of the centralized 
economy is regional ecotechnology - a situation in which the instruments of production are molded to the resources of an ecosystem. The absolute negation of the patriarchal family is liberated sexuality - in which all forms of sexual regulation are transcended by the spontaneous, untrammeled expression of eroticism among equals. The absolute negation of the marketplace is communism - in which collective abundance and cooperation transform labor into play and need into desire. ("Post-Scarcity" 63)

These incantatory lines could well have been uttered by Robinson's Arkady, or indeed any of the other characters that take up his cause in the wake of his death during the first of Mars' revolutions. Bookchin, of course, was more than capable of fleshing out his vision on his own terms, grounding his high rhetoric in a compelling-reasoned account of why "ecologically oriented municipalities" might represent the most promising institutional vehicle for a politics of emancipation:

If we are to remove this fixation on domination that first appeared with the emergence of hierarchy, particularly with the domination of women by men, we are in dire need of local communities, technologies, and a political culture that will bring people into a face-to-face relationship with their natural habitat and the communities around them... Indeed, like the political culture that is meant to bring citizens into a participatory relationship with each other, we can expect that such ecologically oriented municipalities will see themselves as integral parts of the natural world and technology as a way of fostering natural fecundity rather than exploiting or vitiating it. (“Urbanization” 266)

As we know, Robinson is well-aware of how steep the impediments are to the mere imagination, must less realization, of these kinds of political prospects. And in accounting for the path that he picks through that endless series of cultural prohibitions that prevent us from even imagining such scenes, much less according them credence, I 
want now to return to the first occasion where we see Arkady pushing the political envelope, to make this pivotal movement the object of more focused attention.

The event in question occurs onboard the Ares, deep into the crew's voyage from Earth to Mars. It is triggered by a moment of acute tension, as a solar flare bombards the ship with potentially life-threating levels of radiation. Picture the atmosphere of mute dread, as Arkady turns to the ship's terminal to broadcast the third movement of Beethoven's Pastoral Symphony, using the music to dramatize the elemental forces that were then lashing the ship in silence:

He turned up the volume, and they floated together in the long half-cylinder ... a shiver ran down Maya's spine. She had never listened to the old warhorse this closely before, and she looked with admiration (and a bit of fear) at Arkady, who was beaming ecstatically at the effects of his inspired disk jockeying, and dancing like some red knot of fluff in the wind. When the symphony's storm peaked, it was difficult to believe that the radiation count wasn't rising; and when the musical storm abated, it seemed like theirs should be over too. Thunder muttered, the last gusts whistled through. The French horn sang its serene all-clear. ("Red" 58)

It is from the heart of this "tempest," and in the face of this first "dance" with death, that Arkady issues the challenge on which the rest of the trilogy's action hinges. As the "storm" passes, the group begins to relax, and tension gives way to a hubbub of intense conversation:

After a half hour or more, one of those conversations got louder. Maya didn't hear how it began, but suddenly Arkady said, very loudly and in English, "I don't think we should pay any attention to plans made for us back on Earth!" Other conversations went silent, and people turned to look at him ..."I think we should make new plans," he said. "I think we should be making them now. Everything 
should be redesigned from the beginning, with our own thinking expressed. It should extend everywhere, even to the first shelters we build." (58)

In a pattern that will be repeated frequently in the novels, Arkady challenges his cohort to evict the policeman from their heads, to begin shaping their world in accord with their own deepest political convictions:

"Why bother?" Maya asked, annoyed at his grandstanding. "They're good designs." ... "Buildings are the template of a society ... rooms imply the social organization inside them." Arkady looked around, pulling people into the discussion with his gaze... "Buildings express values, they have a sort of grammar, and rooms are the sentences. I don't want people in Washington or Moscow saying how I should live my life, I've had enough of that." (59) Arkady's claims, here, reiterate Foucault's contention that "the fundamental codes of a culture - those governing its language, its schemas of perception, its exchanges, its techniques, its values, the hierarchy of its practices - establish for every man, from the very first, the empirical orders with which he will be dealing and within which he will be at home" ("Order" xxiii). And the defining pressure that Arkady exerts in the early stages of the trilogy, is to insist that the group has been given the occasion to re-found "the space of knowledge," anew, to struggle, together, over the politics that they articulate in their first architectural "statements."

But to get to the stage where these proposals are taken seriously, Arkady must first make the case for political partisanship in an institutional setting that is notoriously, and performatively, apolitical in character. In the early stages of Red Mars, Robinson thus begins negotiating the question of how politicization unfolds in a scientific and technical milieu where a premium has long been placed on "appear[ing] cool, distant, 
indifferent, and disinterested" (Latour, "Gaia" 30). As Latour notes, these affective dispositions are rooted in "the impossibly inflated demands" of a positivistic epistemology that requires the scientist to act as if "disembodied and located nowhere," as if beyond the provincial concerns of interest parties (30). This performative projection of "rational detachment" is meant to serve as a coded testament to "the quality, the objectivity, or the solidity of the scientific disciplines," and as a bulwark against the ideological distortion of research (33). Yet as Arkady insists, these particular modes of intellectual deportment also exert a stifling effect on the political imagination, disguising the extent to which the activities of technical laboratories are always-already political in character.

In glossing Arkady's position, Wark stresses that his fundamental contention is that "ignoring politics is like saying you don't want to deal with complex systems" (178). Wark then cites Arkady's complaint that devotion to the fact-value distinction has bought many in the group to a pass where they "can accept transforming the entire physical reality of this planet, without doing a single thing to change ourselves or the way we live" ("Red" 89). There are key respects in which we can see this dynamic anticipating the painful political rifts that have begun to open up, today, between Earth Systems scientists and their old patrons in government and industry. For having identified that we are indeed "transforming the entire physical reality" of the planet we inhabit, and having established that little progress is being made in "chang[ing] ourselves or the way we live," the old prohibitions against political partisanship are giving way under the pressure: 
What probably appears to most people, scientists included, as a catastrophe - the fact that researchers are now engaged in geopolitics - is what I take as the only tiny source of hope arriving to enlighten us in the current situation. Finally we know what we are facing and with whom we are going to have to face up to it. (Latour, "Gaia" 253)

Seen in this light, there is an eerie prescience to Robinson's speculations concerning a world in which scientists and engineers begin to see that, far from value-natural, their work finds its fullest realization in the value-laden condemnation of business-as-usual, in the summons "to assemble another political body and to live in a coherent cosmos composed in a different way" (Latour, 32).

Yet, with regard to the politics of Robinson's novels, it is telling that Arkady does not succeed in winning all of the "First Hundred" over to his particular vision of the terraforming program. This decision on Robinson's part, this elevation of multipolar political struggle over Marxist-Leninist vanguardism, indicates, I think, an overarching commitment to what Jacques Rancière describes as a politics of "dissensus.” Rancière frames his influential definition of dissensus by way of contrast to a dominant politics of “consensus." Here, in the context of prevailing discursive regimes, political action is seen as legitimate only in so far as it abides by established institutional norms and protocols. Characterizing such approaches as entailing "the reduction of politics to the police," Rancière locates the wellsprings of emancipatory politics in those kinetic moments of antiestablishment "impropriety" that see new and disconcerting claims erupting into the "field of visibility," disturbing the smooth functioning of the party machine (42):

The police says that there is nothing to see on a road, that there is nothing to do but move along. It asserts that the space of circulating is nothing other than the 
space of circulation. Politics, in contrast, consists in transforming this space of 'moving-along' into a space for the appearance of a subject: i.e., the people, the workers, the citizens: It consists in refiguring the space, of what there is to do there, what is to be seen or named therein. (37)

In the debate that unfolds between Arkady and Maya, we see the former acting in precisely this fashion, "staging scenes of dissensus" that are designed to open up what Rancière describes as an "interval for political subjectivation" (69). In his resistance to acting as an obedient functionary of centralized bureaucratic authority, Arkady begins to bring the business of "moving along" into question; and, via the use of a persistent and mischievous obstinacy, he helps to catalyze a collective "refiguring" of the frames of reference in which the group conceive their mission.

It is suggestive that this first episode of dissensus takes place aboard a "ship." For as Foucault concludes his statement on heterotopias he offers an oblique commentary on the Stalinist state, positioning the ship as the antithesis of a totalitarian order in which "espionage [has] take[n] the place of adventure, and the police ... the place of pirates" (27). Celebrating the ship as the heterotopia "par excellence," he proposes that in "civilizations without boats, dreams dry up," and insists that from the sixteenth century onward, the ship itself has served as "the greatest reserve of the imagination" (27):

[I] $\mathrm{f}$ we think, after all, that the boat is a floating piece of space, a place without a place, that exists by itself, that is closed in on itself and at the same time is given over to the infinity of the sea and that, from port to port, from tack to tack, from brothel to brothel, it goes as far as the colonies in search of the most precious treasures they conceal in their gardens, you will understand why the boat has not only been for our civilization, from the sixteenth century until the present, the 
great instrument of economic development (I have not been speaking of that today), but has been simultaneously the greatest reserve of the imagination. (27) In the context of our concern with Robinson's fiction, it is hard not to see the outline of the Ares sketched out in the shape of a vessel both "closed in on itself" and "given over" to a passage through "infinity." Indeed, it seems quite clear that Robinson draws on the liminal, threshold-broaching capacities of "the ship" to help him conceptualize the transition over a political event horizon, into a "no-place" where it becomes possible to loosen the grip of business-as-usual. Like Foucault, Robinson thus seems drawn to the ship as a site of political promise, precisely because it offers passage to places "beyond the reach" of police.

Yet there are also disquieting undercurrents at stake in Foucault's concluding statement, undercurrents that are not fully addressed in his brief reference to the ship as a "great instrument of economic development." For in the wake of decades of postcolonial scholarship, it is impossible not to see the figure of the Middle Passage struggling for recognition between the lines of Foucault's brothel-hopping picaresque. And this line of critique has ramifications for Robinson's political thought experiments as well. For although Robinson's Martian colonists lay claim to a genuine terra nullius, he is still open to charges that his narrative undertakes a romantic revalorization, or retroactive purification, of settler colonial experience.

Robinson is, however, self-reflexive around these questions. Indeed, as Elizabeth Leane suggests, the trilogy is constantly worrying over how to "escape" the "inertia of history," when part of what must be "both escap[ed] and repeat[ed]" is "the colonialist impulse itself" (90). Noting that colonialism and the sciences have long been "fellow- 
travelers," and citing Paolo Palladino and Michael Worboys' observation that "for most of humanity the history of science and imperialism is the history of science" itself, Leane sees the novels conducting a complex and dialogic exploration of the historical and conceptual imbrication of the sciences and colonialism (102). Pointing to the conventional scientific tropes of "seek[ing] new vistas, explor[ing] new fields, go[ing] where no one has gone before" as cases in point, Leane insists that the Mars Trilogy conducts an auto-critique, such that Robinson's narrative is constantly attempting to make "the politicized ...nature of science apparent" (89). Seen from Leane's vantage, there is a sense in which the incident aboard the Ares could be said to turn the literal and figurative dimensions of Foucault's image against each other - as the ship's capacity to stimulate mutinous "reserves of imagination" compels the colonists to begin reckoning with the implications of acting as passive "instruments of economic development."

One of the key paradoxes at the heart of the novels is thus that Robinson tries to use his colonization narrative to begin tackling the question of what decolonizing the sciences might entail. How well he succeeds on this score is up for debate. Postcolonial theorist Lorenzo Veracini takes issue with the trilogy, arguing that that opening pages of Red Mars reproduce a "typically settler colonial scene," one where, true to form, the "settler constitution of space" is seen to unfold "in a void" (146):

Mars was empty before we came. That's not to say that nothing had ever happened. The planet had accreted, melted, roiled and cooled, leaving a surface scarred by enormous geological features: craters, canyons, volcanoes. But all of that happened in mineral unconsciousness, and unobserved. There were no witnesses - except for us, looking from the planet next door, and that only in the 
last moment of its long history. We are all the consciousness that Mars has ever had. (2)

Leane, in contrast, highlights the complex mesh of dialogue and dialectics that develops over the entire course of the narrative. Here, the repercussions of Arkady's provocations continue to reverberate long after the Ares touches down on Mars, echoing through a network of Martian settlements, whose residents never cease arguing over the politics that they articulate in their infrastructures. Deep into the terraforming process, and long after life has begun to flourish on the planet, questions of colonialism and selfdetermination are never far from the surface:

These arguments are multifaceted: are humans justified in colonizing Mars, in terraforming its surface? Should Mars, once established, become independent from Earth? How might Mars interact with an Earth that has become a neocolonial, late-capitalist nightmare, with metanational companies acquiring "flags of convenience" by buying up their foreign debt? The whole trilogy can, from one perspective, be seen as an attempt to theorize, or, more accurately, to narrativize, a postcolonial dystopia on Earth, and a postcolonial utopia on Mars; its central problematic is whether the two can exist simultaneously and interdependently. (86-87)

Fleshing out Leane's point a little further, we should also repeat that at the heart of what distinguishes Robinson's Martian "utopia" from the "late-capitalist nightmare" of life on Earth, is precisely the fact that his "Martians" succeed in divorcing their economic system from the structuring logic of private property. Indeed, the strongest case that can be made on behalf of Robinson's understanding of the relationship of colonialism and the sciences, is that he insists on an essential point when stressing that the latter will remain 
in the grip of the colonial impulse for so long as their development is dictated and bankrolled by the strategic interests of monopoly capital and the extractive industries.

According to this line of argument, we might best conceptualize the settler colonial state as an especially violent expression of the general logic of private property. Seen thus, postcolonial struggle and the anarcho-communist critique of private property find deepest common cause in their mutual opposition to the practices of enclosure and appropriation that have characterized the capitalist mode of production since its inception. From Robinson's vantage, however, the sciences are not only instruments of this process of primitive accumulation, they are also the sites of what Isabelle Stengers refers to as a "parasitic" occupation:

In The Invention of Modern Science I wrote of the connivance of the so-called modern sciences with the dynamics of redefinition that singularize this delocalized, rhizomatic power known as capitalism. We can see the genial hand of capitalism in this complicity, the source of its most formidable singularity: its parasitic nature. While capitalism has destroyed many practices, it also has the ability not to destroy those it feeds on but to redefine them. So-called modern practices are affected by this parasitism, which gives them an identity that weakens any ability to resist their subjugation, pits them against one another, and leads them to condone the destruction of practices whose time has come. (“Cosmopolitics I" 9)

Robinson draws on the same kind of theoretical currents as he attempts to conceptualize the extrication of the sciences from the grip of capital. For Leane, this facet of the trilogy's politics becomes most apparent in the narrative arc of Sax Russel, who, at the outset of the novels, acts as the very image of Latour's detached, disembodied mind. As the trilogy unfolds, however, Sax undergoes what Leane describes as a "conversion" 
process, in which he learns to discover the guiding hand of competing capitals, at work within the confines of the scientific conferences that he had once regarded as a heterotopian retreat from the contradictions and compromises of everyday life:

A scientific conference, for Sax, is like "a world outside time and space, in the imaginary space of pure science, surely one of the greatest achievements of the human spirit - a kind of Utopian community, cosy and bright and protected. For Sax, a scientific conference was utopia." To Sax's horror, however, as the conference wears on, "science began to drift into politics," with the employees of various transnational projects each advocating a position indirectly supporting the relevant project. He is pained to see "science twisted so blatantly." It is a reasonably short step for him to see that science, like the Martian landscape, is always-already "corrupted" by human politics. (98)

The dynamics that Sax contemplates, here, mirror those that Stengers discuses in the opening pages of Cosmopolitics I, as she reflects on the rise of a "big science" in which leading scientists are increasingly drafted into the role of competing project managers. Stengers admits that there is perhaps some grim satisfaction to be derived from the prospect of a "plausible future" in which scientists were compelled to act "as more or less competent employees," who can no longer be differentiated "from anyone else who sells their labor power" (10). For in so far as the sciences have played a critical role in "condoning" and facilitating the "destruction of practices whose time has come," there is a certain poetic justice in their increasingly intense subordination to Tayloristic modes of managerial discipline (9). All the same, Stengers invites us to resist "a future that derives its plausibility from our powerlessness" ("Cosmopolitics II" 407), to bet "on the possibility of different dreams" (“Cosmopolitics I" 10). 
In rejecting an accelerationist logic that would council us that there is "no way out but through," Stengers instead insists that climate change and other "ecological disasters" have given the lie to the old "motto" that "progress will repair the collateral damage that progress has occasioned" ("Another" 100). In place of the cruel optimism purveyed by proponents of accelerationism, Stengers calls for the institution of a "slow science," one rendered vulnerable, and answerable, to the claims of "dissenting voices" (100):

But slow science is not about scientists taking full account of the messy complications of the world. It is about them facing up to the challenge of developing a collective awareness of the particularity and selective character of their own thought-style. This, however, should not be confused with a call for lucid reflexivity to be developed inside thought collectives. It is rather a matter of collective learning through the test of an encounter with dissenting voices around issues of common interest. (100)

The encounter that Stengers anticipates here echoes the one that Robinson's Arkady catalyzes on board the Ares, as his "dissenting voice" works to denaturalize and problematize the value-neutral "thought-style" of his peers. Indeed, in making this argument, Stengers relies on the same kind of political instincts that guided Rancière as he formulated his theory of dissensus. Yet in the cases of Stengers and Robinson, the dissent-catalyzed "refiguring" of political space consistently takes place in relation to the site of the laboratory, and thus to interrelated questions of knowledge, innovation, ecology, and infrastructure.

In pursuing this line of argument further, Stengers makes a critical distinction between the work of "scientific" and "technical" laboratories. Rejecting the portmanteau term "technoscience" - in order to better "resist the effects of fascination associated with 
discourse about the inexorable technoscientific redefinition of the world" ("Cosmopolitics II" 340) - Stengers drives a wedge between the "modern technical laboratory" and the "scientific" laboratory, stressing that rather than providing "reliable witnesses" the former is solely committed to the "produc[tion of] something new" (342). In Stengers' mind, this is a critical distinction, as the "new" artifacts - the "innovations" - produced by technical laboratories, bring with them the capacity to establish new networks and means of association, to populate the world with a profusion of devices and black-boxes that are capable of radically restructuring the way in which prevailing political and ecological regimes function. Following Latour, Stengers thus categorizes the products of the technical laboratory as "hybrid" forms that resist being slotted neatly into "natural" or "social" categories. Indeed, for Stengers, to understand the nature of these artifacts, and their multivalent effects, it becomes necessary to reject the either-or logic of the nature-culture distinction altogether. Construing matters in this fashion, Stengers makes the proposal that technical laboratories "expresses a major political problem" (346), for once divorced from the homogenizing concept of technoscience, it becomes possible to home in on the site of the technical laboratory, to make it the object of political claims:

Unlike practices organized around the requirement of proof, technical practices do not, as such, contravene the obligations of democracy, and the possibility even exists of a convergence between these obligations and the requirements imposed on invention. The modern technical laboratory, if it is actively stripped of the rhetorical resources of modernity, communicates directly with a cultural-socialpolitical question. How can those who are affected by what is being produced be 'invited' to participate in its production? How can they become concerned parties, multiplying questions, objections, and requirements? (346) 
Here, stripping the technical laboratory of the "rhetorical resources of modernity" entails insisting on a working distinction between knowledge and techne, one that does not allow the technical laboratory to appropriate to itself the prestige of the value-natural objectivity that is, in Stengers terms, more properly assigned to those laboratories that subject themselves to the "requirement of proof." Stengers knows, of course, that the progress of scientific and technical research actually evolves in tandem, by way of unpredictable and ongoing exchanges between the diverse "ecology of practices" that constitute scientific and technical research on a procedural plane. Yet she still stresses that in contrast to the "factishes" produced in scientific research laboratories - which have, in Latour's terms, "gain[ed] a complete autonomy from any sort of production" ("Pandora" 127) - the artifacts produced in technical laboratories are specifically designed to cater to the strategic objectives of the corporations that fund their production. Rather than understand the world, technical laboratories aim to change it. And the corporate strategies that structure these efforts at "change" and "innovation" are all too often leached from the picture by a concept of technoscience that frames currentlyexisting technologies as the value-neutral expression of objective knowledge. What this means, for Stengers, and for Robinson's Arkady, is that the technical laboratory represents an exemplary site at which to direct political claims, and at which to begin new forms of "political experimentation."

\section{“MOULDING” THE CITY TO THE RESOURCES OF AN ECOSYSTEM}

Stengers positions her most recent iterations of this argument as an effort to subject science and engineering projects to the test of "general interest." She understands this as 
a speculative political project that would ultimately entail "get[ting] rid of the idea that there is a single right answer" to any of the technical and political problems that assail us, and instead proposes that we must "put what are often difficult choices on the table," subjecting technical research and infrastructural projects to "a process" of sustained and "attentive" collective "scrutiny" ("Another" 3-5):

How can those who are affected by what is being produced [in the modern technical laboratory] be "invited" to participate in its production? How can they become concerned parties, multiplying questions, objections, and requirements? ... The multiplicity of practices that gather around issues and must invent their interrelations, implies an obligation to actively resist the hierarchy of knowledge, to make an active distinction between scientific and technical inventions, to engage in a deliberate process of clarifying the requirements and obligations of every practice. It essentially implies the creation of new types of practices, of "interest" groups capable of promoting ignored dimensions of issues and situations. ("Cosmopolitics II" 346-9)

In advancing this argument, she has highlighted the French experiment with "citizen juries" as prefiguring one possible approach. Brainchild of the German sociologist Peter Dienel, the first citizen juries were convened in the early 1970s, in an effort to provide local residents more say in determining the structure and goals of urban development initiatives. Dissatisfied with methods of consultation that revolved around the "public meeting," Dienel sought to develop a more rigorous process, one that composed juries to reflect the demographic composition of the site in question, that briefed jurors on the background to different proposals, before subjecting developers and politicians to grueling rounds of questioning, which were led by the jurors themselves. In recent years the French Sciences Citoyennes association has had some success with extending the 
reach of citizen juries to address the work of technical laboratories. Inroads began in the health sciences, around politically controversial issues such GMOs and bioengineering. And latching on to this national initiative, Stengers has begun toying with the idea that the citizen jury might serve as a first point of leverage for a much larger political project - one that would ultimately entail developing a broad-based culture of reception and debate, in which informed criticism and sustained collective attention played as active a role in shaping the development of science and engineering as it currently does in the fields of cultural production or party politics.

Yet in view of the systemic tendencies that I have attempted to map out in this dissertation, I suggest that the widespread policy-initiated rollout of "city labs" might actually provide Stenger's political proposals a more viable set of institutional entry points that the citizen jury. For while a public or common stake in the commerciallyowned technical laboratory has proved difficult to define and leverage in practice - a consequence, one suspects, of the enduringly effective bourgeois distinction between public and private spheres - no such ambiguities can prevail indefinitely in the case of labs that claim to take the structure of our cities as the object of their experimental practice. The changes will be too palpable, and the interested parties too numerous, and too close to hand.

And, indeed, this has already become abundantly clear in the current fate of Google's increasingly-troubled Sidewalk Labs development in the Toronto Quaysides. Rolled out to great fanfare in 2017, and boosted by the public support of Prime Minster Justin Trudeau - who instructed Canadians that Sidewalk Labs would "help us build smarter, greener, more inclusive cities," acting as a "testbed" that would "hopefully" be 
scaled up across Canada and other parts of the world (Crane) - the project has since been snarled up in a satisfyingly-complex mire of public relations gaffes, high-profile resignations, and damaging leaks.

In reviewing the original pitch for the 12-acre Quayside site, it is clear that the Sidewalk team had been busy boning up on au courant social innovation terminology. Construed as a public-private partnership between Alphabet's "urban innovation" wing and the three levels of government, Sidewalk Toronto was initially framed as a relatively small-scale experiment in urban renewal and sustainable development, one that would bring Alphabet's extensive technological and financial resources to bear on "prototyping" design solutions for a paradigmatic set of social, environmental, and political concerns. Among the many social and environmental issues that this "smart city" experiment claimed to address, were the provision of affordable housing, the prototyping of "sustainable" transit and waste disposal systems, and the construction of energy efficient, low-waste infrastructure.

Visualizations of the proposed housing and business complex accordingly foreground splashy architectural experiments in tall timber construction, and highlight the project's projected "impact" on "quality of life" and economic dynamism (Figure 4): 

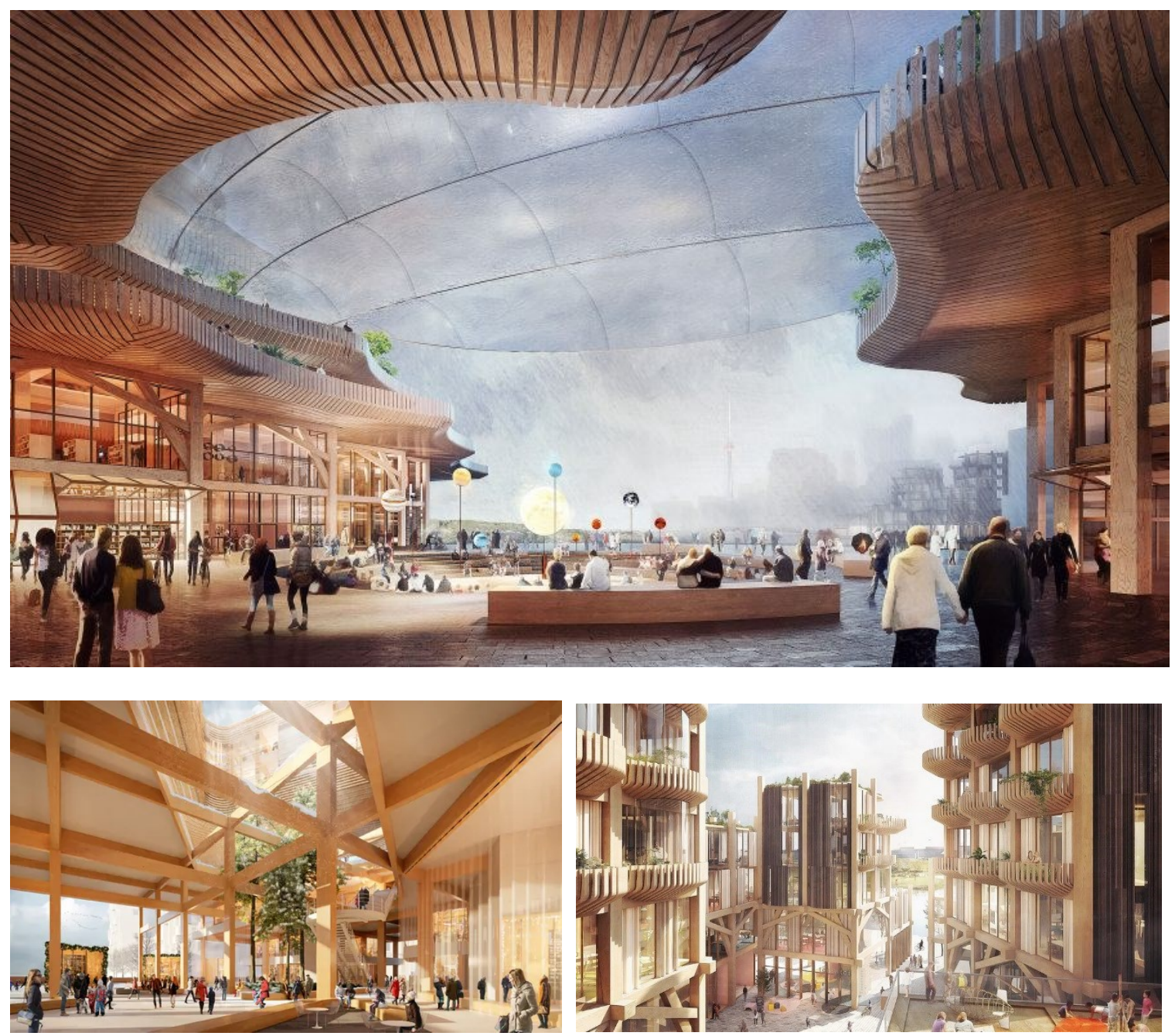

Figure 4. "Renderings of the Quayside neighborhood development in Toronto." Rendering. Heatherwick Studio. 15 February 2019.

The images portend a liberal utopia defined by multicultural inclusivity, climate resilient "urban innovation," and a flourishing local economy that has leveraged the internet of things to produce "smarter" and more "resilient" cities.

Yet as residents, councillors, and media outlets began peeling back the surface veneer, the Quayside development has been exposed as the first phase of a brazen, multistage, land and data grab. Tensions first began surfacing around the issue of 
"privacy" as executive director of the Canadian Civil Liberties Association (CCLA), Michael Bryant, characterized the project as a "constitution-free zone":

We are getting closer and closer to Sidewalk Toronto being in a position where they are going to start building a part of the city that amounts to a constitutionfree zone, where they are able to invade people's privacy and collect information about them in circumstances where normally you would need a warrant to get that stuff. (Draaisma)

Riddled with cameras and data sensors there were said to monitor everything from energy expenditures, to environmental conditions, utilities use, and traffic and pedestrian flows, the development appeared to its critics as a new stage in the ongoing development of "surveillance capitalism." There could be no question that the residents of this self-styled "living laboratory" were set to serve as guinea pigs in a data-farm that would capitalize on every moment of their waking existence. Former Ontario privacy commissioner, Ann Cavoukian, had initially served as an adviser on the project, but would soon resign from her position, warning that Sidewalk's data-gathering protocols were honeycombed with the same kind of loopholes that had seen Cambridge Analytica game the Brexit vote with microtargeted propaganda campaigns. After extensive back and forth with Sidewalk executives, Cavoukian had concluded that there were no measures in place to strip collected data of personal identifiers (CBC, "Not good enough"). Sidewalk Labs claimed to be voluntarily committed to doing so itself, but it made no guarantees that the sites' commercial and government partners would do the same. This would leave the residents of the complex especially vulnerable to data breaches, state surveillance, and microtargeted misinformation campaigns. For privacy watchdogs, these were especially troubling developments, given the Trudeau government's stated support for "scaling up" 
the Sidewalk model, and applying it across Canada. Tensions thus began breaking out on every front. A series of high-profile partners resigned from the project, even as pushback began mounting on a grassroots level.

Indeed, Sidewalk Labs has proved consistently clumsy in its efforts at circumnavigating the consultation process. It seems relatively clear that executives went into the project believing that a combination of large-scale investment, evocative design, high minded jargon, and federal government support would suffice to render the city a pliant vessel for Alphabet's long-term “diversification” strategies. Yet early meetings with local residents are said to have soured as quickly as relations with partners and consultants:

People were asking Sidewalk Labs' Toronto employees how the development was being funded and what the business model looked like, but the American executive was unable to provide details, not even a map of the entire project for public consumption. "We didn't really know how the company works," the source said. Employees were instructed to answer seemingly difficult questions by saying "it's way above my pay grade." "There was a lot of tension.” (Syed)

The pattern of obfuscation and deflection was clearly, and crudely, endemic. Yet the full scale of Sidewalk's designs on Toronto would only become apparent in the summer of 2019, following a leak of internal documents to The Toronto Star. In a series of twenty slides - titled "A Plan at Two Scales," and marked as "proprietary and confidential" (Syed) - the Sidewalk team outlined a second phase of development. Here, it transpired that the 12-acre Quayside development was merely the first gambit in Sidewalk's longerterm play for a far larger prize, a full 350-acres of the Port Lands area, eighty percent of which was currently owned by the City of Toronto. In exchange for bankrolling the 
construction of a light rail system, Sidewalk Labs intended to petition the City of Toronto for a cut of the $\$ 6$ billion in revenue that the area was projected to generate over the next thirty years. Targeting the "incremental revenues" that the City was set to glean from the developed land, Sidewalk offered access to Alphabet's immense cash reserves in exchange for an ongoing share in property taxes, development fees, and spiking land values. Grilled about the plan in an interview with CBC's Matt Galloway, Sidewalk CEO Dan Doctoroff argued that it would unfold to the mutual benefit of company and city, as Alphabet's reserves of "very patient capital" were mobilized to construct infrastructures that municipal, provincial, and federal governments were clearly too cash-strapped to fund themselves:

We are simply saying, because our parent has very patient capital, we can actually put out the money to extend the LRT, and wait to get paid back until there is actually development in the area that would not have been created but for the investment in infrastructure. (Doctoroff)

Positioning the proposal as a fair-minded instantiation of enlightened self-interest, Doctoroff responded to criticism by insisting that the idea was merely "a concept," and went on to suggest that it was "obvious" that "[i]f we actually play a role in financing something that otherwise isn't going to get done, we ... have to get paid back." Seen through the lens of an abstract and market-friendly liberalism, the proposal of course makes a certain amount of sense. But if we begin to pull back and historicize Doctoroff's claim, we see that it provides some alarming insight into the power that major tech monopolies are now attempting to wield over metropolitan centers. Not content with routinely conducting the widespread and extensive forms of tax evasion that Nick Srnicek has shown to be an intrinsic feature of the "platform capitalism" model, tech giants are 
now intending to use their vast, and largely untaxed, cash reverses (Alphabet's are currently listed at $\$ 115$ billion (Jiang)) to siphon off tax revenues and public funds for themselves. Indeed, the use of the disquieting term "very patient capital" is indicative of the extent to which the vast financial resources of the major tech companies leave them in the position to play the long game, delivering "instant infrastructure" in exchange for a creeping appropriation of public funds, and public lands, and an increasingly dominant say in how the city itself evolves as a material, political, and social form:

Sidewalk Labs self-designates itself as "Innovation Manager" in the presentation, allowing it to "set design and innovation guidelines for vertical and horizontal development, including a radical rezoning of the entirety of the area needed to achieve our economics (100\% increase in density compared to City's current plan)." (Syed)

Sidewalk's “Plan at Two Scales" thus appears to invert Stenger's proposal that major scientific and engineering plans should be subject to the test of general interest. Here the "Innovation Manger" subjects zoning laws, city policy, and infrastructural development to the test of private interest. That being said, it has been somewhat encouraging to see that the municipal environment has thus far proven harder to navigate, and dominate, than Sidewalk executives evidently anticipated at the outset. And in tandem with the recent failure of Amazon's effort at establishing a regional headquarters in NYC - the result of a successful grassroots campaign - we are perhaps given some initial reason to believe that Bookchin may have been right to construe municipal politics as a promising terrain on which to contest the dominance of business-as-usual, and on which to begin the construction of "counterpowers" and "counterinstitutions": 
$[I] t$ is only on the local level ... that a new politics can be developed... Here, in municipalities, where people live out their lives in the most immediate and personal sense, we find the locus of real popular power... I have drawn a sharp distinction between politics and statecraft. Suffice it to say that politics, in my view, [entails] the recovery of ... a local public sphere - the municipality - [that stands] in contrast to the statecraft of the nation state which we have so mistakenly designated as 'politics.'... Impure as they may be [municipalities] ... can be reclaimed as a new political sphere by an active citizenry in popular assemblies ... and ultimately developed into a counterpower with counterinstitutions that stand opposed to those of the nation-state. ("PostScarcity" 51)

Elements of this vision, of this tension between national statecraft and municipal politics, surface in the events that have begun to unfold around the Quayside development, where the cozy relationship between Sidewalk Labs and the federal government has come under increasing scrutiny. NDP Member of Parliament, Charlie Angus, has pressed the Liberal government to explain how they arrived at the deal, highlighting "the role of several ministerial staffers who have gone on to work directly for Sidewalk Labs" (qtd in Shekar). Angus' questions arrived hard on the heels of a Globe and Mail report that John Brodhead, a former chief of staff to the federal Infrastructure Minister, had since signed on at Sidewalks Labs, as Director of Policy and Strategy. During his time with the Liberal government, Brodhead played a leading role in the formation of Canada's Infrastructure Bank, and one can see why his connections within the Canadian political establishment would be of interest to Alphabet.

All the same, what is perhaps most intriguing about the controversial, and somewhat precarious, status of the Quayside development, is the extent to which the prospect of acquiring infrastructure rents, and long-term political leverage over the course 
of urban development, has tempted this major tech company into construing the work of its laboratories in relation to the concrete infrastructural and civic concerns of municipalities. Like most of the Silicon Valley giants, Alphabet invests significant resources in the construction of a liberal brand identity that is meticulously attuned to the current tenets of progressive discourse. Yet this brand identity risks becoming harder to maintain in cases where executives are forced to defend flagrantly appropriative development schemes in the face of intense local scrutiny. On the grassroots level we have already seen the formation of a citizens-group, the \#Blocksidewalk Campaign, whose platform was recently profiled in The Toronto Star:

"What we're hoping to achieve is a reset. To put Torontonians back in the driver's seat when it comes to decisions about our city and our future, instead of the Sidewalk Toronto version where we're driven around by autonomous vehicles in a corporate research experiment," Melissa Goldstein, a community activist specializing in affordable housing and homelessness issues.... Goldstein went on to say: "We want these important decisions on the future of the city to be made through fair, democratic... accountable processes led by Torontonians... Not in secret, in back rooms, behind closed doors and without public input. We want to lead instead of being constantly misled ... Everything about this project has been overwhelmingly opaque. It's been impossible to get clear answers about even the most basic things about this project, and after 16 months of trying, I think I speak for everyone when I say that we're pretty much fed up. (Vincent)

Meanwhile, the struggle over the Quayside development has become the object of international attention, and the site of emerging rifts within global business communities. Harvard Business School Professor, Shoshana Zuboff, has warned that "[t]he front line of th[e] war between surveillance capitalism and democracy is being waged in Canada specifically, in the city of Toronto" (qtd in O'Kane). Zuboff's comments were made 
before a Canadian Grand Committee, convened to weigh in on Sidewalk Toronto. They have since been disseminated widely in the national press. And to return to Stenger's political proposals, it does thus seem that her effort at subjecting the work of technical laboratories to the test of general interest might find itself on relatively favourable footing in proximity to public-private city labs that can only justify their existence via appeal to goals that are constitutively, and conventionally, political in nature. Indeed, the Quayside development has already emerged as a site around which counterclaims and dissent have begun to amass. Perhaps the attention-focusing nature of these large-scale social lab initiatives will yet serve to provide a staging ground for a more protracted series of political struggles over the nature of urban climate change adaptation, the structural dominance of monopoly capital, and, by extension, the political uses and abuses of the technical laboratory.

With regard to the Quayside development, there are a number of ways in which public debate could be pushed beyond the customary horizons of liberal party-political discourse. Criticisms have thus far focused, overwhelmingly, on the conventional liberal flashpoints of civil liberties and taxation. But what has yet to be touched on, in any substantive fashion, is whether the development has any right to claim that it is serving as a testing bed for the development of "sustainable" urban infrastructure. This is no peripheral question. When the waterfront site was first zoned for development, back in 2001, the newly-instituted tri-government agency, Waterfront Toronto, was mandated with acquiring partners who could assist the City of Toronto in piloting a comprehensive climate change mitigation and adaptation strategy. The first phase of the program entailed initiating a flood-protection plan. Planning began all the way back in 2001, but the 
project ratcheted up in the last couple of years, as Waterfront Toronto rolled out a plan to restore the Don River's wetlands and reopen the original river mouth - measures that were designed to protect the City against stormwater surges, while redressing some of the damage that decades of industrial growth have exerted over the river's native ecosystems. Work has also begun on equipping the Port Lands area with stormwater management infrastructure, while buildings on the Villers Island Site are set to be constructed using relatively low-tech energy-efficient design models such as passive housing, solar access, and district energy systems. Many of these construction techniques were already applied in Waterfront Toronto's previous development, the Corus Quay, which was constructed to meet the stringent standards of the LEED (Leadership in Energy and Environmental Design) rating system.

But how exactly do Sidewalk Lab's Quayside plans slot into this overarching scheme? Yes, they do plan to build dramatic tall timber structures, developed in accord with the LEED rating system. But the site is also meant to serve as a testing bed for an autonomous car program, and is set to be fitted with a dense mesh of smart-city tech. Both pilot schemes are currently framed as sustainability initiatives, because they are said to represent experiments in energy-efficient design. Like many large tech corporations, Alphabet uses this kind of rhetoric to fend off concerns over the ongoing expansion of its energy-hungry data-processing centers; and the company has accordingly made a show of transitioning its miles of servers to a renewable energy base. Meanwhile, Google executives consistently tout the idea that intensive data analysis will help to improve global energy efficiencies. On this point, however, it is worth repeating economist William Stanley Jevons's celebrated paradox, that "it is wholly a confusion of ideas to 
suppose that the economical use of fuel is equivalent to a diminished consumption. The very contrary is the truth" (Jevons, 123). Even as Google has used its immense financial resources to purchase huge amounts of renewably-sourced energy, the tech company's net energy consumption of course continues to rise at pace (Wang). And in light of Jevons' Paradox, it does thus seem that it is wholly a confusion of ideas to equate Sidewalk Toronto with anything resembling a pathway to sustainable models of urban subsistence. Indeed, the effort that the Quayside development makes at conflating smart city tech with sustainability sees it serving as vessel for an accelerationist, and political regressive, approach to the question of climate change mitigation and adaptation. We should also remember, that the projects that Waterfront Toronto previously initiated at the Don Rover already attempt to reconceptualize the relationship of the city and the local ecologies in a more sophisticated fashion than anything we see taking place at the Quayside development. It is precisely this Port Lands region into which Sidewalk intends to expand, as it attempts to assume the role of "Innovation Manager." If successful, this would see Alphabet in position to redirect the entire course of the Port Land development in accord with its own strategic objectives. It would be a significant loss if, in the process, these early, tentative experiments in "molding" the city "to the resources of an ecosystem" were overpowered by avatars of a platform capitalism that has learned to masquerade as a deep-pocketed green messiah, while offering precious little in the way of vision (Bookchin, "Post-Scarcity" 63).

This lack of vision is all the more glaring given that we are currently witnessing the first signs of a major sea-change in the field of architecture, developments that are extensively chronicled in urbanist Ashley Dawson's recently published Extreme Cities. 
Billed as an exploration of "the peril and promise of urban life in the age of climate change," Dawson's book can also be read as an early, and especially promising, humanistic response to the onset of social innovation lab models (i). Extreme Cities offers detailed breakdowns of a series of major architectural and engineering projects; Dawson reports on a variety of international initiatives, including the construction of an artificial barrier island off the coast of Nigeria; a vast seawall on the coast of Indonesia; and a sprawling patchwork of ambitious flood defense initiatives in the New York City region. Reversing a longstanding tendency in which "environmentally oriented architecture has mostly been applied at the level of the building rather than at the scale of the city" Dawson charts the coalescence of a new design sensibility in which "increasing awareness of Earth's fragility" is pushing architects and "urban designers" to develop "speculative design innovations" that operate on the far "larger scale of cities and even urban regions" (137). Echoing the ecologically-oriented municipalism that Bookchin began advocating over fifty years ago, urbanists and architects are now "think[ing] about environmental design in relation to the ecological life and death of contemporary cities" (137) - a trend that sees them "jump[ing] scale from isolated architectural objects such as buildings" in order to think "on far broader planes" (137):

What, after all, is the point of designing a LEED-certified green building if it's located in a flood zone? Engaged architects and urban designers have begun to take a broader, more holistic approach, viewing neighborhoods alongside surrounding cities and regions, and focusing on the far-flung infrastructure networks that bind together cities, their rural hinterlands, and global sites. As a consequence, landscape design has to a certain extent superseded traditional architecture as the fundamental way of approaching cities. Cutting-edge designers 
now tend to work in interdisciplinary teams, alongside landscape architects, engineers, biologists, and even anthropologists and sociologists. (137)

Among the most comprehensive and ambitious of the projects that Dawson chronicles in Extreme Cities, is New York's post-Hurricane Sandy architecture competition, Rebuild by Design. Set into motion in the wake of Hurricane Sandy, this marquee architecture competition was overseen by Rockefeller Foundation's Social Innovation Labs network, and partially funded by the US Department of Housing and Urban Development. Taking their cues straight from the social lab playbook, the "process began with an intensive, three-month program of field research" spearheaded by an interdisciplinary Research Advisory Board (141). Composed of experts in a range of fields, the board was charged with directing a roster of ten interdisciplinary design teams, who were sent out to scour "the Sandy-affected area," assessing the "region's vulnerabilities to future risks" (141). Summing up the comprehensive scale of this consultation phase, Dawson reports that "[i]n all, a jaw-dropping total of 535 community organizations were engaged in this field research" (141). Following this extensive research, the ten design teams then drew up plans that were tailored in response to specific vulnerability assessments; these included a ten-mile-long, fourteen-foot-high seawall that is set to skirt the southern tip of Manhattan; a landscape architecture initiative to secure the region's major food distribution hub against flooding and grid failures; and a number of relatively large-scale green corridors and marshlands restoration projects (Figure 5): 


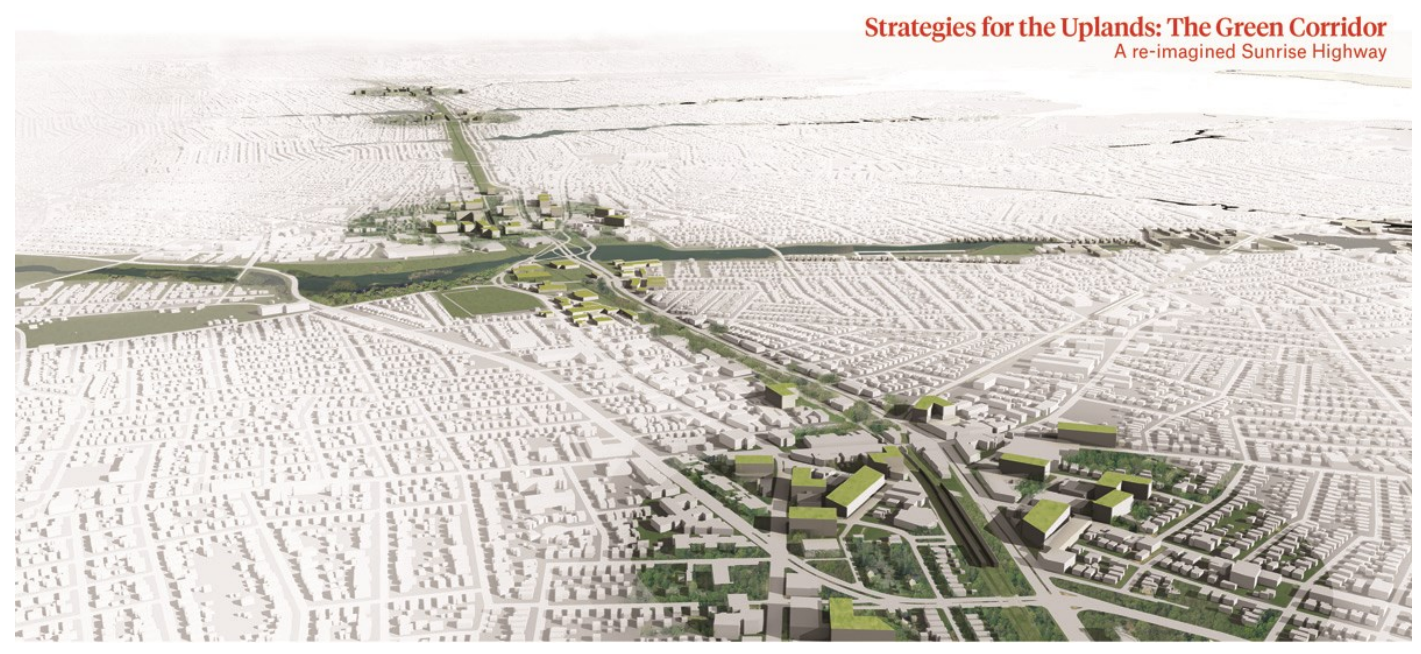

Figure 5. "Bird's-Eye View Of The Freeport Region" Rendering. Interboro Partners. From "Living with the Bay: A Comprehensive Regional Resiliency Plan for Nassau County’s South Shore”, figure in 234. 25 March 2015.

Though taking place on a grander scale than anything that is currently underway in Toronto, there are facets of the Rebuild by Design initiative that echo Waterfront Toronto's Don River program. In both cases we seem to witness a strange blurring of worlds, in which the more dimly-apprehended demands of tomorrow are refracted through a design sensibility that is still wholly continuous with the "monocultural" aesthetic of yesterday's gentrification projects (Figures 6 and 7). Indeed, reflected in the open, airy surfaces of these images, even climate change seems to be rendered "sanitary, shiny" and "safe" (Moss): 


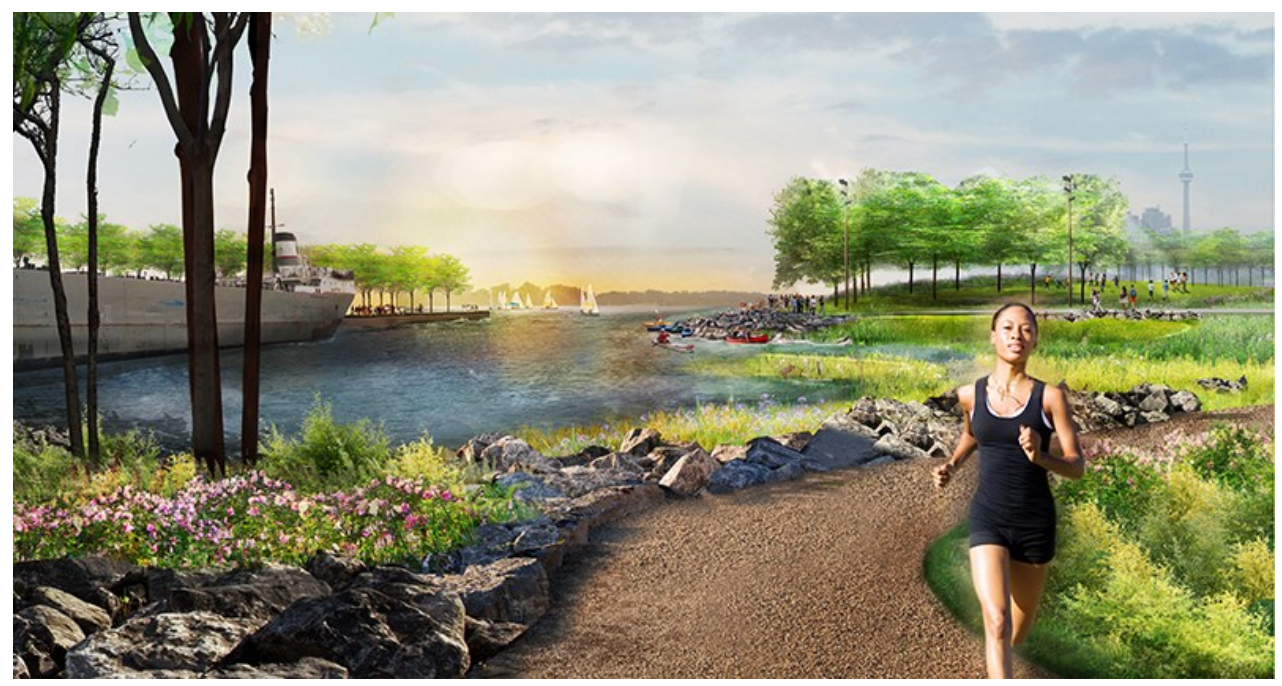

Figure 6. "Artist Rendering Looking West Across the Naturalized Mouth of the Don River in Full Vision Scenario." Rendering. Waterfront Toronto. From "Port Lands Flood Protection and Enabling Infrastructure Due Diligence Report," figure in 5. 20 October 2016.

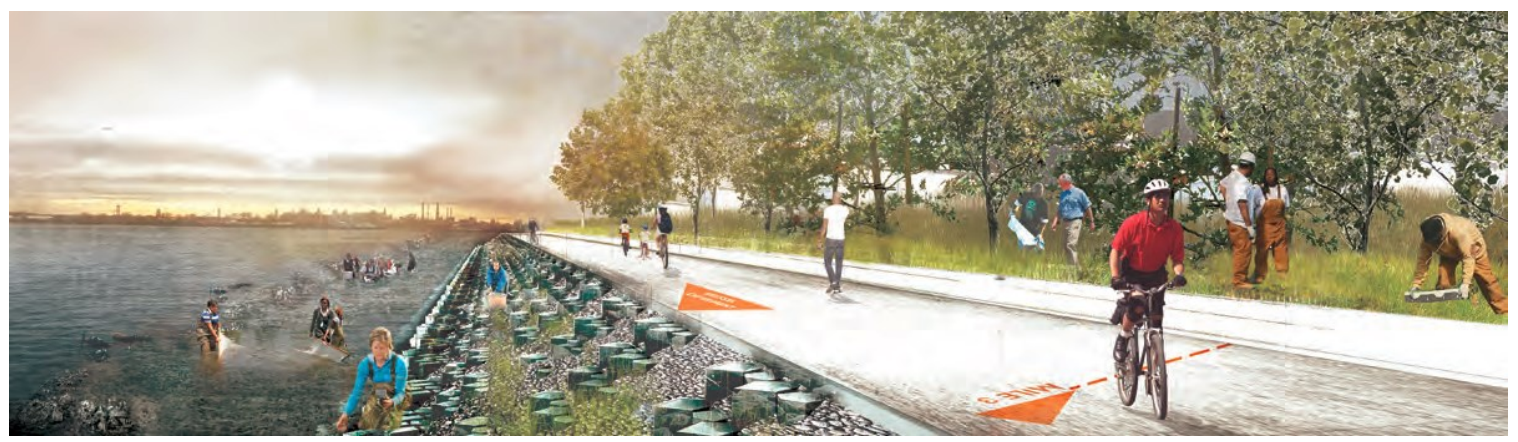

Figure 7: “Artist Rendering Hunts Point Lifelines.” Rendering. PennDesign / OLIN. Form "Rebuild by Design / Hunts Point Lifelines, figure in 1. 6 April 2014

All the same, the results of the competition have been enthusiastically received by industry tastemakers. Dawson quotes an evaluation from the influential thinktank, Urban Institute, as indicative of the project's general reception:

Rebuild by Design broke the mold of traditional design competitions with its approach to teamwork and encouragement of creativity ... Including the public in the early stages of design development and continually incorporating their feedback was vital to creating proposals that represented the needs of large groups 
of stakeholders and gathered support from a number of different sectors of society. (141)

The particular appeal of Dawson's take on the six selected projects, however, is that he looks beyond the fanfare and self-congratulation that has attended the rollout of these initiatives, to "pay just as much attention to whatever is neglected or omitted as to what is asserted" (Stengers, "Another" 8). For while he is open to the idea that "urban design innovations may offer the greatest hope in a global culture that otherwise regards climate change with dread, enervation, and despair," his analysis is generally geared toward highlighting "the enduring challenge of creating more just cities in an era of climate change" - a project that entails raising a variety of disquieting questions about the politics that are disclosed in these major engineering feats and architectural statements (139; 140). In this respect, Dawson manages to walk a fine line, highlighting limitations, complicities, and oversights, while never entirely losing sight of the kernel of utopian promise that inheres within these efforts at breaking beyond what Hassan would define as an exclusively "market-driven, planning approach" to architecture and urban planning (Hassan, 89). As he discusses, and commends, Rebuild by Design's overarching ambition, he arrives at terms of assessment that seem to recall Forrester's early experiments in Urban Dynamics:

The city is consequently regarded as a complex system where tidal currents, sewage flows, and the global circuits of container ships (to name but a few) are inextricably intertwined with the vagaries of human affairs. This holistic approach is a welcome departure from the binaries between human beings and the natural world that have dominated capitalist modernity in the past. (140) 
Among the handful of Rebuild by Design plans that Dawson reviews in depth, it is clear that he is most attracted to SCAPE Landscape Architecture's charismatic Living Breakwaters project. Designed in collaboration with experts in fields as "diverse as hydrodynamic modeling, marine biology, public education, and oyster restoration" (161), Living Breakwaters aims to reverse the damage that decades of industrial activity have exerted over the Staten Island region's biodiversity, while at the same time buffering shorelands against stormwater surges. Driven into retreat by dredging and industrial pollution, local oyster stocks have undergone precipitous decline, while the region's beaches have experienced such extensive erosion that inland areas are now known to be vulnerable to devasting floods. To counteract this process, while avoiding the pronounced risk of overtopping that comes with the installation of seawalls, SCAPE envisages the construction of a "necklace" of offshore "breakwaters" - landmasses that are specifically engineered to reduce wave action. It is, however, SCAPE's efforts at moving beyond the typical breakwater approach, that most captures Dawson's imagination; the project's " 13,000 feet of concrete and recycled glass composite barriers" are designed to serve as a habitat for oysters, and will be seeded with oyster spat following their construction (162):

As these oysters create extensive beds that grow organically, it is hoped that they will expand the size of the underwater structures, further enhancing the barriers' ability to reduce wave energy. As the SCAPE team puts it, "conceived as living systems, [these Living Breakwaters] build up biogenically in parallel with future sea level rise." In addition, as filter feeders, the oysters would sift out pollution and toxins from the water, making it a more desirable habitat for other marine animals such as crustaceans and fish. (162)

The approach, here, reflects the logic of an ecosystems services model that attempts to promote the regeneration of linchpin species, species that play critical roles in regulating 
and promoting the health of an entire ecosystem. In this case, SCAPE also intends to harness the natural properties of oyster growth to serve as biogenic feedback mechanism, such that the breakwaters will grow organically in the face of rising sea levels. Here, we see some initial evidence of an approach to landscape architecture that begins to take seriously the prospect of catabolic collapse, by piloting forms of "regional ecotechnology" that are designed to "foste[r] natural fecundity rather than exploi[t] or vitiat[e] it" (Bookchin, "Urbanization" 267). Indeed, artist renderings of the site could well have been drawn from the pages of Robinson's Blue Mars (Figure 8):

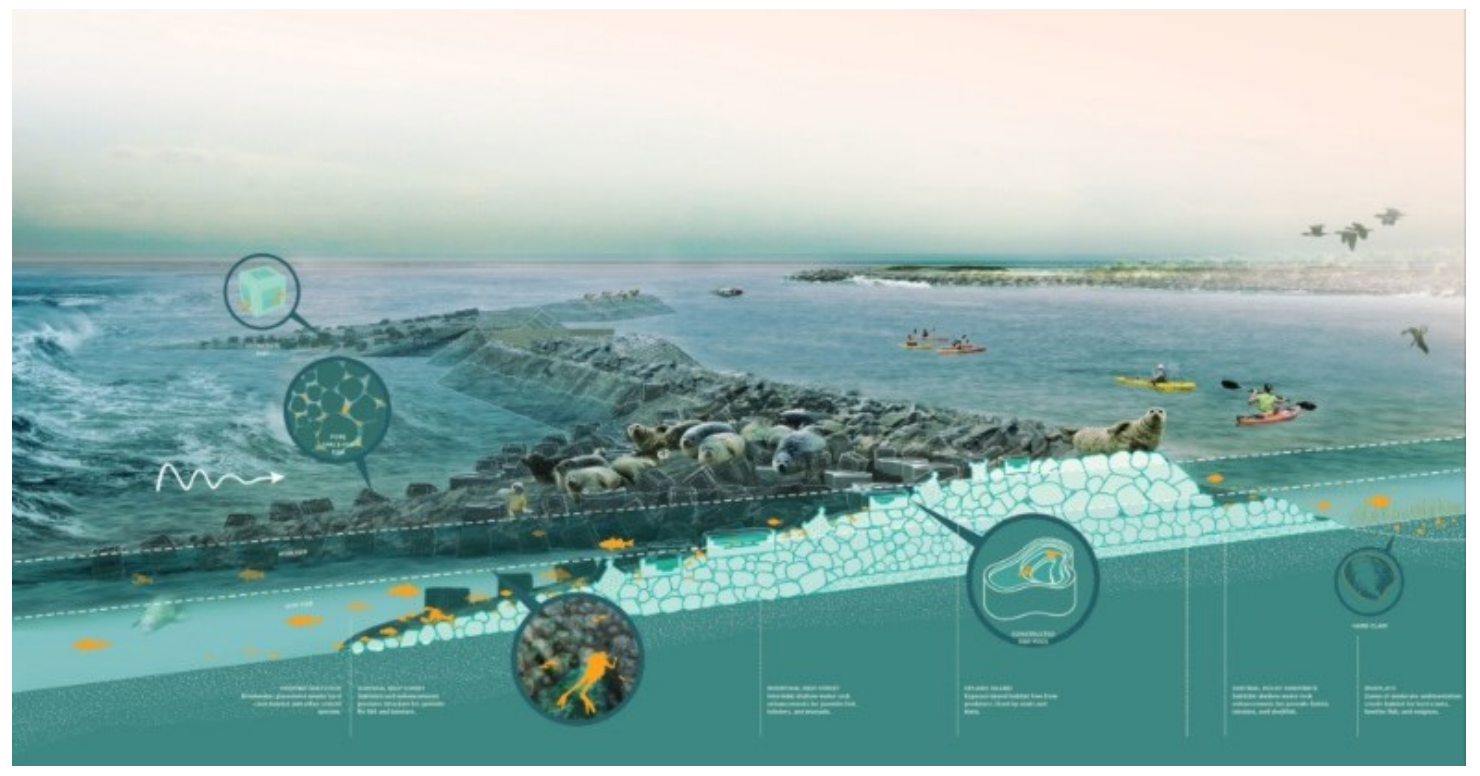

Figure 8: “Growing Ecological Resiliency.” Rendering. SCAPE / Landscape Architecture. From "Rebuild by Design / Living Breakwaters, figure in 43-45.

Yet as Dawson turns from the fine detail of Living Breakwater's plans, he begins to situate them in relation to cutting edge research in Earth System Science, reading SCAPES' vaunting ambitions against the disquieting backdrop of ocean acidification. This results in a sobering commentary on the difficulties that attend projects that attempt 
to "restore" ocean ecologies in the face of a destabilized Earth System, one that is now undergoing a new and violent redistribution of forces, cycles, and tendencies:

The developed nations are pumping so much carbon dioxide into the world's oceans, which absorb about a third of emissions each day, that they are altering the chemistry of the world's waters fundamentally. Ocean acidity is projected to increase by a factor of five by the year 2100 , according to the National Oceanic and Atmospheric Administration. The planet has not seen a transformation in the world's oceans this dramatic for 50 million years. In such acidic water, the shell of a common adult mollusk will dissolve in forty-five days.... As acidity increases, shells become thinner, growth slows down, and death rates rise. Juvenile oyster spats stand no chance in such an environment. Oyster spat use a form of calcium carbonate that dissolves particularly easily in acidic waters and are consequently especially vulnerable to this transformation of the world's oceans. But this is not just a problem for future generations. Scientists hypothesize that acidification is responsible for the crisis in the shellfish industry in the Pacific Northwest, where oyster seed production plummeted by as much as 80 percent between 2005 and 2009. (166)

Among the many things that we can learn from this reluctantly withering appraisal of Living Breakwaters' conceptual limitations, is that in so far as these early experiments in regional ecotechnology can be said to represent a departure from business-as-usual, they represent only the first hesitant sketches of "another way." But perhaps it should not surprise us that even the most promising of these initial attempts appears so dispiritingly partial. However impressive Rebuild by Design’s $\$ 920$ million budget appears on paper, in relation to the sums that the world's tech titans spend annually on inhouse R\&D - on user interfaces, surveillance, robotics, AI, and targeted advertising - the resources currently allotted to large-scale mitigation and adaptation initiatives remains paltry: 
Tech companies claimed the top five spots in the U.S. for research and development spending again last year, investing a combined total of $\$ 76$ billion. Amazon was at the top of the list, spending $\$ 22.6$ billion in 2017, 41 percent more than in 2016 (when it also topped the list). (Molla)

Though our habituation to the institution of private property accustoms us to these kinds of prospects, we should I think make some effort to pause over this disturbing dispensation of social resources and research capacities. Clearly, we are a long way from any scenario in which the work of technical laboratories was indeed subject to the test of general interest. Yet thanks to the provocations of Robinson's speculative fiction, we have at least entertained the possibility that there is a flipside to prevailing tendencies and conditions, one that concerns the political potentialities that might be unlocked, were the prototyping practices of technical laboratories guided by new lights, and subject to the influence of new systems of incentivization.

\section{CONCLUSION: LINES OF FIGHT AND FLIGHT}

We also know, however, that in order to merely conceptualize such possibilities, much less realize them, Robinson had to transport us 34 million miles away from the surface of the Earth. And looking at the political struggles that are now unfolding in Toronto, one could easily conclude that Alphabet's immense financial and technical resources will simply overpower local residents' attempts at reasserting their "right to the city" (Lefebvre). Such is the narrative that cyberpunk has been imagining for us for the better part of three decades, and the odds of success are undoubtedly narrow. Municipalities are labouring under the same conditions of secular stagnation that launched social innovation 
policymaking in the first place. Hungry for economic stimulus, and years deep into cuts and austerity, there is a real risk that municipal governments will serve as easy prey for tech monopolies that have the financial capacity to animate local economies with sudden and instantaneous infusions of "patient capital." On this score, however, we should not forget that what appears as strength in one light, appears as a frailty in another. For the "glutted" corporate accounts of the Silicon Valley giants are themselves signs of a troubled global economy, one where profitable investment has become increasingly hard to come by:

This glut of corporate savings has - both directly and indirectly - combined with a loose monetary policy to strengthen the pursuit of riskier investments for the sake of a decent return. At the other end, tax evasion is, by definition, a drain on government revenues and therefore has exacerbated austerity. The vast amount of tax money that goes missing in tax havens must be made up elsewhere. The result is further limitations on fiscal stimulus and a greater need for unorthodox monetary policies. Tax evasion, austerity, and extraordinary monetary policies are all mutually reinforcing. (Srnicek, 26)

How much faith can we continue putting in the idea that this rickety economic system is actually capable of kickstarting a new and sustained cycle of accumulation, much less an ecologically "sustainable" one? Ironic, then, that although the entrepreneurial theory of Josef Schumpeter has become the element in which late capitalist policymaking lives and breathes (with its unrelenting valorization of "innovation," "creative destruction," and “entrepreneurialism"), few of Schumpeter's acolytes repeat his predictions of capitalism's demise, much less attempt to think through the ramifications of such an event. Schumpeter himself was not so coy. For in answer to the question of whether a 
fully post-capitalist society could indeed "work," he responded in the most emphatic terms:

Of course it can. No doubt is possible about that once we assume, first, that the requisite stage of industrial development has been reached and, second, that transitional problems can be successfully resolved. One may, of course, feel very uneasy about these assumptions themselves or about the questions whether the socialist form of society can be expected to be democratic and, democratic or not, how well it is likely to function. All that will be discussed later on. But if we accept these assumptions and discard these doubts the answer to the remaining question is clearly Yes. (167)

Were we to take this statement seriously, were we to be shaken free from our era's glib but highly performative faith in the capitalist world-system's inevitable and endless perpetuation, we might consider charging a significant number of these new "social innovation labs" with modeling escape routes and contingency plans. The central question is this: How can viable modes of subsistence be secured for a global population of some nine billion and counting, should secular stagnation continue to deepen at one and the same time as the agricultural base of the economy comes under increase climatic strain? It is hard to stress enough the monumental scale of this question, and the lack of serious thinking that has attended it. Today's UBI schemes, and experiments in regional ecotechnology, have yet to scratch the surface of the question. For if the seismic contraction of the labour share of income continues to unfold unchecked, at one and the same as crop failures and climate migrancy accelerate, we may well find ourselves looking on as the signal doctrines of marketization theory turn to ashes in the mouths of their one-time champions - as far from saving the state from itself, the market proves unable even to save itself. Faced by the prospect of a mounting humanitarian crisis, cities 
may be left with "no alternative" but to attempt the prototyping of functionally "postcapitalist" urban infrastructures and modes of urban subsistence. ${ }^{18}$

Given policymaking's inherent stake in preserving some semblance of continuity with prevailing hegemonic relations, it would doubtless know these initiatives by other names. Yet as the mind-numbingly insistent repetition of terms like "growth" and "competitiveness" makes plain, we are as yet a long way from such a point. And in the face of these contradictions, social innovation policy can sometimes seem to be best characterized as a semi-ideological and semi-procedural attempt at reconciling diverging worlds: delivering a flagging global economy the accelerant of intensified technological innovation, on the one hand; while, on the other, attempting to reckon with the ramifying social and ecological blowback of business-as-usual. Seen thus, the push and pull that Hassan describes playing out in his experience of the social lab, might best be read in the manner of Immanuel Wallerstein - as a site-specific instantiation of a world-system entering into terminal crisis, into an "oscillating" moment of violent indeterminacy wherein the system finds itself "encounter[ing] problems it can no longer resolve," such that it begins to "bifurcate," vibrating between alternate paths ("Introduction"76):

\footnotetext{
${ }^{18}$ Philosopher and social lab facilitator, Etienne Turpin, has recently coined the term "humanitarian infrastructure" in an effort to anticipate and mitigate the onset of "the largest refugee crisis since the end of WWII." Arguing that "climate change is already disrupting human settlement and production patterns around the world," Turpin proposes there has "never been a greater need for advanced humanitarian design, research, and education that moves well beyond disciplinary boundaries to produce new forms of collaboration with frontline actors and agencies." Indeed, in an "age marked by the increasingly volatile and unpredictable effects of climate change and attendant human conflict," Turpin suggests that "it is now clear that civilization will be characterized by a nearly permanent state of humanitarian crisis." In order to meet "[t]his 'new normal' of proliferating humanitarian crises," Turpin calls for "a convergence of disciplinary fields and knowledge practices that can help students learn how to effectively work in complex, multi-centred and multi-stakeholder teams to respond adequately to these challenges." In the final analysis, Turpin seeks to move beyond the political paralysis that is so often induced by catastrophizing rhetoric, and proposes that "development of humanitarian infrastructure should not be understood as a design trend but, instead, as the emerging paradigm for intellectual and scholarly practice in the Anthropocene" ("Designing for the Anastrophe").
} 
The process of bifurcating is chaotic, which means that every small action during this period is likely to have significant consequences. We observe that under these conditions, the system tends to oscillate wildly. But eventually it leans in one direction. It normally takes quite some time before the definitive choice is made. We can call this a period of transition, one whose outcome is quite uncertain. (77) Current events already appraise us of the extent to which the postwar global development program has begun to stall and kick into reverse, as a new tendency toward regional isolationism begins to take hold. In this new geopolitical context - defined by the onset of anthropogenic climate change and the rigors of secular stagnation - the distinction between the citizen and the migrant has emerged as a key political fault line. States are breaking with the expansive, incorporative ideology of free-trade liberalism, triumphantly reconstructing themselves as gated-communities writ large. And as Dawson points out in his discussion of the "sustainable" Eko Atlantic development in Nigeria, this authoritarian strain of post-liberal, post-welfare-state capitalism seems primed to draw up its walls and sea-defenses for the benefit of the affluent, with little regard the many that are left on the other side as the waters start to rise:

Eko Atlantic is where you can begin to see a possible future - a vision of privatized green enclaves for the ultra-rich ringed by slums lacking water or electricity, in which a surplus population scramble for depleting resources and shelter to fend off the coming floods and storms. (59)

Indeed, Benjamin Bratton is surely quite correct to argue that the gap between the citizen and the capital-holder is now closing faster with every passing day:

The rich world's response to climate change is clearly one of fortification and adaptation rather than mitigation ... The migration crisis we're seeing now is not just political it is also ecological. I think you will see a much stronger fortification 
of places where you can still grow food ... [Meanwhile] UBI becomes [the] way [in] which [states] protect capital order and political order ... [A]s these processes become more pronounced and as the terms of citizenship come to include not just things like education and health care but also an actual cash dividend, the line of demarcation of who gets in and who gets out, who gets the dividend and who doesn't, will become more severe ... If we are just reading the tea leaves from this moment, then trends would be ones toward Elysium. (Bratton, 127-128)

Opponents of such trajectories will need to use whatever cunning we can muster, to begin fashioning arcs and life rafts in the shadow of the fortress walls. If present trends continue unabated, if capital remains locked in the downward spiral of its own selfunmaking, the battle in the coming years will be less to "overthrow" the old order, and more to survive the chaotic fallout of its auto-abolition. Such assertions doubtless overstep the limits of caution and good sense, but in so doing they at least have the merit of helping to undo the paralysis of political imagination that characterized these recent decades, when it has been so often said that it is easier to imagine the end of the world than the end of capitalism. It is evidently no longer quite so difficult to imagine the latter. The vultures are already circling. And if we are to have any success in fending off the fascistic and absolutist pretenders that already wait in the wings, we will need to communicate a more charismatic and viable set of political and infrastructural "alternatives" than are currently on the table. And thus rather than clinging to the sureties of the old order - humanistic or otherwise - I suspect our energies might be better spent in drawing on whatever narrative and technical resources aid us in making "anastrophe" the tellingly little-used antonym of catastrophe - the watchword of our thought and action (Turpin). Indeed, as one scans the horizon for alternatives, it would seem that those interested in "prototyping" viable extra-capitalist infrastructures and means of post- 
capitalistic subsistence - and this should be anyone with a stake in heading genocide and starvation off at the pass - we may have few other lines of flight and fight available to us than those that pass through the laboratory itself. 


\section{References}

"Crossings." An Inquiry into Modes of Existence. AIME. 2012. http://modesofexistence .org/. Web. 1 May 2019.

Aiden, Erez, and Jean-Baptiste Michel. Uncharted: Big Data as a Lens on Human Culture. London: Penguin, 2014. Print.

Althusser, Louis. "Ideology and ideological state apparatuses (notes towards an investigation)." The Anthropology of the State: A Reader Ed. Aradhana Sharma and Akhil Gupta. Malden: Blackwell, 2016: 86-111. Print.

Anker, Elizabeth S., and Rita Felski, eds. Critique and Postcritique. Durham: Duke UP, 2017. Print.

Assad, Arjiang, Saul Glass. Profiles in Operations Research: Pioneers and Innovators. New York: Springer, 2011. Print.

Badura T., Ferrini S., Agarwala M. and Turner K. Valuation for Natural Capital and Ecosystem Accounting." European Commission. Centre for Social and Economic Research on the Global Environment, University of East Anglia. Norwich, 2017. http://ec.europa.eu/environment/nature/capital_accounting/pdf/Valuation_for_nat ural_capital_and_ecosystem_acounting.pdf. Web. 30 June 2019.

Bakhtin, Mikhail, Rabelais and His World. Bloomington: Indiana UP, 1984. Print.

Bateson, Gregory. Steps to an Ecology of Mind. New York, Ballentine Books: 1972. Print.

Baxter, Michael. "Machine learning, data, anthropologists and ethnography: big data needs thick data." Information Age. 5 March 2019. https://www.informationage.com/data-anthropologists-ethnography-123480020/. Web. 2 July 2019.

Bell, Larry. "Shady circumstances cloud huge solar energy plant bailout." CFACT. 5 December 2014. https://www.cfact.org/2014/12/05/shady-circumstances-cloudhuge-solar-energy-plant-bailout/. Web. 1 July 2019.

Bennett, Eric. Workshops of Empire: Stegner, Engle, and American Creative Writing During the Cold War. Iowa City: U Iowa P, 2015. Print

Bennett, Jane. "A Vitalist Stopover on the Way to a New Materialism." New Materialisms: Ontology, Agency, and Politics. Ed. Coole, Dianna, Samantha Frost. Durham: Duke UP, 2010: 47-69. Print.

Bennett, Jane. Vibrant Matter. Durham: Duke UP, 2010. Print. 
Brouillette, Sarah. UNESCO and the Fate of the Literary. Stanford: Stanford UP, 2019. Print.

Bookchin, Murray. Post-Scarcity Anarchism. Berkeley: Ramparts Press, 1971. Print

Bookchin, Murray. "The Ecological Crisis, Socialism, and the Need to Remake Society." New Compass. http://new-compass.net/articles/ecological-crisis-socialism-andnew-society. Web. 1 June 2019.

Bookchin, Murray. Urbanization Without Cities: The Rise and Decline of Citizenship. Montreal: Back Rose Books, 1992. Print.

Bourdieu, Pierre. The Field of Cultural Production: Essays on Art and Literature. Edited by Randall Johnson. New York: Columbia UP, 1993. Print.

Bourdieu, Pierre. Science of Science and Reflexivity. Cambridge: Polity Press, 2004. Print.

Bourdieu, Pierre. The Social Structures of the Economy. Cambridge: Polity Press, 2005. Print.

Bratton, Benjamin. "Beyond Elysium." Interview with Michaela Busse. Migrant 4: Dark Matters. Migrant Journal Press, 2018: 123-129. Print.

Brennan, Timothy. "The Digital-Humanities Bust: After a decade of investment and hype, what has the field accomplished? Not much." The Chronicle of Higher Education (2017): B12-B13. Web. 30 June 2019.

Brenner, Robert. The Economics of Global Turbulence: The Advanced Capitalist Economies from Long Boom to Long Downturn, 1945-2005. London: Verso, 2006. Print.

Brown, Nicholas. Autonomy: The Social Ontology of Art under Capitalism. Durham: Duke UP, 2019. Print.

Brown, Wendy. "Neoliberalized Knowledge." History of the Present: A Journal of Critical History. 1 (2011): 113-129. Print.

Brown, Wendy. Undoing the Demos. Boston: MIT UP, 2015. Print.

Brouillette, Sarah. “Keyword: Industry. SHARP. 21 July 2016. Conference.

Brouillette, Sarah, and David Thomas. "Forum: Combined and Uneven Development," Comparative Literature Studies, No 53, 3, 2016. Print.

Building Change Trust. "Social Innovation - A Look at Fab Lab." Building Change Trust. 
10 December 2015.https://www.buildingchangetrust.org/blog/Social-Innovation-A-Look-at-Fab-Lab. Web 30 May 2019.

Caffentzis, George. In Letters of Blood and Fire. Oakland: PM Press, 2013. Print.

CBC News. "Funding for Ontario colleges and universities to be tied to 'performance outcomes." CBC. 11 April 2019. https://www.cbc.ca/news/canada/toronto/ ontario-colleges-university-performance-funding-budget-1.5094751. Web. 18 May 2019.

CBC News. "'Not good enough': Toronto privacy expert resigns from Sidewalk Labs over data concerns." CBC News. 21 October 2018. https://www.cbc.ca/news/ canada/toronto/ann-cavoukian-sidewalk-data-privacy-1.4872223. Web. 30 June 2019.

Clover, Joshua. "The Causality Runs Both Ways: A Conversation with Joshua Clover." The Rumpus. Interview with Jack Chelgren. 1 January 2018. https://therumpus.net /2018/01/the-rumpus-interview-with-joshua-clover/. Web. 28 June 2019.

Clover, Joshua. "The Public Contradiction.” MLA Subconference. Austin, 7 Jan 2016. Unpublished Conference Paper.

Coole, Dianna, Samantha Frost, ed. New Materialisms: Ontology, Agency, and Politics. Durham: Duke UP, 2010. Print.

Crane, David. "What's ahead for Sidewalk Labs development in 2019?" IT World Canada. 31 December 2018. Web. 30 June 2019.

Dasym, "The Rise of the Digital Conglomerate." Dasym. 14 March 2018. https://www.dasym.com/ the-rise-of-the-digital-conglomerate/. Web. 30 June 2019.

Davis, Ben. 9.5 Theses on Art and Class. Chicago: Haymarket, 2013. Print.

Davis, Shara L., "Strategic Plan Development." United States Fab Lab Network. March 2012. http://usfln.org/wp-content/uploads/docs/US-Fab-Lab-FINALReport-3-6-12-PDF.pdf. Web/ 30 June 2019.

Davis, Mike. Planet of Slums. London: Verso, 2007. Print.

Dawson, Ashley. Extreme Cities: The Peril and Promise of Urban Life in the Age of Climate Change. London. Verso Books, 2017. Kindle edition.

Deckard, S., Lawrence, N., Lazarus, N., Macdonald, G., \& Mukherjee, U. P. Combined and Uneven Development: Towards a New Theory of World-Literature Oxford: Oxford University Press, 2015. 
Delany, Ella. "Humanities Studies Under Strain Around the Globe." The New York Times. 1 December 2016. https://www.nytimes.com/2013/12/02/us/humanitiesstudies-under-strain-around-the-globe.html. Web. 20 June 2019.

Deschamps, Tara. "Google sister company releases details for controversial Toronto project." The Guardian. 24 June 2019. https://www.theguardian.com/world/2019 /jun/24/google-toronto-smart-city-sidewalk-project-alphabet-redevelopment. Web. 30 June 2019.

Deleuze, Gilles, and Félix Guattari. A Thousand Plateaus: Capitalism and Schizophrenia. London: Bloomsbury Publishing, 1988. Print.

Diamanti, Jeff. M., "Energyscapes, Architecture, and the Expanded Field of Postindustrial Philosophy.” Postmodern Culture 26.2 (2016). Web. 07 Sept 2017.

Dignan, Larry. "Cognizant buys stake in ReD Associates, aims to meld digital with social science." ZDNet. 28 April 2016. https://www.zdnet.com/article/cognizant-buysstake-in-red-associates-aims-to-meld-digital-with-social-science// Web. 2 July 2019.

Dienel, Peter. "Planning cells: a gate to 'fractal' mediation." Ed. O. Renn, T.Webler, P. Fairness and Competence in Citizen participation: Evaluating models for Environmental Discourse. Dordrecht: Kluwer, 1995: 117-141. Print.

Doctoroff, Dan. Interview with Matt Galloway. "Sidewalk Labs defends compensation plan for waterfront project." CBC News. 20 February 2019. https://www.cbc.ca/news/canada/ toronto/sidewalk-labs-waterfront-toronto-dandoctoroff-metro-morning-interview-1.5025892. Web. 30 June 2019.

Draaisma, Muriel. "Sidewalk Labs project means Toronto to have 'constitution-free zone,' CCLA warns." CBC News. 06 Mar 2019. https://www.cbc.ca/news/canada/ toronto/sidewalk-labs-quayside-waterfront-toronto-constitution-free-zone-cclaletter-1.5044813. Web. 30 June 2019.

Drucker, Peter. "The Purposes and Objectives of a Business." The Essential Drucker. Oxford: Butterworth-Heinemann 2001. E-book.

Eliot, T.S. "The Love Song of J Alfred Prufrock." Collected Poems 1906-1962. London: Faber \& Faber, 2009. Print.

Endnotes. “A History of Separation,” Endnotes 4, October 2015: 71-167. Print.

English, James. "Everywhere and Nowhere: The Sociology of Literature After "the Sociology of Literature.” New Literary History 41.2 (2010): v-xxiii. Print. 
European Commission. "CITYLAB City Logistics in Living Laboratories." Innovation and Networks Executive Agency. Horizon 2020. https://ec.europa.eu/inea/en horizon-2020/projects/h2020-transport/urban-mobility/citylab. Web. 30 June 2019.

European Commission. "Horizon 2020: Societal Challenges.” European Commission. https://ec.europa.eu/programmes/horizon2020/en/h2020-section/societalchallenges. Web. 29 June 2019.

European Commission. Horizon 2020: The Framework Programme for Research and Innovation. Brussels: European Union, 2011. Web. 12 Sept 2018.

European Commission. Horizon 2020: Work Programme 2018-2020: 5. Leadership in enabling and industrial technologies - Introduction. European Commission, 2018. https://ec.europa.eu/research/participants/data/ref/h2020/wp/20182020/main/h2020-wp1820-leit_en.pdf. Web 2 July 2019.

European Commission. Testing Social Policy Innovation. European Commission. Employment, Social Affairs and Inclusion, 2014. https://ec.europa.eu/social/Blob Servlet? docId=11919\&langId=en Web. 12 Sept 2018.

FET Advisory Group. The need to integrate the Social Sciences and Humanities with Science and Engineering in Horizon 2020 and beyond. European Commission, December 2016. Web. 15 Sept 2018.

Felski, Rita. The Limits of Critique. Chicago: Chicago UP, 2015. Print.

Felski, Rita. Uses of Literature. Malden: Wiley-Blackwell, 2011. Print.

Forrester. Jay. "Counterintuitive behavior of social systems." Technology Review 73.3 (1971): 52-68. Print.

Forrester, Jay. "Systems Analysis as a Tool for Urban Planning." IEEE Transactions on Systems Science and Cybernetics 6.4 (1970): 258-264. Print.

Forrester, Jay. Urban Dynamics. Cambridge: MIT P, 1969. Print.

Forrester, Jay. World Dynamics. Cambridge: Wright-Allen Press, 1971. Print.

Fossati, Ela Callorda, Florence Degavre, and Benoît Lévesque. "L'innovation sociale: retour sur les marches d'une construction théorique et pratique. Entretien avec Benoît Lévesque." Revue de la régulation. Capitalisme, institutions, pouvoirs 23 (2018). Print.

Fortun, Kim. "Ethnography in late industrialism." Cultural Anthropology 27.3 (2012): 446-464. Web. 30 June 2019. 
Fortun, Kim. "From Latour to late industrialism." HAU: Journal of Ethnographic Theory 4.1 (2014): 309-329. Web. 1 July 2019.

Foucault, Michel, and Jay Miskowiec. "Of Other Spaces." diacritics 16.1 (1986): 22-27. Print.

Foucault, Michel. The Order of Things. London: Routledge, 2005. Print.

Friedman, Zack. "Student Loan Debt Statistics In 2019: A \$1.5 Trillion Crisis." Forbes. 25 February 2019. https:/www.forbes.com/sites/ zackfriedman/ 2019/02/25/ student-loan-debt-statistics-2019/\#74e97cd3133f. Web. 1 June 2019.

Geoghegan-Quinn, Máire. "Horizons for Social Sciences and Humanities.” Speech. Vilnius: Lithuanian Presidency Conference, 2013. European Commission. Web. 19 Sept 2018.

Georghiou, Luke. RISE Group. A European Ecosystem for Social Innovation. European Commission, Directorate-General for Research and Innovation. Luxemburg: 2018. Web. 18 Sept 2018. Speech.

GZA, "Breaker, Breaker.” Beneath the Surface., MCA Records, 1999, track 7. Spotify https://open.spotify.com/album/4QMKELvG0VNODbiFigj4K9. Web 29 June 2019.

Haggerty, Kevin D., and Richard V. Ericson. "The Surveillant Assemblage." The British Journal of Sociology. 51.4 (2000): 605-622. Print.

Harman, Graham. "Demodernizing the Humanities with Latour." New Literary History 47 (2016). Print.

Harman, Graham. "The Well-Wrought Broken Hammer: Object-Oriented Literary Criticism. New Literary History 43.2 (2012):183-203. Web. 30 June 2019.

Harvey, David. The New Imperialism. New York: Oxford University Press, 2003. Print.

Hassan, Zaid. The Social Labs Revolution: A New Approach to Solving our Most Complex Challenges. Oakland: Berrett-Koehler Publishers, 2014. Print.

Hawkins, Nehemiah. New Catechism of the Steam Engine. New York: Theo Audel, 1904. Print.

Hayek, Friedrich. The Road to Serfdom: Text and Documents. Chicago: U of Chicago P, 2009. Print.

Hayles, N. Katherine. How we think: Digital Media and Contemporary 
Technogenesis. Chicago: U of Chicago P, 2012. Print.

Hiltzik, Michael. "Peter Drucker's Revolutionary Ideas Old but Still Fresh.” Los Angeles Times. 31 December 2009. https://www.latimes.com/archives/la-xpm-2009-dec31-la-fi-hiltzik31-2009dec31-story.html. Web. 30 June 2019.

IEA. “Energy Technology Perspectives 2014: Harnessing Electricity's Potential.” IEA. 1 June 2014. https://webstore.iea.org/download/summary/439? fileName=EnglishETP-2014-ES.pdf. Web. 1 July 2019.

Jameson, Fredric. "The Aesthetics of Singularity." New Left Review. 92. (2015). Web. 24 April 2015.

Jaschik, Scott. "The Shrinking Humanities Job Market." Inside Higher Education. 28 August 2017. https://www.insidehighered.com/news/2017/08/28/morehumanities-phds-are-awarded-job-openings-are-disappearing. Web. 29 June 2019.

Jay, A., D.R. Reidmiller, C.W. Avery, D. Barrie, B.J. DeAngelo, A. Dave, M. Dzaugis, M. Kolian, K.L.M. Lewis, K. Reeves, and D. Winner. "Overview." Impacts, Risks, and Adaptation in the United States: Fourth National Climate Assessment, Volume II [Reidmiller, D.R., C.W. Avery, D.R. Easterling, K.E. Kunkel, K.L.M. Lewis, T.K. Maycock, and B.C. Stewart (eds.)]. U.S. Global Change Research Program, Washington, 2018. https://nca2018.globalchange.gov/chapter/1/. Web. 30 June 2019.

Jégou, François, and Ezio Manzini, editors. Collaborative services. Social innovation and Design for Sustainability. Vol. 1. Milan: Polidesign, 2008. Print.

Jenkins, Michael and Brian Schaap."Background Analytical Study 1: Forest Ecosystem Services 1." United Nations Forum on Forests. April 2018. https://www.un.org/esa/forests/wp-content/uploads/2018/05/UNFF13BkgdStudy ForestsEcoServices.pdf. Web. 30 June 2019.

Jevons, William Stanley. Coal Question: An Inquiry Concerning the Progress of the Nation, and the Probable Exhaustion of Our Coal Mines. London: MacMillan, 1866. Google Books. Web. 30 June 2019.

Kao, Joise. “Ontario's 2019 budget reveals plan to significantly tie university funding to performance outcomes." The Varsity. 11 April 2019. https://thevarsity.ca/2019/04/11/ ontarios-2019-budget-reveals-plan-tosignificantly-tie-university-funding-to-performance-outcomes/. Web. 30 June 2019.

Klein, Lauren F., Matthew K. Gold, "Digital Humanities: The Expanded Field." Debates in the Digital Humanities. Minneapolis: U Minnesota P, 2016: ix-xvi. Print. 
Kreighbaum, Andrew. "Trump Seeks to Ax Humanities Endowment." Inside Higher Education. 19 March 2019.https://www.insidehighered.com/news/2019/03/19/ trump-proposes-axing-nea-ne. Web. 30 June 2019.

Lane, David C., John Sterman. "Profiles in Operations Research: Jay Wright Forrester." Systems Dynamics Society. https://www.systemdynamics.org/assets/docs//jwfprofile-in-op.pdf. Web. 30 June 2019.

Latour, Bruno. AIME: An Inquiry into Modes of Existence. Cambridge: Harvard UP, 2013. Print.

Latour, Bruno. "Bruno Latour, a veteran of the 'science wars,' has a new mission." Science. 10 October 2017. Interview with Jop de Vrieze. http://www .sciencemag .org/news/2017/10/bruno-latour-veteran-science-wars-has-new-mission. Web. 30 June 2018.

Latour, Bruno. Facing Gaia: Eight Lectures on the New Climatic Regime. Cambridge: Polity Press, 2017. Print.

Latour, Bruno. "Give Me a Laboratory and I will Raise the World." Science Observed: Perspectives on the Social Study of Science. Ed. Karin Knorr-Cetina and Michael Mulkay. London: Sage, 1983: 141-170. Print.

Latour, Bruno. "The New Climate.” Harper's Magazine. 2 July 2019. https://harpers.org/ archive/2017/05/the-new-climate/. Web. 1 June 2019.

Latour, Bruno. Pandora's Hope: Essays on the Reality of Science Studies. Cambridge: Harvard UP, 1999. Print.

Latour, Bruno. Reassembling the Social. Oxford: Oxford UP: 2007. Print.

Latour, Bruno. The Pasteurization of France. Trans. Alan Sheridan. Cambridge: Harvard UP, 1993.Print.

Latour, Bruno. We Have Never Been Modern. Cambridge: Harvard UP, 2012. Print.

Latour, Bruno. "Why Has Critique Run out of Steam? From Matters of Fact to Matters of Concern." Critical Inquiry 30 (2004): 225-248. Print.

Latour, Bruno, and Christophe Leclercq, editor. Reset Modernity! Cambridge: MIT Press, 2016. Print.

Latour, Bruno, and Vincent Antonin Lépinay. The Science of Passionate Interests: An Introduction to Gabriel Tarde's Economic Anthropology. Chicago: Prickly Paradigm P, 2009. Print. 
Latour, Bruno, and Steve Woolgar. Laboratory Life: The Construction of Scientific Facts. Princeton: Princeton UP, 2013. Print.

Leane, Elizabeth. "Chromodynamics: Science and Colonialism in Kim Stanley Robinson's Mars Trilogy." Ariel 33 (2002): 83-104. Print.

Lefebvre, Henri. Writings on Cities. Ed. Eleonore Kofman, and Elizabeth Lebas. Oxford: Blackwell, 1996. Print.

“Living Breakwaters Rebuild By Design Competition.” Scape Studio. www. scapestudio.com/projects/living-breakwaters-competition/ Web. 10 Sept. 2018.

Lovelock, James. Gaia: A New Look at Life on world. Oxford: Oxford Paperbacks, 2000. Print.

Lovelock, James. The Revenge of Gaia: Why the Earth is Fighting Back - and How we Can Still Save Humanity. London: Penguin, 2006. Print.

Macherey, Pierre. Theory of Literary Production. London: Routledge, 2006. Print.

Malm, Andreas. The Progress of This Storm. London: Verso, 2018. E-book.

Mandel, Ernest. Late Capital. London: Verso, 1999. Print.

Mandler, Peter. "Ben Pimlott Memorial Lecture 2014: The Two Cultures Revisited: The Humanities in British Universities Since 1945," Twentieth Century British History, 26.3, (2015): 400-423. Print.

Mandler, Peter. "Educating the Nation: II. Universities." Transactions of the Royal Historical Society 25 (2015): 1-26. Print

Marx, Karl. Capital: Volume 1: A Critique of Political Economy. London: Penguin Classics, 1992. Print.

McGann, Jerome. A New Republic of Letters. Cambridge: Harvard UP, 2014. Print.

Meadows, Donella, Dennis Meadows, Jorgen Randers, William W. Behrens. The Limits to Growth: A Report for the Club of Rome's Project on the Predicament of Mankind. New York: Universe Books, 1972. Print.

Meister, Robert. "Confronting the Corporate University: From Cold War Federalization to Financialized Higher Education." Public Seminar. 29 March 2017. http://www.publicseminar.org/2017/03/confronting-the-corporate-university/. Web. 29 June 2019. 
Melamed, Jodi. Represent and Destroy: Rationalizing Violence in the New Racial Capitalism. Minneapolis: U Minnesota P, 2011. Print.

Meredith, Stephen. "Michael Young: An Innovative Social Entrepreneur." Alternatives To State-Socialism in Britain. Ed. Peter Akers and A Alastair J. Reid. Palgrave, 2016. Print.

Michaels, Walter Benn. The Beauty of a Social Problem: Photography, Autonomy, Economy. Chicago: U Chicago P, 2015. Print.

Molla, Rani. "Amazon spent nearly $\$ 23$ billion on R\&D last year - more than any other U.S. company Tech companies claimed the top five spots again this year." Recode. 9 April 2018. https://www.recode.net/2018/4/9/17204004/amazonresearch-development-rd. Web. 30 June 2019.

Moore, B., Underdal, A., Lemke, P., \& Loreau, M. "Amsterdam Declaration on Earth System Science." Challenges of a Changing Earth: Global Change Open Science Conference. Amsterdam, 2001. http://www.igbp.net/about/history/2001 amsterdamdeclarationonearthsystemscience.4.1b8ae20512db692f2a680001312.ht ml. Web. 1 June 2019.

Moretti, Franco. Distant Reading. London: Verso, 2013. Print.

Moretti, Franco. Graphs, Maps, Trees: Abstract Models for a Literary History. London: Verso, 2005. Print.

Morton, Timothy. "An Object-Oriented Defense of Poetry." New Literary History 43.2 (2012): 205-224. Print.

Moss, Jeremiah. Interview with Robin Grearson. "The Aesthetics of Gentrification, and New York’s Top-Down Approach to Change.” Hyperallergic. 9 May 2018. https://hyper allergic .com/440547/the-aesthetics-of-gentrification-and-newyorks-top-down-approach-to-change/. Web. 30 June 2019.

Mourlaert, Frank, Diana MacCallum and Jean Hiller, "Social innovation: intuition, precept, concept, theory and practice." The International Handbook on Social Innovation. Ed. Frank Mourlaert. Cheltenham: Edward Elgar, 2013: 13-25. Print.

Niesen, Max. 'The war against the humanities.' Business Insider. 26 June 2013. https://www.businessinsider.com/the-war-against-humanities-2013-6. Web. 30 June 2019.

Nietzel, Michael. "Whither The Humanities: The Ten-Year Trend In College Majors" Forbes. 7 Jan 2019. https://www.forbes.com/sites/michaeltnietzel /2019/01/07/ whither-the-humanities-the-ten-year-trend-in-college-majors/\#15b936e264ad. Web. 30 June 2019. 
Noys, Benjamin. "Matter Against Materialism: Bruno Latour and the Turn to Objects/" Theory Matters: The Place of Theory in Literary and Cultural Studies Today. Ed. Middeke, Martin, and Christoph Reinfandt. Springer, 2016: 80-

O'Kane, Josh. "In ethics report, NDP calls on Ottawa to halt Sidewalk Labs commitments pending further consultations." Globe and Mail. 18 June 2019. https://www.theglobe andmail.com/business/article-in-ethics-report-ndp-railsagainst-proposed-toronto-smart-city/. Web. 30 June 2019.

Pannapacker, William. "The MLA and the Digital Humanities." Chronicle of Higher Education. 28 December 2009. Web. 08 Sept 2018.

Potočnik, Janez. "A throw away economy cannot be competitive.” UNEP meeting "Towards a Sustainable Economic Paradigm: from Labour to Resource Productivity." 4 April 2013. http://europa.eu/rapid/press-release_SPEECH-13284 en.doc. Web. 1 July 2019. Speech.

Praytor, Stephen. "How Many People Live in Slums Around the World?" Borgen Magazine. 17 September 2017. http://www.borgenmagazine.com/how-manypeople-live-in-slums/. Web. 30 June 2016.

Provenzano, Brianna. "Will Elizabeth Warren's antitrust plan to break up big tech work?" Pacific Standard. 28 Match 2019. https://psmag.com/economics/will-elizabethwarrens-antitrust-plan-to-break-up-big-tech-work. Web. 30 June 2019.

Prynne, J. H. “Die a Millionaire.” Poems. Hexham: Bloodaxe Books Ltd, 2015: 13-16. Print

Rancière, Jacques. Dissensus: On Politics and Aesthetics. London: Bloomsbury Publishing, 2015. Print.

Rebuild by Design. "Hurricane Sandy Design Competition.” Rebuild by Design. www.rebuildbydesign.org/ our-work/sandy-projects Web. 08 Sept 2018.

Rédaction. "A fablab burned down in France by anarchists." Makery. 28 November 2017. http://www.makery.info/en/2017/11/28/apres-lincendie-de-la-casemate-lacommunaute-des-fablabs-reagit/. Web. 8 June 2019.

Reillon, Vincent. "EU framework programmes for research and innovation: Evolution and key data from FP1 to Horizon 2020 in view of FP9." EPRS European Parliamentary Research Service. European Union, 2017. http://www.europarl.europa.eu/RegData/ etudes/IDAN /2017/608697/EPRS_IDA\%282017\%29608697_EN.pdf. Web. 30 June 2019.

Research and Destroy. "Communiqué from an Absent Future." We Want Everything. 24 
September 2009 https://wewanteverything.wordpress.com/2009/09/24/ communique-from-an-absent-future/. Web. 29 June 2019,

Robinson, Kim Stanley. Blue Mars. New York: Bantam, 1997. Print.

Robinson, Kim Stanley. Green Mars. New York: Bantam, 1995. Print.

Robinson, Kim Stanley. “Kim Stanley Robinson: The Good Anthropocene.” Locus. 10 December 2018. Interview with Stephen H. Segal. Web. 30 June 2019.

Robinson, Kim Stanley. Red Mars. New York: Bantam, 1993. Print.

Rogers, Adam. "The Climate-Obsessed Sci-Fi Genius of Kim Stanley Robinson." Wired. 22 October 2018. https://www.wired.com/story/kim-stanley-robinson-red-moon/. Web. 30 April 2019.

Rubenstein, Michael. Public Works: Infrastructure, Irish Modernism, and the Postcolonial. Notre Dame: U of Notre Dame P, 2010. Print.

Ruse, Michael. "Earth's holy fool?" Aeon. 14 January 2013. https://aeon.co/essays/gaiawhy-some-scientists-think-it-s-a-nonsensical-fantasy. Web. 30 June 2019.

SCAPE Studio. "Living Breakwaters Rebuild by Design Competition." Scape Studio. www.scapestudio.com/projects/living-breakwaters-competition/Web. 10 Sept. 2018.

Schmidt, Benjamin. "The humanities are in crisis." The Atlantic. 23 August 2018. https://www.theatlantic.com/ideas/archive/2018/08/the-humanities-face-acrisisof-confidence/567565/. Web 29 June 2019.

Schneider, Benjamin. "Alphabet Announces Plan to Turn Toronto Neighborhood into Living Laboratory." City Lab. 17 October2017.https://www.citylab.com /life/2017/10/sidewalk-labs-living-laboratory/543165/. Web. 30 June 2019.

Scholz, Trebor. "Market ideology and the myths of Web 2.0." First Monday 13.3 (2008). https://firstmonday.org/article/view/2138/1945. Web. 13 April 2014.

Schumpeter, Joseph A. Capitalism, Socialism and Democracy. Abington: Routledge, 2010. Print.

Serres, Michel. The Natural Contract. Ann Arbor: U Michigan Press, 1995. Press.

Shekar, Shruti. 'NDP MP Charlie Angus calls government to 'push the pause button' on Sidewalk Labs Project.” Betakit. 25 January 2019. https://betakit.com/ndp-mpcharlie-angus-calls-government-to-push-the-pause-button-on-sidewalk-labsproject/. Web. 30 June 2019. 
Soufron, Jean-Baptiste. "In France, cyber criticism turns violent as "activists" burn a fablab to protest the diffusion of digital culture." Hacker Moon. 25 Nov 2017. https://hackernoon.com/in-france-cyber-criticism-turns-violent-as-activists-burna-fablab-to-protest-the-diffusion-of-4ad378251c5b. Web. 30 June 2019.

Spahr, Juliana. Du Bois's Telegram: Literary Resistance and State Containment. Harvard UP, 2018. Print.

Srnicek, Nick. Platform Capitalism. Malden: Wiley, 2016. Print.

Stengers. Isabelle. Another Science is Possible: A Manifesto for Slow Science. Trans. Stephen Muecke. Cambridge: Polity Press, 2018. Print.

Stengers, Isabelle. Cosmopolitics I. Trans. Robert Bononno. Minneapolis: U of Minnesota P, 2010. Print.

Stengers, Isabelle. Cosmopolitics II. Trans. Robert Bononno. Minneapolis: U of Minnesota P, 2011. Print.

Stengers, Isabelle. In Catastrophic Times: Resisting the Coming Barbarism. Open Humanities Press, 2016. Print.

Stengers, Isabelle. "Introductory Notes on an Ecology of Practices." Cultural Studies Review 11.1 (2005): 183-196. Print

Stiner, Scott. "How To Use Ethnographic Research To Help Your Business." Forbes. 1 June 2016. https://www.forbes.com/sites/forbestechcouncil/2016/06/01/how-touse-ethnographic-research-to-help-your-business/\#4728561153da. Web. 28 June 2019.

Summers, Larry. "The Age of Secular Stagnation: What It Is and What to Do About It" Foreign Affairs. March 2016. https://www.foreignaffairs.com/articles/unitedstates/2016-02-15/age-secular-stagnation. Web. 2 July 2019.

Summers, Larry. "Why stagnation might prove to be the new normal." Larry Summers. 15 December 2013. http://arrysummers.com/2013/12/15/why-stagnation-mightprove-to-be-the-new-normal/. Web. 2 July 2019.

Syed, Fatima. "Alphabet's Sidewalk Labs was secretly considering big plans for Toronto neighbourhood." National Observer. 15 February 2019. https://www.national observer. com/2019/02/15/news/alphabets-sidewalk-labs-was-secretlyconsidering-big-plans-toronto-neighbourhood.Web. 30 June 2019.

Szalay, Michael. New Deal Modernism: American Literature and the Invention of the Welfare State. Durham: Duke University Press, 2000. Print. 
COP (Conference of the Parties). "COP 21 Paris Agreement." Paris: UNFCCC, 2015. https://unfccc.int/resource/docs/2015/cop21/eng/109r01.pdf. Web. 30 May 2018.

Taylor, Charles. A Secular Age. Cambridge: Harvard UP, 2007. Print.

Technopolis Group. Allinson, Rebecca, Kincsö Izsak, Elina Griniece. "Catalysing Innovation in The Knowledge Triangle." European Institute of Innovation \& Technology. 2012. https://eit.europa.eu/sites/default/files/EIT_publication_Final.pdf. Web. 29 June 2019.

Tolstoy, Leo. War and Peace. Trans. Richard Pevear and Larissa Volokhonsky. New York: Vintage Classics, 2008. Print.

Turner, Fred. From Counterculture to Cyberculture: Stewart Brand, the Whole Earth Network, and the Rise of Digital Utopianism. Chicago: U Chicago P, 2010. Print.

Turpin, Etienne. "Designing for the Anastrophe: Humanitarian Infrastructure as Anthropocene Research." Asia Research Institute, National University of Singapore. Singapore, 05 May 2017. https://ari.nus.edu.sg/events/designing-forthe-anastrophe-humanitarian-infrastructure-as-anthropocene-research-by-dretienne-turpin/. Web. 30 May 2019. Public Lecture.

Urban, Greg, and Kyung-Nan Koh. "Ethnographic research on modern business corporations." Annual Review of Anthropology 42.1 (2013): 139-158. Print.

Veracini, Lorenzo. Settler Colonialism. Basingstoke: Palgrave Macmillan, 2010. Print.

Vincent, Donovan. "Newly formed citizens group aims to block Sidewalk Labs project." The Star. 25 February 2019. https://www.thestar.com/news/gta/2019/02/25/ newly-formed-citizens-group-aims-to-block-sidewalk-labs-project.html. Web. 30 June 2019.

Wang, T. "Energy consumption of Google from 2011 to 2017 (in gigawatt hours)." Statistia. 31 May 2019. https://www.statista.com/statistics/788540/energyconsumption-of-google/. Web. 30 June 2019.

Wallerstein, Immanuel. World-Systems Analysis: An Introduction. Durham: Duke UP, 2004. Print.

Wallerstein, Immanuel. The Modern World-System I: Capitalist Agriculture and the Origins of the European World-Economy in the Sixteenth Century, Vol. 1. Los Angeles: U of California P, 2011. Print.

Wark, McKenzie. Molecular Red: Theory for the Anthropocene. London: Verso Books, 
2015. Print.

Westley, Frances, P. Miller, editors. Experiments in Consilience: Integrating Social and Scientific Responses to Biodiversity Conservation Challenges. Washington: Island Press, 2003. Print.

Westley, Frances, Sam Laban, et al. Social Innovation Lab Guide. The Rockefeller Foundation, 2015. Web. 18 Sept 2018.

Wiener, Norbert. The Human Use of Human Beings: Cybernetics and Society. New York: Perseus Books Group, 1988. Print.

Woodhall, Maureen. "Financing higher education: The potential contribution of fees and student loans." International Higher Education 22.8 (2001): 223-8. Print. 